University of Louisville

ThinkIR: The University of Louisville's Institutional Repository

Electronic Theses and Dissertations

$5-2015$

\title{
A few good men and women : the rhetorical constitution of military personnel identity.
}

Ashly Bender Smith

University of Louisville

Follow this and additional works at: https://ir.library.louisville.edu/etd

Part of the English Language and Literature Commons, and the Rhetoric and Composition Commons

\section{Recommended Citation}

Smith, Ashly Bender, "A few good men and women : the rhetorical constitution of military personnel identity." (2015). Electronic Theses and Dissertations. Paper 2094.

https://doi.org/10.18297/etd/2094

This Doctoral Dissertation is brought to you for free and open access by ThinkIR: The University of Louisville's Institutional Repository. It has been accepted for inclusion in Electronic Theses and Dissertations by an authorized administrator of ThinkIR: The University of Louisville's Institutional Repository. This title appears here courtesy of the author, who has retained all other copyrights. For more information, please contact thinkir@louisville.edu. 


\title{
A FEW GOOD MEN AND WOMEN \\ THE RHETORICAL CONSTITUTION OF MILITARY PERSONNEL IDENTITY
}

\author{
By \\ Ashly Bender Smith \\ B.A., Texas State University - San Marcos, 2008 \\ M.A., New Mexico State University, 2010
}

\begin{abstract}
A Dissertation
Submitted to the Faculty of the

College of Arts and Sciences of the University of Louisville

In Partial Fulfillment of the Requirements
\end{abstract}

For the Degree of

Doctor of Philosophy

in English/Rhetoric of Composition

Department of English

University of Louisville

Louisville, Kentucky

May 2015 
Copyright 2015 by Ashly Bender Smith

All rights reserved 

A FEW GOOD MEN AND WOMEN:

THE RHETORICAL CONSTITUTION OF MILITARY PERSONNEL IDENTITY

By

Ashly Bender Smith

B.A., Texas State University - San Marcos, 2008

M.A., New Mexico State University, 2010

A Dissertation Approved on

March $12^{\text {th }}, 2015$

by the following Dissertation Committee:

Bronwyn T. Williams

Karen Kopelson

Debra Journet

Aaron Jaffe

D. Alexis Hart 


\section{DEDICATION}

This dissertation is dedicated to my family for their endless support and, also, to the men and women of the U. S. Armed Forces, whose presence in my life-not only as fellow citizens but also as family, friends, and students - inspired this project in the first place. 


\section{ACKNOWLEDGEMENTS}

When I first started thinking about this project, Dr. Bronwyn T. Williams told me a well-known parable about a rabbit whose director was a lion. I am deeply grateful that Dr. Williams agreed to be my director, the lion in my corner. His timely encouragement and advice — much, much more than just that first story—-helped me to finish this project and this program. I would also like to thank Dr. Karen Kopelson and Dr. Alexis Hart for their careful reading and helpful feedback that pushed me to develop my ideas and the contributions in this project. I am also grateful to Dr. Debra Journet and Dr. Aaron Jaffe for their support and help through this entire process.

In addition, I would like to thank Dr. Nancy Wilson for hiring me as a writing center tutor and introducing me to the field of Rhetoric and Composition. Under her direction in the writing center and in her classes, I discovered a field that encouraged my commitment to working closely with students to help them become more effective communicators. Similarly, I am grateful to the many faculty who have guided my apprenticeship in this field through my graduate studies. I am also thankful for my colleagues at the University of Louisville who have supported me by listening to my hunches and reading my drafts in our dissertation group. Barrie Olson, Shannon Howard, Caroline Wilkinson, and Jessica Winck, in particular, have been especially gracious and helpful as I worked through this dissertation, and I am forever grateful to them.

Finally, I would never have made it to this point without my family, who have supported me as I pursued ideas and theories they didn't understand in places that are far from home. Since they are legion, naming all the family who listened and helped me through this process would likely take another dissertation. Still, their patience and love 
is a greater gift than I could ask for. And, of course, I am thankful to my husband, Daniel

Smith, for being by my side and providing a calm center in the storm that graduate student life can often be. Here's to our next adventure together. 


\section{ABSTRACT \\ A FEW GOOD MEN AND WOMEN: \\ THE RHETORICAL CONSTITUTION OF MILITARY PERSONNEL IDENTITY}

Ashly Bender Smith

May $8^{\text {th }}, 2015$

In this dissertation, I examine the public negotiation of service member identity by multiple stakeholders as a way to better understand the available rhetorical strategies for affecting ideological constructions of identity. While current Rhetoric and Composition research attends mostly to student-veterans, I draw on cultural and rhetorical theorists, such as Louis Althusser, Kenneth Burke, Maurice Charland, to identify the rhetorical approaches used to construct military personnel identity, particularly in the post-9/11 era. Through analysis of films, recruiting materials, and the publicly-shared stories of personnel, I extend current understandings of constitutive rhetoric and rhetorical identification - which tend to focus on the work of the rhetor as he or she addresses a target, constituted audience - to consider the interventions made by other institutional and individual stakeholders.

In the first two chapters, I provide the scholarly and cultural context for this dissertation. In the first chapter, I review cultural studies and rhetoric scholarship regarding ideology, rhetoric, and identity to form the groundwork for a study that enriches our understanding of not only military personnel but importantly of the way in which rhetors - as representatives of institutions and as individuals - negotiate, 
challenge, and shape ideological understandings. In the second chapter, I argue that the general ideological understanding of military personnel — as seen in film — is that they are physical, aggressive, and superior in their pursuit of morally-guided endeavors. This construction of military personnel identity establishes the basic perceptions of service members and forms the ideological definition that other stakeholders begin from when adding to or challenging common notions of personnel.

Chapters Three and Four examine the rhetorical strategies and tactics used by the Military institution and military service members (acting as individuals and citizens) to intervene in dominant ideological constructions of their identity. Through an analysis of Military recruiting materials, I argue that the Military makes use of a unique form of constitutive rhetoric, which I call recruiting rhetoric, to refine the popular representations of military personnel. In Chapter Four, I examine the publicly-shared stories of American military personnel and the rhetorical features used therein which demonstrate that military service members' primary intervening approach is the use of the stories to reshape the current topoi used in public discourse about service members. These efforts by current and former military personnel serve as models for the ways in which individuals can affect powerful ideological constructions of their identity and thereby facilitate the reproduction of more accurate public representations.

In my concluding chapter, I discuss the implications that my analysis has for the development and extension of constitutive rhetoric and other rhetorical strategies used to shape ideological understandings of identity generally and of military personnel identity in particular. 
TABLE OF CONTENTS

ACKNOWLEDGMENTS




\section{CHAPTER I}

\section{THE RHETORICAL NEGOTIATION OF MILITARY PERSONNEL IDENTITY}

In April of 2013, I attended the NCAA Men's Basketball Championship in Atlanta, GA. During a time-out, the announcer drew the crowd's attention to a group of military service members dressed in dress uniforms who had been invited as guests to the game. The announcer requested that the crowd give a round of applause to recognize the service and sacrifice of these men and women who serve(d) our country. Of course, the crowd readily and enthusiastically complied. My participation, and likely many others' in the audience, seemed a bit routine even if it didn't lack investment; I have experienced this same ritual at nearly every large public event I have attended, from sporting events to theme parks.

It has been just over a decade since the September 11, 2001, attacks on the World Trade Center in New York City. Roughly since then the United States has engaged in military conflicts with Afghanistan, Iraq, and a handful of other countries in the broadlydefined War on Terror. As a nation, we have lived with this distant war as a constant, if not always pressing, aspect of our lives. In this context, the military and military service members have become just as much a part of the public life. These members of our culture are beginning to seem ever-present, their presence evoked in almost every shared space.

High visibility of the military during times of war is not unexpected. Military conflicts are often charged political events that engender plenty of public discussion. In 
turn, the military complex as well as its individual members are brought into the spotlight. The current treatment of the military and its personnel in the public conversation seems distinct in some ways from the treatment during earlier conflicts, particularly from $20^{\text {th }}$ Century engagements. Perhaps the most noticeable difference is the frequency and visibility of individual service members in public forums, often acting beyond the official control of the military complex. Cultural changes including the popularity of social media, reality television, and so on, have made it so that both celebrity personnel, like J. R. Martinez, as well as those service members posting videos to YouTube can speak to broad and varied audiences about military life. In the past, the American public generally heard from military personnel in the form of interviews with magazines or newspapers or the circulation of letters written from the front that were passed around from person-to-person or sometimes published in local newspapers. At times, the public might have heard from service members at rallies or events, and maybe those speaking events were reproduced on television news programming. These ways of engaging the public conversation certainly persist today. However, there is a significant difference in the ways in which they are consumed.

In the past, if an editorial, for example, was published in a local newspaper, it was unlikely that many people beyond that local context would access it. Even if an interview was published in a national publication or a speech was published on national news programming, the audience able to consume that product was constrained by material limitations such as access, cost, and time. The rise of the internet and social media use, as well as the increasing pervasiveness of "smart" devices, over the past decade has made it much easier for more people to access and, importantly, to share the moments in which 
military personnel are speaking to the American public. In addition to increased access and visibility of these more traditional forms of interaction, service members are able to address the American public through social media sites like Facebook and YouTube, to name just two that have large and varied audiences. They also participate in online forums, blogs, and other sites that may have a more narrow audience. This new context allows for more interaction between the general American public and military personnel. Increased access to the voices of military service members through these venues not only intensifies the visibility of the military in day-to-day life but also sparks conversations about what it means to be in the military. It encourages the reconsideration of public, cultural understandings of the military and military personnel.

In the field of rhetoric and composition, scholars are invested in better understanding the role of military personnel in contemporary American culture, although much of their scholarship attends to working with veterans in the classroom. Given the surge in student-veterans in the classroom from 2009 to 2011, there has also been much attention to responding both effectively and considerately when student-veterans share their military experiences in the classroom, often with instructors and classmates who are not familiar with the realities of war (Doe and Langstraat; Corley; Burdick; Leonhardy; Thompson). Other scholars discuss the practical logistics of working with students who are currently-serving in the military (Paquette and Warren; Hinton). In some cases, rhetoric and composition scholarship has moved beyond the classroom to consider the 
effects of military jargon or the rhetorical motives behind certain military slang (Anson and Neely; Carter and Williamson) ${ }^{1}$.

The multiple voices that are currently competing to shape our perceptions about American military personnel also encourage a reconsideration of the ways in which public, cultural understandings are negotiated by different ideological stakeholders - in this case, the State, the Military, personnel themselves, and even civilians. In this dissertation, I examine the rhetorical strategies used by the Military institution and by personnel to intervene in ideological beliefs and expectations about who military personnel are and what their role is in contemporary, post-9/11, American culture. To do this, I first consider a number of films released since 2002 that feature characters who are or who have served. The discussion of these films, particularly in light of historical representations of military characters, provides a description of the dominant ideological construction of service member identity, the construction which is engaged by the Military and by personnel. My examination of the Military's and personnel's efforts to reshape military personnel identity is guided by the following questions:

- What particular rhetorical strategies or tactics can be used to intervene in dominant cultural understandings of an identity category?

- How does the Military's rhetoric constitute personnel identity differently than the dominant representations, for example representations seen in films? How is the

\footnotetext{
${ }^{1}$ Three valuable collections regarding student-veterans are Generation Vet: Composition, StudentVeterans, and the Post-9/11 University (Eds. Sue Doe and Lisa Langstraat, 2014), Kairos 14.3 (Summer 2010), and Teaching in the Two-Year College 36.4 (May 2009).
} 
Military's hailing of service members similar and different from other kinds of interpellation done by the State or even other individuals?

- How do military service members work to intervene in dominant conversations about their identity and cultural role?

- Why are certain rhetorical strategies and tactics for constituting military service member identity more effective for the Military? For personnel? What advantages or disadvantages do the rhetorical strategies/tactics used by each stakeholder offer?

- What do the efforts of different stakeholders tell us about how ideological standards and expectations can be changed over time?

In this pursuit, I draw largely on cultural and rhetorical theories that consider the role of identity in the maintenance and reproduction of ideological systems. Unsurprisingly, my understanding of ideology and identity is informed by the work of Louis Althusser and those intellectuals who have enriched and interrogated his theorizing, including Michel Foucault, Michel de Certeau, Stuart Hall, Judith Butler, and others. Kenneth Burke and Maurice Charland, as well as other rhetoricians, are equally crucial to this study given their focus specifically on the relationship between rhetoric and identity. These scholars offer important work on ideology, identity, and rhetoric that tends to focus on the relationships between those in power and those on the margins. Further, this work often studies the ways in which those on the margins create and assert agency for themselves. 
As members of the Military, personnel are not often considered to be "on the margins," since inclusion in a State apparatus provides service members with a good amount of institutional power. Despite their institutional affiliation, though, American military personnel often are marginalized since 1) they account for less than one-percent of the population and, 2) many civilians, for a variety of reasons, hold personnel apart from themselves. Moreover, this under-considered population can offer important insights about the intersection of ideology and rhetoric as a result of their unique ideological position.

First, service members are subjects "caught in the middle," so to speak, since they are both members of the State and members of the general population. This position gives them the opportunity to affect ideological change both inside and outside of the stateinstitutional apparatuses of the ideology. This is not to say that the efforts of military personnel always challenge dominant ideologies; we must remember that — as members of an ideological institution - they are sometimes also working to reinforce or even strengthen those understandings. Nevertheless, investigation of the rhetorical approaches used by a population holding this kind of dual position can offer new insight into how ideology may be adapted over time. Additionally, by considering the approaches and strategies used by different stakeholders to (re)shape current understandings military personnel identity, we can begin to see how efforts to define identity must be carefully negotiated with all those invested in deciding what the dominant representation is.

Second, most scholarship on rhetorical ideological responses focuses on the efforts of subjects who hold positions that are widely accepted as minority or disenfranchised positions within the given ideological system. Although United States 
military personnel have experienced varying levels of support over the past century, in the post-9/11 context most service members are revered by the general population, even if the Military institution is not. Their honored position in our current culture is reinforced by the kinds of rituals referenced in the opening of this chapter, as well as campaigns to "Support the Troops; Not the War" and many others. Little scholarship has taken interest in the rhetorical efforts used by those in seemingly privileged cultural positions to challenge or negotiate ideological identity understandings. In this dissertation, I explore the negotiation of this complex and fraught identity and aim to add to our understanding of how the State, its apparatuses, and individuals work to re-shape ideological perceptions not only of military personnel identity but also all identity categories.

The work herein offers insight into the ways that both institutional apparatuses and individuals can challenge and affect ideological standards. By looking at the rhetorical constructions of identity presented by institutions and individuals, this study also reveals the strategies used by powerful players in an ideological system to craft the kinds of standards and representations that best serve their purposes. In addition to enriching our understanding of rhetoric used to negotiate ideological identity categories, this study aims to call attention to the available spaces for agency within institutions that are generally assumed to be fairly rigid. Overall, the insights offered by this work will add to our notions of how identities are formed and adapted over time through the actions of both institutions and individuals in a contemporary context, as well as highlight the current efforts of American military personnel to establish a mutually acceptable understanding of their role in our culture. 
We are living in a moment in the United States that is marked by the constant presence of war. Although the war in Iraq is ostensibly over and troops are "pulling out of Afghanistan," a good number of our military personnel continue to be deployed there. Further, American efforts in the popularly-named War on Terror do not seem to be abating, particularly given the apparent political concern over tense (and sometimes revolutionary) events in Iran, Syria, Nigeria, and other countries in which terrorist influence is present. While popular support of service members has not always been strong in the US, it certainly is in this post-9/11 context, and it is important to consider how and why understandings of the military and military personnel may be changing and to what ends, intentional and unintentional.

To embark on this investigation though, we must understand the ways in which representations and public discourse can shape a national ideology and the understandings of its people. To that end, this chapter explores prominent scholarship in cultural studies and rhetoric regarding the establishment and negotiation of identity in public spaces.

\section{The Relationship between Ideology and Identity}

When considering the ways that military are perceived and understood by their own culture, there are many aspects that could be explored. This project focuses on the way that the public, the military institution, and service members are defining military personnel identity because identity is one of the most important features of an ideology. Identity makes ideology livable because it is one of the dominant aspects shaping the practical acting-out of ideology. 
Althusser framed ideology as the beliefs and practices of a community that shape the ways in which the subjects understand each other and their conditions. It shapes how that community interacts with its own members, its apparatuses, and others that are not included in the community. Importantly for this project, Althusser's understanding of ideology suggests that we cannot identify ideological standards except in the communications between subjects, and subjects and institutions, because its existence is formed and reproduced through actions and interactions. The existence and reproduction of cultural beliefs and behaviors occurs in these communications, and it is in these interactions we must look to see how a given ideology may be changing or being challenged.

Further, these beliefs and practices, according to Althusser, are enacted through the lens of identity, because identity, as multifaceted as it is for each member, dictates the appropriate actions and responses in a given situation. In his early exploration of ideology in "Ideology and Ideological State Apparatuses: Notes toward an Investigation," Althusser offers up his famous theory of interpellation which affirms that identity serves as one of the main tools for defining roles in the interactions between members of the community and also who belongs or does not belong. The significance of identity in an ideological system suggests that one of the most effective ways create a broad reaching change in ideological understanding is to successfully adapt the ideology's conception of an identity category.

One conflict that arises in Althusser's discussion of interpellation in his oft-read essay, though, is that there isn't much room made available for subjects to challenge the identity roles assigned to them. This lack of agency is understandable given Althusser's 
understanding of capitalism as a strongly top-down model, particularly in the late 1960s when this essay was written. This model was pervasive in the State Apparatuses, especially the Repressive State Apparatus to which the military would belong. Certainly, even today, there is a strict definition put forth by the military institution in regard to military identity. This identity is engrained through basic training as well as continued disciplining throughout a service member's career. Yet, in a contemporary setting, subjects including military personnel have more access to technologies and locations that offer them more agency than Althusser's model allows. Even with these new opportunities — which admittedly are also influenced by ideology and ideological apparatuses-Althusser's formulation of ideology offers two important bases for this study. First, the beliefs and practices that govern the subjects of an ideological system are established and reproduced through the interactions of the subjects and the ideological apparatuses. Second, those conceptions are strongly regulated through the identity roles with which the subjects associate.

In practice, identity acceptance and performance is not overly deterministic, as many later theorists have argued. Not unlike this project, much of this scholarship attends to the ways in which identity formations are and can be challenged or negotiated by subjects through public discourse. This negotiated identity can be understood as ideological identity, as opposed to personal identity. Ideological and personal identity may and often do overlap, but they are not necessarily the same. To elucidate this point, Stuart Hall explains, in "Signification, Representation, and Ideology: Althusser and the Post-structuralist Debates," that personal identity refers to the beliefs someone has about his own identity: what identities he takes up, which aspects of an identity he takes up, or 
how multiple identities work within him. In contrast, ideological identities are crafted through public expressions of an identity which shape and reshape understandings of that identity over time in response to changing beliefs and experiences of the subject baseboth those who associate themselves with that identity and those who don't. This process works to normalize the ideological standards and expectations regarding those who take up that identity. It is this process of adapting the ideological identity constructions that is under consideration in this project.

Hall offers an important basis for understanding ideological identity negotiation in his theory of identification. In "Who Needs Identity?," he argues that identification is an act of power that can be harnessed by the individual to challenge ideological norms. Identification happens when an individual sutures the ideology's construction of who he is with his own understanding and articulation of who he is as a subject. The identification process is only made possible, though, because subjects of the ideology have shared social understandings, specifically in this case about identity. For example, by the time an 18-year-old signs up to join a service, he or she has seen multiple expressions of who a service member is, as well as what that means, not only from materials offered by recruiters but also in movies and other media. Therefore, he or she already has some expectations and understandings of military personnel identity from which he or she begins to build their personal understanding. Hall calls these shared understandings "representations" and asserts that they are essential to the working and reproduction of culture, and thus ideology. Based on Hall's theory, public representations of identity are the best texts for considering how ideological beliefs are being tweaked 
and reproduced by different stake-holders because it is these public constructions that influence shared understandings rather than the beliefs that make up personal identities.

When considering these public texts of identity though, Judith Butler argues in much of her scholarship that we must remember that these representations are shaped by the norms made available by ideological standards. In addition to her famous theorizing of gender and sexuality as socially constructed in Gender Trouble, Butler also argues in Giving and Account of Oneself that when one answers the question "Who am I?," the answer is necessarily shaped by the definitions made available to the individual by the ideological system. This is true even if, as Hall advocates, the individual is crafting a hybrid definition of her or his identity, because the pieces the individual is repurposing were still provided by the ideology. One instance in which this process can be seen is in the constructions presented by Daddy Bloggers. These men who write about their paternal experiences are often pulling from the traditional expectation that mothers are most involved in discussing and sharing parenting advice and that fathers are more removed. Even as they challenge this expectation they must draw on it to reshape it by rejecting it wholesale or only taking parts of it and combing it with repurposed aspects of others representations. Because of this process necessitates recognizing and using normalized constructions, Butler argues that individuals must recognize the limits of what they are able to know and present about their identity in the public arena. Further, despite these human limitations, it is the responsibility of the individual to critically interrogate the available ideological definitions and to aim for more nuanced and accurate representations of themselves. Butler understands this critical engagement as 
performativity, "that aspect of discourse that has the capacity to produce what it names" (Butler, Osborne, and Segal 202).

Both Hall and Butler promote the use of public identification as a challenge to ideological norms. Their work has helped to create a more robust understanding of ideology and identity categories that in turn allows us to consider the ways in which institutional systems use identity as well as the ways in which individuals can use institutional standards to more personal, accurate, and subversive purposes. These theories of identification and performativity understand the public demonstration of identity as a purposeful choice and performance of identity, even as that expression is influenced by normalizing cultural standards. Yet, they offer little in terms of strategies to enact this challenge. In pursuit of these strategies we must look to the ways in which Rhetorical Studies theorizes the use of identification in public arenas. Much of this work is produced by Kenneth Burke and the scholars of constitutive rhetoric.

\section{Rhetorical Strategies of Identity Performance and Negotiation}

In Rhetoric of Motives, Kenneth Burke argues for the primacy of identification in rhetoric, as opposed to persuasion. Burke's use of the term identification is not the same as Hall's, who uses the term to describe when an individual aligns him- or her-self with an identity category. Instead, Burke uses identification to refer to the way in which a speaker works to convince his audience that they are a certain kind of person, often the same kind of person as the speaker. Although Burke agrees with the common description of rhetoric as the art of persuasion, he explains that a speaker "persuades an audience by the use of stylistic identifications... and the speaker draws on identification of interests to establish rapport between himself and his audience" (46). This understanding 
foregrounds identification because it must be established before other forms of persuasion can be used. Burke further bolsters the importance of identification through his understanding of the exigency for rhetoric in a given situation. Rhetoric is made necessary because of a perceived division or disagreement which rhetoric generally aims to reconcile by persuading the audience to come into agreement with the speaker (25). Identification is the first step of this reconciliation because it "confront[s] the implications of division... Identification is compensatory to division" (22).

While Burkes goes to great lengths to assert identification as the first goal of a rhetor, it is often not a rhetor's primary goal. More often, one is hoping to convince the audience that they should do or believe something, such as vote for a certain candidate or be more vigilant about recycling. How then do we understand rhetorical texts whose main purpose is to persuade an audience to take up an identity, for example military recruiting? In these texts, identification is often the featured rhetorical goal for the duration of the audience's engagement with the artifact (speech, pamphlet, commercial), which means that the majority of the rhetorical features support this goal as opposed to, for example, the audience engaging a particular action or belief.

To address texts with identification as the primary purpose, scholars of constitutive rhetoric have extended Burke's work by analyzing the rhetorical strategies used to persuade audience members to adopt and perform particular identities. In his seminal article, "Constitutive Rhetoric: The Case of the "Peuple Quebecois," Maurice Charland establishes the intellectual history of constitutive rhetoric and three of its major strategies through an analysis of establishment of the Quebecois identity. The Peuple Quebecois are citizens of Quebec, Canada, who believe that Quebec should be separate 
from the rest of Canada based on their historical ties to France rather than England (136). Charland draws mainly on Burke and Althusser to connect identity and identification firmly with rhetoric. He does this by defining identity as a rhetorical effect because it is only understandable through the language of the ideology in which it exists $(133,137)$. In other words, language and identity are inextricably tied together within an ideological system, which in turn necessitates the existence of identity as a way to categorize its subjects. Charland asserts that constitutive rhetoric accounts for the process by which individuals come to recognize themselves as particular kinds of subjects.

These ideological identity positions are not always easily accepted by the subjects who are associated with or who take up these identities. In contexts in which subjects are uneasy with their assigned ideological identities, there is a space for creation of a new identity and constitutive rhetorics can be used to create a new identity for these subjects to claim. As Charland explains, constitutive rhetorics "capture alienated subjects by rearticulating existing subject position so as to contain or resolve experience dialectical contradiction between the world and its discourses" (142). For this reason, much of constitutive rhetoric scholarship considers the constitution (or failed constitution) of political or social movements which typically feature disempowered groups. The constitution of these identities is understood to happen through what Charland labels “ideological effects," or rhetorical strategies.

The first ideological effect is the establishment of the ultimate identification, drawn from Burke (Charland 139). This ultimate identification reduces the individual differences between the audience and the speaker as well as between audience members. Thus the identification occurs not just with the speaker but also with the rest of the 
audience. The success of this first effect leads to the creation of the collective subject, the creation of the identity category. The second ideological effect is to persuade the audience that the identity has historical precedence, that there were earlier people who were members of the identity community. This normalizes the identity category and creates what seems like a natural space for it in the ideological system. Charland continues to draw on Burke, naming this second ideological effect consubstantiality (140). This gives the identity a historical narrative and makes the members transhistorical subjects who support and reproduce the motives and purposes of the group. Charland demonstrates this process by explaining how those crafting the Peuple Quebecois identity used historical French figures living in Canada to show the precedence of French influence and create a historical timeline that challenged British rule, particularly in Quebec. The connection with these figures and this timeline, among other examples offered, led the audience to feel connected to each other and to a particular shared history; thereby, they were encouraged to act in their own and each other's shared interest.

If the first two strategies are successful, the audience will feel compelled to take up actions that perform and reproduce that identity, which is the third ideological effect. These actions are often part of the overall goal for those using constitutive rhetoric, although the primary expressed goal of constitutive rhetoric is to affect the audience's identification with the identity that is being constituted. In Charland's example, the success of the establishment of the peuple Quebecois is demonstrated in creation of new political parties and increased support of bills and laws that supporting the Quebecois (146-47). In accordance with the third ideological effect, the performance of these actions 
must seem to be a free choice. Charland points out that this freedom is an illusion because, once the individual has taken up the identity position, the telos and logics of that identity will necessitate particular actions (141). Nonetheless, the sense that those actions are choices is essential to successfully constituting the identity and the subjects maintaining its existence.

Not all instances of constitutive rhetoric are successful, as Helen Tate and Kenneth S. Zagacki have established. The ideological effects established by Charland are primarily strategies used to constitute identities. Even if these strategies are used successfully, that doesn't necessarily equate to the establishment of the new identity. To understand better how constitutive rhetoric works, Tate argues that we must also "examine the whole complex of the discursive context in which it is enacted" for those deploying constitutive rhetoric as well as those studying it (28). This is important because, as her study of the co-opting (and thus failure) of white lesbian feminist rhetoric shows, these strategies are deployed using language in public forums, and those representations and words can be reused by others with less than concordant purposes. In addition to considering the ways in which others may use the original constitutive rhetoric, Zagacki argues that historical and cultural dispositions are also important, especially if there are differences between the constituter and the audience. By not considering that the Iraqis primarily identified themselves by their religious affiliations, which are rife with historical implications, President Bush was unable to firmly establish the Iraqis as a democratic people. They rejected the notion that their first identification should be with their national government. In Zagacki's and Tate's scholarship it is 
apparent that these constitutive strategies must be considered in the socio-cultural context in which they are being deployed.

While Charland offers some initial rhetorical strategies for constitutive rhetoric, and Tate and Zagacki emphasize important contextual factors, the majority of the work on constitutive rhetoric considers that ways in which those in powerful positions disseminate constitutive discourse. Of course, the power that these actors have is not always necessarily political, economic, or social since much of this work considers the constitutive work of minority groups. Still, even those who are part of minority groups have power within those groups to widely disseminate information through speeches, pamphlets, or other texts—-such as the officers and paper editors of the various women's organizations in Tate's study. Because of this, there has been less consideration of the ways in which members of these new or forming identities may also be employing these constitutive strategies. This project hopes to address this by considering how military personnel are taking advantage of new technology as well as the current cultural responses to personnel in an effort to intervene in understandings about their identity.

Further, since much the scholarship on constitutive rhetoric focuses on the creation of new identities, such as the peuple Quebecois or the woman-identified women in Tate's study, this study of military personnel identity offers insight into the ways in which existing identity categories can be redefined. By examining the approaches used by various stakeholders, including the State, the Military and its members, we can begin to understand the various rhetorical approaches that can be used to intervene in ideological understandings and beliefs. Constitutive rhetoric provides an important basis for considering what rhetorical strategies are being used to affect contemporary 
understandings of military personnel identity. However, since each stakeholder and context consider is different, it is necessary in the subsequent chapters to supplement constitutive rhetoric with other, appropriate theories, which will be discussed therein.

\section{Advantage of Public Places in Affecting Ideological Identity}

In the discussion so far I have emphasized that the actions and discourse we are considering here are those that are happening in public arenas. The public nature of these practices is important because rather than looking at how individuals perceive their personal identity, we are hoping to understand how service members are attempting to change the way the ideological community perceives who military personnel are. The concern here is not as much focused on how personnel perceive themselves but rather their efforts to influence the way that others perceive them.

Public places, shared places, are important to the maintenance and reproduction of ideology because, despite the importance of family in teaching ideology, much of the dissemination and repetition of ideological standards occurs in the shared places in which subjects are able to interact with one another and to see interactions between other subjects. Althusser makes this claim in his discussion of Ideological State Apparatuses (ISAs) — he offers Education, the Arts, Communications, and others as examples (145). These ISAs are powerful institutions that govern interactions, and each ISA has associated public arenas. Ultimately, like Hall's emphasis on shared understandings, these public places are important to studying the way in which ideology is adapted because they are the shared places where those shared understandings are being engaged, reproduced, and even challenged. 
In these public places, discourse and interactions are largely regulated by ideological standards and expectations. As Michel Foucault explains in this famous text Discipline and Punish, through both normalizing discourse and the use of the panoptic gaze, subjects' behaviors, beliefs, and interactions are regulated. Because, as Foucault argues, discourse is shaped by those in power and because the prevalence of the panoptic gaze discourages deviations from the norm, subjects' words and actions in these shared places function, for the most part, to reinforce and reproduce the ideology. This means that when subjects act or speak in public arenas those in power have already shaped the discourse - both language and practices - that are available in that place. Any alternatives enacted that are contrary to that available discourse would be met with some form of discipline. The quick disciplining of abnormal behavior may come from the institutions of the ideology, but it is just as likely to come from the subject himself and/or from his fellow subjects.

Despite this, constituents of an ideology do make use of these public places in nonstandard ways, often in an effort to intervene in ideological standards and to ultimately change the expectations and norms of the ideology. In his famous text, The Practice of the Everyday, Michel de Certeau explores the practices used by subjects of an ideology to adapt the system to their own lives. He is especially interested in the practices that are not sanctioned and make use of ideological standards in non-standard ways, ways that he labels as tactics in contrast to the sanctioned strategies. These tactics and strategies, de Certeau explains, occur in places and spaces. These italicized terms make a distinction between the ways public arenas are understood that is similar to the distinction between strategies and tactics. Places are locations that are defined by the ideology as 
sanctioned and proper: for example, public parks. A place can become a space, however, if subjects use that place in ways that are not sanctioned and/or if they apply a meaning to the place that is not in accordance with the definition given by the ideological system. de Certeau explores a variety of ways in which tactics are used to push back against ideological understandings, including walking in the city, reading as poaching, and quoting. His discussion of storytelling, however, offers a compelling example for this study given its prominent use by military personnel. Stories, as de Certeau describes them, are important because they "carry out a labor that constantly transforms places into spaces... [and] They also organize the play of changing relationships between places and spaces" (118). Places are full of the "proper" and are the inflexible embodiment of ideology, but through stories people make meaning, and thus space, within place. Stories are able to do this, in part, because they are necessarily bound up in geography, if not physically then at least metaphorically. This is partially an inherent aspect of the fact that they create relationships and thus trajectories of understanding and practices (115-16). For example, many stories shared by military personnel, as will be explored in the subsequent chapters, are aimed at bringing them closer to the civilian population as opposed to previous constructions that often created boundaries between civilians and the military. While stories and storytelling use many tactics in their subversive efforts, ultimately they offer a prime example of how individuals can influence and intervene in ideological understanding.

Thus, we see that public places are shared forums in which ideological norms are reinforced and reproduced, but also public places are also arenas in which ideology can be challenged. Publics can be defined in more ways than simply areas that allow two or 
more individuals to interact. In Publics and Counterpublics, Michael Warner defines a public as a historically-situated and self-organized collection of strangers. This definition of publics emphasizes that a given public is inflected by its context. In addition, members of a public must participate for the public to exist and for an individual to count as a member of the public, and members must participate with each other through texts for the public to continue to exist $(88,73,90)$. Because the members of the public are connected primarily through their membership (remember they are "strangers"), any public address must simultaneously be personal and impersonal—connect to the individual while at the same time addressing the entire body (76).

Importantly for this study, though, Warner also describes a special kind of public which he calls a counterpublic. A counterpublic adheres to all the qualifications of a public but a crucial difference is involved. Publics are culturally dominant groups, they are sanctioned by the ideology. In contrast, counterpublics are subaltern groups. Because of this, counterpublics are additionally defined as aiming to challenge and disturb the normalization of dominant publics (56-57). In this case, counterpublics are almost always creating spaces, to use de Certeau's term; they are using tactics and stories to turn sanctioned places, often those inhabited by publics, into meaningful spaces. The aim of these actions, stories included, is to eventually change the rules and expectations that define the place and, by my own extension, the ideology constructing that place. In this way, a place is turned into a space and - through constant challenge and reinforcement of non-sanctioned practices - eventually, in the hopes of the counterpublic, that space is turned back into place. 
One area where counterpublics often appear in contemporary society is online. Digital forums, such as social media platforms but also other online sites, generally allow more—or at least appear to allow more—input from individuals who are not normally considered to be the ones in power. As the internet became more recreationally accessible in the early 1990s, many suggested that online spaces could be bastions of personal agency — and presumably less under the control of the State—largely based on the fact that it was easier for individuals to address creators and corporations (Manovich; Bolter and Grusin; Guzzetti; and many others). While these hopes have some validity, it's clear that the same dominating forces that control other public places in the United States are gaining ever-greater power in the digital realm. Cynthia Selfe and Richard Selfe reveal the early presence of these ideological standards in their prominent 1994 essay, "The Politics of the Interface: Power and Its Exercise in Electronic Contact Zones," about the way that operating systems reflect the logic of the business world with desktops, folders, and white hand cursors. Today, the government is often considering new ways to manage the perceived rampant chaos and lack of security on the internet through bills like Stop Online Piracy Act and Protect IP Act and constantly expanding copyright restrictions. Corporations do their part by, for example, infiltrating popular sites like YouTube which were once for individual users, or by bringing legal action against fan-fiction writers (Burgess and Green; Jenkins). Nevertheless, these digital and social forums continue to offer opportunities for space-making, subversive, intervention work to begin, and often thrive.

\section{Conclusion}


With these notions of place, space, and publics in mind, I aim in this project to explore expressions of military personnel identity that are circulated in forums where individuals can interact not only with each other-as in Warner's publics - but also where subjects and apparatuses interact, places where individuals and institutions converse. In particular, I examine in the following chapters 1) the ways in which the State uses films to establish for its constituents the characteristics of military personnel identity; 2) the Military's use of recruiting materials to more specifically define personnel identity for potential recruits, for other civilians, and arguably for itself; and 3) service members' sharing of personal stories through digital technologies as a way to speak back to the State and to speak to civilians.

In the next chapter, "Becoming More than John Wayne and Rambo: Understanding Military Personnel Identity in Post-9/11 Films," I argue that the general ideological understanding of military personnel is that they are innately dedicated and moral warriors. This construction of service members is drawn from an analysis of 30 films that include a major character that either is currently serving or has served in one of the five branches of the U.S. Armed Forces and that were released after September 11, 2001. While settings, plots, and actors may change, the audiences of these films are consistently taught that personnel are individuals who develop and maintain physical strength and endurance; that they are often forced into difficult decisions that challenge their moral code, though they always prevail; and that ultimately they are the kinds of people who rightfully invoke admiration for their superior nature. This construction of military personnel identity establishes the basic perceptions of service members and 
forms the ideological definition that other stakeholders begin from when adding to or challenging common notions of personnel.

The third chapter, “'Be All You Can Be': The Military's Use of Recruiting Rhetoric to Shape of Personnel Identity," examines the construction of military personnel identity in the Military's recruiting materials. Through analysis of these materials, I argue that explicit recruiting contexts require particular rhetorical strategies that are based on but slightly different from the moves in typical constitutive rhetoric. In constituting the potential recruit as a military service member, the Military offers a unique example of provisional hailing that uses enlistment as a gate-keeping tool for full attainment of the interpellated identity. Further, the Military uses the rhetorical strategy of definition to nuance the ideological claim that service members are superior-adding that the traits of military superiority are morality, professionalism, and warrior nature. Finally, secondary audiences—including family and friends—are constituted as supportive and proud as a way to reaffirm the constitution of military personnel. In addition to seeing how the Military further develops understandings of service member identity, this chapter extends constitutive rhetoric by theorizing its application in recruiting contexts.

In Chapter Four, “'The Greatest Bridging Tool': Service Members' Stories as an Intervention in Public Discourse," I examine the publicly-shared stories of American military personnel and the rhetorical features used therein to intervene in the available public discourse about their identity and role in post-9/11 U.S. culture. Drawing on narrative scholars and rhetorical theories of identity constitution, I demonstrate that the service members' stories are responsive to contemporary expectations about service member identity and that the stories' shared features are used rhetorically to constitute a 
new relationship between civilians and military personnel. The primary intervening approach, as I show, is the use of the stories to reshape the current topoi used in public discourse about service members. These efforts by current and former military personnel serve as models for the ways in which individuals can effect powerful ideological constructions of their identity and thereby facilitate the reproduction of more accurate public representations.

In my concluding chapter, I discuss the implications that this project has for the development and extension of constitutive rhetoric and other rhetorical strategies used to shape ideological understandings of identity generally and of military personnel identity in particular. We must understand better the processes by which identities are constructed and shaped in public places so that we can better identify and respond to the perceptions we are being encouraged to internalize.

Because military personnel are members of the State and also of our communities, shaping the ideological understandings of military personnel is a high-stakes negotiation in which many parties are invested. With this project, I aim to add to the growing body of scholarship on military and veteran studies by highlighting the complex and sometimes competing notions of military service members that we carry into the world. In doing so, I hope that we can be-and help others be-more responsive and considerate when working with veterans, whether that is in the classroom or beyond. As fewer and fewer Americans are personally connected to our service members, our understandings of them will be more and more crafted by the State and its apparatuses through sanitized official statements, crafted silver-screen stories, and hear-say. The men and women of the Armed Forces will continue to be separated from the population to which they are supposed to be 
deeply connected. Just as importantly, however, my aim with this project is to enrich our understanding of the strategies and tactics used by different stakeholders to reinforce but also intervene in ideological standards and beliefs, particularly regarding understandings of identity categories. There are many different stakeholders who hope to influence dominant beliefs about military personnel identity, and by examining the complex strategies and tactics used to negotiate this identity, we can better understand how identities can be effectively adapted over time. 


\section{CHAPTER II}

\section{BECOMING MORE THAN JOHN WAYNE AND RAMBO:}

UNDERSTANDING MILITARY PERSONNEL IDENTITY THROUGH POST-9/11

\section{FILMS}

In a recent orientation for Composition instructors at the University of Louisville, the guest speaker from the campus's Office for Veterans Affairs advised instructors not to ask their student-veterans, in reference to their service, "Is it just like The Hurt Locker?" His tone was humorous but his point was that not only do many service members not see combat but also naïve questions about an individual's service can be unsettling for veterans. More to the point of this study, his example demonstrates the pervasive influence of popular culture on civilians' understandings of who military personnel are and what their service experiences are like. This tendency is natural since the way in which people interpret and understand new situations is generally by drawing connections between information they already have and applying that information to the new context.

Most Americans do not in fact have much interaction with military personnel. In a 2011 study entitled "The Military Civilian Gap: War and Sacrifice in the Post-9/11 Era," the Pew Research Center found that "while most Americans today have family members who once served or are currently serving," most of these Americans are over 50 (77\%). Only $33 \%$ of younger Americans, ages 18-29, have a family member who has served or is currently serving. This is at least partially the result of the dwindling military 
population, which is currently at $.05 \%$ of the American population above the age of 18 , as compared to $12 \%$ during World War II. Given these disparities, there is little surprise in the fact that many Americans rely on popular culture representations to shape the ways in which they interact with personnel and to inform their expectations of military personnel.

The temptation to draw on popular culture constructions is further encouraged by the influential role of entertainment in current U.S. society, as well as by the very nature of the constructions themselves. Films with military content are often framed as being "based on a true story," and over the past fifteen years, there are have been more than a few reality series that either focus specifically on military activities, such as Stars Earn Stripes (2012) and American Fighter Pilot (2002), or that feature veterans, like the Dancing with the Stars whose Season 13 winner JR Martinez is a veteran of the recent war in Iraq. The military's embedding of journalists with specific units — and thus their controlling of the reported story-has created a sanctioned screen version of war that encourages civilians to consume military life as spectators, with their knowledge shaped by what they see on the screen $(\text { Stahl } 3)^{2}$. Despite the fact that films, reality television, and even news reporting are carefully structured and edited, and many viewers are aware that the "reality" is superficial, these popular media representations make a powerful impression on the public understanding of the military generally and personnel particularly.

\footnotetext{
2 Journalists were present in war zones long before the Persian Gulf War, but in Militainment Inc.: War Media, and Popular Culture, Roger Stahl argues that the development of "spectator war" began primarily at this time due to increased military control over where journalists go in areas of conflict and how/what they report.
} 
In this chapter, I examine the constructions of military personnel in popular media, specifically film ${ }^{3}$, to explicate the ideological definition of service member identity and the ways in which that understanding is composed and reproduced.

Articulating the cultural expectations and beliefs about military service members is important if we hope to understand how other groups intervene in ideological understandings. Thus, this chapter serves to provide a basis for the discussion in the next two chapters which consider the ways in which the Military and personnel themselves are attempting to intervene in this broad ideological understanding.

To better explain the cultural work undertaken in these films, I will first offer a more thorough discussion of the influence of popular media on shared cultural understanding, as well as the expectations of the audience in consuming and interpreting ideological constructions. I will also review the historical relationship between the military and the film industry and the effect this relationship has had on the representations of military in film since the World Wars. This review is important to understanding the current tensions that are influencing how military personnel are represented in film following the September $11^{\text {th }}$ attacks. These two reviews provide a background for the subsequent discussion of five prominent characteristics that are offered in contemporary films featuring military characters.

\section{Ideology and the Dissemination of Shared Understandings in Popular Culture}

\footnotetext{
${ }^{3}$ Although military personnel are represented across a broad range of popular media (film, television, video games, and more), this chapter focuses on the constructions offered in film for two main reasons. First, film offers a comparatively concise and cohesive narrative. Second, as Bronwyn Williams and Amy Zenger have noted, the long history and cultural dominance have film have made its genres and features deeply influential in the creation of other media, such as television shows, video games, and so on (8-9). Moreover, the pervasive nature and high consumption of film -in addition to the range of genres considered herein-offers a more varied audience than other a medium like video games, allowing for a stronger description of the ideological understanding of military personnel identity.
} 
Many cultural studies scholars have long asserted the power of popular culture texts in shaping ideological understandings of identity, as well as other beliefs and practices within an ideology. Much of this work, including my own, leans on Althusser's theorizing of ideological state apparatuses (ISAs) which work to maintain and reproduce an ideology by modeling and normalizing ideological standards. The variety of available ISAs - Education, Religion, Communication Media, and so on - also allows the State to influence its varied subject base and address the different aspects of subjects' lives. Importantly, these institutions can also be seen to participate in the disciplining practices of the State that Foucault later points out in Discipline and Punish, since they moderate the available and approved positions (and variations on the positions) for subjects in the ideological system. Due to their prominence in shaping ideological beliefs and practices, these ISAs are of crucial importance to identifying dominant understandings in a society.

As we move into discussing the role of films in ideological regulation, I want to briefly mention that while Althusser's concept of ISAs is important to this understanding, much has changed since he developed his tentative list. Within his list, he suggests that entities that are responsible for things like television programming and "the Arts" are part of different ISAs (143). Given the rise and current dominance of popular culture including movies, television, books, and so much more, in this chapter I treat entities that create such texts as part of the Entertainment ISA. This ISA works to manage and reproduce American ideology through media that are disseminated primarily with the purpose of entertaining (rather than informing or educating, though they also do these things). Through the public circulation of these texts, the Entertainment ISA participates in the maintenance and continued education of the ideology's population. 
Movies, in particular, are a powerful medium for the Entertainment ISA. The prominence of film in the United States has led to the development of genres that structure both the available discourse for a film as well as audiences' experiences with the film. In "A Semantic/Syntactic Approach to Film Genre," Rick Altman explains that genres evolve over time and become established as audiences and producers find "a common ground... a region where the audience's ritual values [their support of movies that reinforce their expectations and desires] coincide with Hollywood's ideological ones" (14-15). Further, audiences that develop ritual support for a particular genre can form a community to which film-makers can appeal and thereby "lure spectators into carefully chosen, ideologically determined subject positions" (14). While there are a range of different movies that incorporate military characters or content, the military film or war film often features the experiences of a few men overcoming differences and personal problems to persevere as a team in combat—such as in John Woo's Windtalkers (2002). Audiences are conditioned to expect Sergeant Joe Enders (Nicholas Cage) and Private Ben Yahzee (Adam Beach) to ultimately develop an unbreakable bond based on their shared experience despite their initial difficulties and tensions-represented by Enders oft-displayed flaws and his orders to kill Yahzee rather than letting him be captured. By the end of the film, Enders and Yahzee are fighting together-as friends not just partners - and audiences are encouraged to view Enders sympathetically because he overcomes his flaws and does the "right" thing, which in this film means sacrificing himself to save Yahzee. The development of this relationship in Windtalkers, and other films of its ilk, is relatively predictable — as is Enders ultimate death on the battle fieldgiven the well-established nature of the war film genre. This predictability, though, is 
important because at least one function of genre is clearly to disseminate and reinforce ideological understandings and expectations, in this case of service members and their role in society.

It is also important to note that the understandings and expectations audiences consume on the screen are not limited to that screen. As films participate in shaping ideological interpretations on the screen, they also offer informative models for how subjects should behave and think in their real life interactions. These public texts become like a database of what cultural theorist Stuart Hall calls "shared understandings," or representations ("The Work of Representation" 18). Focusing on identity understandings, Hall explains that a subject crafts his identity from these shared understandings, beginning with what is available and then piecing together the version of his identity that is best for him and for the particular situation he finds himself in at a given moment ("Who Needs Identity" 16-17). From this process, we can see how important and informative these dominant public representations are. Arguably, the understandings disseminated in popular texts become even more significant when subjects are engaged in an unfamiliar situation — such as interacting with a veteran — and the readily available understandings informing their actions, beliefs, and expectations are those they see on screen.

Despite the power and influence of the understandings that ISAs are producing, we must be careful to recognize that audiences retain a significant amount of agency when engaging with these standards. First, subjects can regulate the shared understandings that gain popularity in the public sphere through their support and reproduction of agreeable representations and their rejection of unacceptable variations. 
Foucault argues that this process often coincides with the disciplining standards of the State. However, later cultural studies theorists such as Michel de Certeau, Stuart Hall, and many film and television scholars argue that subjects do not passively take on the interpretations offered by the producer or the State. Hall explains that though producers encode texts with their institutional assumptions and understandings, for the text to "have an 'effect' (however defined), satisfy a 'need' or be put to 'use,' it must first be... meaningfully decoded" by the audience ("Encoding/Decoding" 130). Through this decoding, audiences actively interpret texts and use them in purposeful ways that may or may not match the intended understandings of that text's creator. A contemporary example of this process is the ways in which individuals use popular culture texts like movies and songs to create mash-ups that comment on current events in unique ways that are sometimes at cross-purposes with the original intent (Jenkins). Audiences' agency requires that producers of texts that reproduce ideology must be responsive to changes in the constituency's consumption even as it works to maintain dominant understandings.

The responsiveness of the movie industry can be seen in its attention to current events and popular perspectives, which are then used as inspiration for new films. As a result, movie producers and screen writers may select to incorporate a variation of a standard identity to test its viability with the broader constituency. Variations that are accepted are more likely to be reproduced, providing a normalizing process for inflected versions of the dominant understanding. In this way, the Entertainment ISA and constituency work together to maintain acceptable ideological understandings that are not static but rather allow the ideology to survive despite changes in the society. Because movies are an important site for this negotiation, this study of the changing expectations 
of military personnel identity uses film representations to identify the dominant expectations and understandings that are currently at work in American culture. To understand this situation though, we must first consider the historical representations of personnel in film because those earlier constructions have a marked influence on the current negotiation of military personnel identity.

\section{The Military With/In the Film Industry}

It should come as little surprise that the military institution and the film industry have a long and varied relationship that begins as early as World War I. Many of our earliest narratives center on the war experience, making it a popular topic for this new version of storytelling. Further, the display of war on screen offered a popular way to create the visual spectacle that is often associated with film. As the popularity of movies became clear, the military quickly realized the mobilizing power movies could have in raising public support and in recruiting enlistees. The military also realized that film was important for increasing the public's understanding of the military, an informational purpose that grew in importance in the 1960s as a seemingly ever-widening gap began growing between the population and the military. These functions-recruiting and informing - continue to be the primary reasons the military works with the film industry, since, as noted film critic Charles Champlin argues, "movies [have become] the source of most people's knowledge of the American fighting men and women" (Champlin xv). Nonetheless, changes in public perception and assessment of the military—as well as changes in general cultural beliefs - have affected film representations of the military and its personnel over time, leaving an indelible mark on the cultural understanding of military personnel identity. 
As early as World War One, the branches of the Armed Forces agreed to offer support in the form of filming locations, filming technologies, background actors, and even money for films that portrayed the military in a positive light. The military appointed advisors to carefully critique scripts to determine whether the film qualified for funding and also to participate in filming to assure positive and reasonably accurate representations of the military (Suid). These forms of support and the requirements for that support continue to inform whether or not a branch assists on a film to this day. Of course, plenty of films that include military content and characters are made without support, for a variety of reasons. Nevertheless, through the World Wars, film representations of the military were largely the same as the military's representations of itself, a consistency that reflects Althusser's assertion that ISAs and the State work together and toward similar goals.

The strong alignment between the film industry's and the Military's representations was also an effect of cultural perspectives at the time. Americans largely supported the United States' participation in these wars, and generally they believed that military service was one of the greatest demonstrations of civic responsibility and thus a duty for all American men (Suid 209). This sense of duty combined with the use of conscription during this time meant that more Americans, and thus audiences, would have a greater familiarity with military life. Further, it was culturally accepted that military training would make enlistees into a monolithic group. Perhaps no greater example of this is that in Discipline and Punish, Foucault uses military training as the paragon example for the way disciplining works in society at large. In this cultural context, military personnel were not considered separate from the military as an 
institution, and thus their identity need did not need to be constructed separately. On screen, this cultural perception manifested itself in representations of the Military that showed it as a unified and cohesive organization, with little attention to the individuality of personnel.

While representations tended to be of the Military rather than personnel themselves, these constructions were often demonstrated by the actions of individual characters who stood in for the military as a whole. This is partially an effect of the fact that most movies center on a leading character, although scenes of large formations on the ground and in air were popular at this time as well. Famous movie actors, such as Humphrey Bogart, Errol Flynn, Robert Taylor, and John Wayne, filled these lead male roles and brought the values and experiences of the military to life on screen. These lead characters as well as their supporting casts allowed additional traits, other than monolithic unity, to be associated with the Military and its service members. Notably, during the World Wars and the time leading up to Vietnam, the characteristics of order and masculinity also marked representations of the Military. These features persist into the present, but in this period they are logical beliefs about the Military given the cultural expectations of military training and the contemporary restrictions on gender for service members. In an extensive study of military films released in the $20^{\text {th }}$ century, Stephen Powers, David J. Rothman, and Stanley Rothman note that from 1946 to 1966 military characters with positive ratings strongly correlate with the demonstration of a sense of duty and adherence to authority and discipline — characteristics that can be read as expressions of military order (87). The understanding of the Military as masculine is perhaps most strongly asserted in the war films of John Wayne. 
In his influential text Guts and Glory: The Making of the American Military

Image in Film, Lawrence Suid dedicates an entire chapter to the influence of Wayne on the public's understanding of the military, in particular the Marine Corps. According to Suid, Wayne is the first stereotypical military man. This suggests that although at this time Wayne's representation is likely being read as reflective of the military institution, he is also the first prominent representation of military personnel identity. Wayne's military characters work to define both the institutional and the individual identity as physical and aggressive, often privileging violence over intelligence (Suid 133). The works of Wayne were so influential that Josiah Bunting, who was an officer in Vietnam and author of the acclaimed novel Lionheads, summed it up by saying that "all [military men] in Vietnam were influenced by the whole aura of machismo... the influence of John Waynism" (qtd. in Suid 132). The persistence of his influence even today is demonstrated in Battle: Los Angeles when a lieutenant describes an improvised trap for an alien ship as "some real John Wayne shit." The popularity of Wayne's characters offers insight into the strong masculine characteristic associated at the time with the Military institution, but his enduring prominence also shapes the individual military personnel identity that arises later.

Until the United States' participation in the Vietnam War, representations of the military tended to define the institution and its members as unified, orderly, and masculine ${ }^{4}$. The social ferment in response to the Vietnam War, however, led to changes

\footnotetext{
${ }^{4}$ Of course, some films from this period, such as The Best Years of Our Lives (1946) and The Caine Mutiny (1954), had more subversion portrayals of the military and its members, but overall the unified and positive representations were more common. Additionally, cultural perceptions at the time generally held that films and the film industry were generally supportive of the military, which meant that more disruptive films or even elements within films were more likely to be overlooked.
} 
in the public's beliefs and expectations about the military and its personnel. An antiauthoritarian and anti-establishment tone marked public opinion during this time and led to the production of funded war films which were positive and superficial and the more common unfunded films which presented the military in less than favorable ways.

It is during this time that military personnel identity becomes more obviously separate from institutional military identity. This is demonstrated primarily by the contrasting representations of officers and regular personnel. In films between 1966 and 1990, Power, Rothman, and Rothman find that "senior-ranking officers ... are much more likely to be portrayed negatively. At the same time the image of the ordinary soldier, the grunt, has not suffered at all," with only $20 \%$ negative portrayals (85). This portrayal is clearly seen in popular films of the time, including The Dirty Dozen (1967), The Deer Hunter (1979), Apocalypse Now (1979), and others. Notably, the positive constructions of ordinary personnel are no longer strongly associated with the kind of institutional loyalty that was present in earlier films. These characters more often make "overtly anti-authoritarian stands and elevate individuality" (90-91). Sometimes this individuality is communicated simply by not including officers in the film at all and situating military figures in isolated and unexpected contexts.

This emphasis on the individualism of positively marked military personnel persists into the 1990s, even in films that represent the military institution more positively - a prime example of this is Top Gun. Additionally, while in earlier films, the moral code was demonstrated through loyalty to the institution, in these later films a service member's moral code is defined by humane ethics, which is often shown as a 
contrast to the institution's compromised morality (Powers, Rothman, and Rothman 96). Because of this, service members are also seen as renegades.

Unfortunately, when personnel are presented as bucking the rules of the institution, they often end up in extraordinary positions that necessitate their reliance on violent and vicious methods (Powers, Rothman, and Rothman 96). The Rambo series is an enduring example of military personnel who are forced into these kinds of circumstances. In 1985's Rambo: First Blood Part II, Rambo (Sylvester Stallone) is sent to Vietnam to search for MIA (missing in action) personnel. After being captured while rescuing, instead of just documenting the location of, the missing military men, Rambo is forced to fight for his own freedom, quite brutally. Even when military characters aren't being ordered around and abandoned by corrupt military officers as Rambo is, the personnel who are placed in these compromised positions are essentially forced to behave in less than honorable ways. Suid argues that as a result of this pattern in films service members become marked by "negative human qualities such as cowardice, pettiness, and self-aggrandizement" (199). This is particularly true of films released in the 1990s which begin to include characters who suffer from post-traumatic stress disorder and are thus unpredictable and often violent, such as in the Lethal Weapon movies and Another 48 Hours (Powers, Rothman, and Rothman 190). By the mid-‘90s, film representations of military personnel are relying primarily on the individualized, renegade service member - whether that person is marked positively or not. The legacy of John Wayne and the loyalist military member stood as a faint imprint seen in the machismo and masculinity that renegade personnel carry into situations in which they are far from the 
control of officers. The events of September $11^{\text {th }}, 2001$, however, resulted in a significant change in the framing of both the Military and service members on screen.

Following the 9/11 attacks, the American public who had previously been divided by its own individuality and diversity was suddenly united in grief and shock. In addition to the intense patriotism that emerged after the attacks, many Americans also felt a sense of disbelief and insecurity that tied directly the nature of the attacks. The last major attack on American soil from a foreign party was, in the mind of many Americans, on Pearl Harbor in 1941. In that case, there was little question as to who would punished and what weapons could best respond. The fact that contemporary terrorists do not represent a nation is often unsettling for those coming together under a patriotic banner. No such clarity existed for Americans after 9/11, even when Al Qaeda and Osama bin Laden became the clear perpetrators. The resulting insecurity stemmed, as Mathias Nilges explains, from the "chaotic threat of global terrorism as well as the complexities of postFordist subjectivity" (32). Further, the unimaginable and extreme nature of the attacksin particular on the World Trade Center towers-made it seem as though representation was impossible (Randell 142).

To galvanize and promote the sense of patriotism after 9/11, Dick Cheney and Karl Rove quickly met with Hollywood executives "to explore how the industry could be mobilized for the ensuing "war on terror"” (Stahl 9). Hollywood was initially wary based on the fact the industry often waits years before representing such tragedies, as well as the seeming improbability of adequately representing the event. Nevertheless, it quickly became clear that the public's patriotism was the dominant feeling and that the public was actually very responsive to war films (Suid; Stahl; Randell). Many films were thus 
released earlier than originally intended, including Behind Enemy Lines, We Were Soldiers, and even the seemingly critical Black Hawk Down (Stahl; Suid).

In light of the earlier constructions of the Military in movies, post-9/11 films offer interesting constructions of both the Military and service members that are marked by a negotiation between the pre- and post-Vietnam War legacies just discussed. Drawing on the work of Frank Wetta and Martin Novelli, as well as Robin Andersen, Roger Stahl argues in Militainment, Inc that these films are marked by a "new patriotism" (Wetta and Novelli's term) that ignores the reasons for war (80). This approach to military films means that critiques of the Military institution are not viable, a certain difference from films that were produced following the Vietnam War. Like previous films, these movies tend to avoid representing the Military but not necessarily because constructions of the institution are negative. Instead these films focus on the service members who are doing the work of the institution without regard to the political reasons mobilizing them.

This framing of personnel as the embodiment of the Military draws on early representations of service members who were loyal to the institution. It does not precisely match those constructions though. For one, the increased value placed on individualism in American ideology in the second half of the $20^{\text {th }}$ century makes blind loyalty to the institution a characteristic that is not very viable to the public. Instead, Stahl argues that "new patriotism" is also marked by a "loyalty to one's comrades in arms [which] fully eclipses any sense of duty to ideal or policy" (80). This loyalty blends that early emphasis on loyalty with the more recent trope of individualism. This band-of-brothers form of loyalty is reinforced by the added characteristic of U.S. military personnel as ultimately good, civilized, and humanitarian (Takacs 154-56). The film Black Hawk Down, which 
presents the story of the Battle of Mogadishu in which a straight-forward strike was foiled by local assistance to the enemy, provides a prime example of this characterization of military personnel. Early on the soldiers are shown in a helicopter lamenting their inability to do much for the locals who are being slowly starved to death-demonstrating the ethical and humanitarian nature of these personnel who nevertheless obey instructions not to get involved without much question. Once overwhelmed in the combat zone, these same soldiers take on extraordinary tasks to rescue their fellow men. These motivations and actions have become standard in many war films that have been released over the past twelve years.

What is important, at least for this study, is that the post-9/11 characteristics associated with the military and military personnel are negotiating a careful balance between two earlier and competing constructions. This negotiation is clearly an attempt to address a similar struggle occurring in the public discourse about the role of the military institution and its members. Much of the scholarship discussed above has focused on how screen representations have shaped the relationship between the citizen and the Military, with mostly incidental attention to the citizen's relationship with military personnel. However, as Hollywood increasingly releases films about and from the service member's perspective, it is the ideological relationship between civilians and service members that is primarily affected. Therefore this study uses film to investigate the current definition of military personnel identity by focusing on the features and roles that are sanctioned in these screen representations. In doing so, I will offer a sketch of the ideological constructions of service members that other invested parties-including the 
Military and personnel themselves - engage as they also work to refine and reshape these broad standard understandings (which will be explored in depth in the next two chapters). Sketching Military Personnel Identity in Post-9/11 Films

In selecting the data pool for this chapter, I was careful to consider what collection of films would best offer insight into the contemporary, dominant understanding of military personnel identity. This dissertation is primarily focused on post-9/11 definitions of military personnel identity, so the films in this study were all released in or after 2002, with two exceptions. Black Hawk Down and Behind Enemy Lines were included because Black Hawk Down was the first military-related film released after September $11^{\text {th }}$ and the release date of the other was purposefully moved up in response to the tragic events of that day (Suid; Stahl). Other older films have certainly made an impression on the public mind, such as the Rambo series and Saving Private Ryan, but the limitation to the post-9/11 time frame emphasizes current tensions in the understanding of military personnel identity while also offering a manageable boundary for the study.

In addition to the release-date criteria, two other criteria were important in compiling the movies for this study. First, because this study is concerned with the dominant ideological definition of service member identity, the films studied would need to have been viewed by a large audience. Therefore, almost all the films were in the top 100 grossing films, in terms of box office profits, for the year they were released. This criteria nearly ensures a sizable audience — with exceptions made for repeat attendeesbut it admittedly does not account for films seen on personal screens once the movie was out of theaters. For this reason a handful of other films which seemed to have a 
significant cultural impact, like The Hurt Locker, were included. Finally, in an attempt to see a complex representation of military personnel, the genre of the films was not limited, but the films needed to include a plot-driving character who was either currently serving in the U.S. Armed Forces or had previously served. This criteria eliminated films like Transformers series in which military personnel are incorporated but their role is primarily to show institutional military response and the characters are not actually participating in the main plot of the film. Overall, all the films in this is study were released after September $11^{\text {th }}, 2001$; earned top-100 box office earnings in the year it was released, with a handful of exceptions; and featured a plot-driving character who was currently or had previously served in one of the five branches of the Armed Forces. A full list of the films can be seen in Appendix A.

Often, when we describe an identity we focus on two aspects. First, there's the description of features or characteristics of those claiming that identity. We might say, for example, that professional athletes are strong and fit. In addition, identities are sometimes explained by establishing their relationship with other types of people. As in, teachers are those who are employed by a school to educate students - a representation that is, in fact, dominant in films featuring teachers. Across the movies considered here, I attended to moments when these kinds of descriptions are being forwarded, whether that is through scripted lines or simply through visual demonstration. In the next section, I will sketch the features and relationships that are normalized in post-9/11 films featuring military characters. Although I discuss the features and the relationships separately, it's important to keep in mind that these aspects of identity, as well as others, are tightly woven together. The separations made here are used to help tease out the ways in which 
Americans are encouraged to view and interact with service members so that a better understanding of the Military Personnel Identity category can be gained.

\section{Characteristics and Relationships of the Post-9/11 Service Member in Film}

Nearly every film that features a service member includes a demonstration of their physicality through push-ups, running, or other similar feats. At this point, it is practically cinema short-hand for "This person is in the military." This physical fitness is one of the most dominant features associated with service members. We can add to a list of prominent features closely-cropped hair cuts and styles and being organized and cleanand perhaps a few more physical cues that are "give aways." Beyond these visual indications, there is a few other major characteristics that these films add to cultural understandings of personnel. When imagining traits of a good service members, we can add committed, moral, natural, and elite to the list. The perception of personnel as being representative of the American public is also an important construction in public representations.

\section{Committed and Loyal}

Although commitment and loyalty might seem like obvious important characteristics for service members, the expression of it in films with military characters has changed over time. As discussed earlier, early films featuring the Military tended to represent it, its members, and the State as unified and aligned. However, as Suid and Powers, Rothman, and Rothman demonstrated, the social discontent with the Military during and after the Vietnam War-as well as the increasing value placed an individualism — encouraged a military personnel identity that was distinct from the Military and the State. The later constructions of service members as renegades further 
cemented them as a separate but related entity of the State in the public mind. Because of this divide between personnel and both the Military and the State, representations of their commitment and loyalty were often attached to their fellow enlisted men or to their personal, moral cause.

After 9/11, there is a move to rehabilitate the State and the Military because those defending and securing the American nation should be good (Takacs 156). However, movie producers are forced to contend with the Vietnam-era negative construction, as well as increasing criticism of the United States' actions in the Middle East as the conflicts there wore on. To cope with this, as scholars have argued, there is less attention to the State's motives in films. While the State is often distanced from the actions in the film, the commitment between the Military and service members is restored. Further, personnel's commitment and loyalty is shown as not simply to their work or their fellow enlisted members but also, to some extent, to the Military institution.

To achieve this sense of dedication to the service members, the films considered here often include a speech by an officer in which the political motivations for the war are minimized and the commitment to doing one's duty is emphasized. While this move is important to securing American ideology even beyond the particular circumstances of the moment, it's current popularity offers insight into the perceived need to stabilize the core values of the ideology, which here are commitment and duty. In Jarhead (2005), this can be seen clearly in the battalion leader's speech to newly arrived Marines, as the leader excites them about their deployment by dismissing the political agenda and bonds them in their shared activity. He explicitly informs the men, "Fuck politics. We're here. All the rest is bullshit." While this sounds fairly negative about their presence in the war 
zone, in fact it is part of a speech aimed to excite the men for their combat experience, as shown by its inclusion with other more common but similar phrases like "First to fight" and "Ooh-rah," which are both rallying calls specific to the Marine Corps. Through these phrases the men are invoked as specially-trained professionals who are deeply united by their commitment to their jobs, each other, and the Marine Corps. In turn, audiences are encouraged to also see personnel in this way. Further, these characteristics serve to valorize personnel and the Military, and thereby encourage audiences to value and respect those in the military.

In other cases, the Military's commitment to personnel is shown by emphasis on loyalty and support in a certain unit or team. Despite being set during the Vietnam War, We Were Soldiers (2002) is one of the best examples of construction of service members. In this film, Lieutenant Colonel Hal Moore (Mel Gibson) is tasked with taking one of the first air cavalry units into engagements with the North Vietnamese which Moore believes will end in near-massacre for the Americans. Before they are deployed, Moore is seen studying the history of General George Custer and his famous loss at the Battle of Little Bighorn, trying to develop a plan that might actually be successful. Moore's loyalty to his men encourages audiences to understand that this commitment and bond is a driving feature of service members. Even though he is an officer, his critique of Military and State decisions encourages audiences to align him and the traits he represents moreso with enlisted men as opposed to those representing the institution.

Moore's commitment is reinforced in two scenes that take place after they have been deployed to Vietnam First, just before he and his men leave the base for the battle site, Moore refutes the validity of his superior's instruction — "Simple orders, Hal: find 
the enemy and kill them"- by lamenting the high number of soldiers who will die in the battle. He ends by resignedly saying, "Let's go do what we came here to do." By following these orders, he demonstrates service members' commitment to their institutional orders, but his clear reservations also shows his loyalty to his fellow soldiers. This expression of loyalty to one's comrades is made even clearer during the battle. Once on the battlefield, as he repeatedly promises throughout the film, Moore refuses to leave the battle until all his men have been flown out. After repeated orders to do just that, Moore takes the radio and says "I'm in the middle of a fight" and that he can't just leave. Not only is this his promise to his men, Moore rightly suspects that his superiors want him to have an advisory meeting with them simply so that they can abandon the rest of his men in the battle they are currently losing. Obviously there is a tension here between Moore's commitment to the Military and to his fellow men. Nevertheless, throughout the film, Moore and his men are aware of the disadvantages they face, but they still persevere in their duty. Ultimately, the actions of these characters reinforce that loyalty and commitment are strong features of all service members.

Unlike the words of the battalion leader in Jarhead, the loyalty associated with military personnel in We Were Soldiers is based not on their shared enjoyment in military activities but rather that their shared combat experience forces them to rely on one another for physical safety and emotional survival. In movies like these two, the disregard of the political justifications for military actions is not only about protecting the State from public criticism. It is also works to normalize and reproduce the construction of service members as unified, loyal, and committed to both their work and each other.

\section{Born to Be Moral Warriors}


In films, but also across all public representations, military personnel are consistently represented as being moral and ethical individuals. Even in movies during and following Vietnam, enlisted personnel were typically represented as a victims of a corrupted Military. As discussed earlier, these characters either pursued renegade missions on their own, driven by a sense of justice, and/or they were shown as scarred by horrible war experiences. Unfortunately, as Powers, Rothman, and Rothman explain, often the actions of these personnel require them to engage in brutal actions that distance service members from the public. Although representations of the Military and the State changed in the 1990s and following the 9/11 attacks, popular constructions of service members still emphasize the moral and ethical nature of personnel.

Often demonstration of morality by military characters also encourage the understanding that those who serve are "naturals" at their job. The combination of morality and natural inclination assures audiences that military personnel will make the "right" decisions not just because of training but because of an innate sense of justice. The emphasis on the moral warrior nature of personnel is perhaps best explain in the evolutional of the character B.A. Baracus (Quinton 'Rampage' Jackson) in 2010's ATeam. While the team is falsely imprisoned for stealing money printing plates, BA becomes a pacifist. When he explains this to Hannibal (Liam Neeson) and Face Man (Bradley Cooper), he tells them he has always felt that he has been "at war." Hannibal responds that that is "what being a warrior" is about—but BA doesn't want that life anymore. Despite this claim, he decides by the end of the film that he is not against violence if it is done in the service of something he believes in. BA's final understanding of "warrior" is crystallized by Hannibal's quotation of Ghandi: "It is better to be violent, 
if there is violence in our hearts, than to put on the cloak of nonviolence to cover impotence." BA and Hannibal (and arguably the A-Team generally) provide the audience with understandable models for military heroes who are admittedly violent but they are first moral.

While this characterization of service members carries forward a post-Vietnam trend, there is an important difference in post-9/11 films. The morality of personnel in earlier films served not only to educate the public about service members but also to reinforce the public suspicion about the Military's as well as the State's corruption more broadly. This purpose still persists in some movies, such as The Green Zone, but for the most part the violent yet moral service member performs his actions beyond the scope of his official military duties. For example, the actions of the A-Team are done, for the most part, as they work to repair their reputation, not in the line of duty. Though the team is imprisoned by the Military, the institution mostly receives a pass on blame because the team is set-up by the real thieves. Even when the set-up is revealed to be partially orchestrated by a military officer, his actions are explicitly described as aberrations in the system. Therefore, although this film participates in what Stahl and others describe as "new patriotism" that tends to ignore the actions and justifications of the State, it also provides an example of the assertion that military personnel are ethical warriors.

Being innately moral warriors, however, is not the only way that service members are shown to "naturals" for their military work. They are also consistently represented as the kind of people who are able to withstand the brutal nature of combat. The A-Team's Baracus hints at this when he claims that he has always felt at war, and Hannibal assures him, essentially, that that feeling is the reason he's such a good soldier. This perception is 
reinforced through the common representation of service members, particularly new service members, as eager to go into combat. In both Jarhead and Battle: Los Angeles (as well as a number of other films), the newly minted corpsmen are watching scenes of battle on a screen (movie and television, respectively) when they learn that they will be deployed into combat. This news, in these scenes and other comparable ones, is met with intense excitement. Corpsman Swofford (Jake Gyllenhaal) and his fellow men, in Jarhead, jump out of their seats, hug each other, and generally engage in raucous behavior. Similarly, in Battle: Los Angeles, the corpsmen respond with shouts of "That's us! That's us!" when the news reports that they will be evacuating the Los Angeles coastline due to the alien invasion. In the nearly party-like atmosphere that follows deployment news, these films emphasize the expectation that service members enlist because they want to fight and be involved in war. Good military personnel are not wary of the dangers of combat; they are thrilled by them.

It's true that the military characters who are most excited about combat are often young and have not yet been in battle. Yet, many of these films seem to purposefully include more experienced personnel who are similarly committed to combat-based missions. Early in Battle: Los Angeles, as the viewer is introduced to the main characters. One of them, Lance Corporal Kearns (Jim Parrack), is first shown in a meeting with a Marine psychiatrist as Kearns is trying to convince the psychiatrist that he is ready to be back in the field. In response to the doctor's questions about how he's doing, Kearns admits that he was shaky and rattled by loud sounds that resembled gunfire or explosions but that now he is ok, he is ready. The doctor decides to wait at least another week before clearing Kearns, which Kearns seems disappointed with but accepts. The character of 
Kearns is constructed (at least partially) to communicate to the audience that personnel who are familiar with the cost of combat experience nevertheless are committed to that aspect of their service. Kearns' commitment to his job and his service again are shown as aspects of the ideal service member.

In addition to these combat-eager characters, the notion that service members are better able to handle combat experiences is shown through characters that are negatively marked by military experiences but return to combat anyway. In Battle: Los Angeles, the main character Staff Sergeant Nantz (Aaron Ekhart) is dealing with the recent loss of his team during a combat situation. As a result of this experience, Nantz is shown requesting to "get out" of the Marines before he is called to do his one last duty of responding to the alien invasion. Nantz is reluctant to enter a new combat zone with a new team, but he fulfills his duty nonetheless. Although he is not eager to return to war, it is his experiences and skill that helps the team succeed when they become trapped in an area controlled by the alien enemy. His acceptance of his duty and the fact that he is crucial to the team's survival suggests to audiences that military personnel are they kind of people who are not only able to handle combat but are particularly skilled at succeeding in such contexts.

\section{Superior Yet Relatable Citizens}

Encouraging audiences to understand service members as the kind of people who are inherently successful in military experiences also reinforces the perception that personnel are elite members of American society. The construction of service members as elite is reinforced through a broad range of characteristics. The suggestion that they are efficient and effective fighters is certainly one of these characteristics, but it is also seen 
in the use of superior physicality, high endurance, and resourcefulness as stereotypical features of service members. Often this is demonstrated through the physical demonstrations mentioned earlier: running, push-ups, pull-ups, etc.

But, their elite nature further emphasized through the fact that many films with military characters and topics feature either special teams or discussion of the superiority of a particular branch. It is not altogether surprising that films about military operations would chose to focus on special military teams like the Navy SEALs, the Army Rangers, and others—-such as in Zero Dark Thirty, Black Hawk Down, A-Team, and others. The entertainment industry is not generally in the habit of creating blockbuster films about the average since most audiences want to be impressed and inspired by the content on the screen; elite military teams are just more compelling than most other rank-and-file service members.

This logic is perhaps most clear in GI Joe: Rise of Cobra (2009), in which two of the main characters are shown to be superior to skilled members of U.S. forces and also the multi-national GI Joes force. When first attacked, Duke (Channing Tatum) and Ripcord (Marlon Wayans) defend their package against both Cobra forces and the Joes (who are ultimately trying to help them). They are the last men standing (though they are out-numbered) and refuse to release the package even when the Joes inform them that they are both on the same side. Then, during testing, Duke scores in the top half percent of everyone ever tested. These two early affirmations of Duke's skills suggest his own elite ability as well as the superiority of American forces generally. Even beyond special examples like Duke in GI Joe, the premiere nature of American military members is confirmed through the frequent naming of personnel as heroes. For example, in Dear 
John (2010), where the title character's service is mainly a plot device to tell the story of long-distance and tribulation-riddled romance, other characters are regularly impressed by John's (Channing Tatum) abilities and described him variously as brave, heroic, and loyal. In these representations of service members as elite, films return to the legacy of John Wayne and his demonstration of honorable military service. Contemporary films though push this further by recognizing the individuality of personnel despite their membership in a State institution that requires a considerable amount of unification. Audiences are encouraged by these characters to see the understand personnel as distinct from the Military even as those personnel are held above the general population.

While these characteristics of moral and physical superiority encourage the American public to honor and glorify military service and personnel, they do little to help the public understand that personnel were once — and to some extent still are —-much like them. This creates a tension between the public and service members on a personal and an ideological level. First, the distance created by this impression of positive superiority can make it difficult for personnel to interact with the civilian public in meaningful ways. The awkwardness that can mark the public's interaction with personnel can be seen throughout the film The Lucky Ones (2008), which follows three soldiers who road trip across the United States after their connecting flights are grounded. Throughout the film, each of the three characters interacts with civilians who are doing work for them, such as renting them a car, serving them food, and the like. When the soldiers thank them, the civilian workers reply, "No, thank you" in reference to the characters service. In response the soldiers often tentatively say okay or seem at a loss for words before walking away. The pervasive sense among civilians that they are obligated to thank personnel for their 
service is an expression of the sense that service members are a superior community, and ultimately it creates a barrier in meaningful communication between personnel and the American public. As the "Global War on Terror" continues and more and more veterans return to the civilian domain, the tensions between personnel and the public are becoming more present in public discussion. Films increasingly address this issue by representing personnel as also "of the people" and humanizing military characters. In this way, these films also offer an attempt to close the gap between civilians and service members.

One way this humanization occurs is by characterizing personnel as a diverse group whose members have a variety of interests and associations beyond their military service. The emphasis on diversity is especially important in closing the gap between the public and personnel because it offers a counter-balance to the framing of service members as elite, which of course encourages the distance by challenging the construction of the United States as democratic and diverse. The Constitution's original designation "We the people" and Abraham Lincoln's later emphatic invocation "of the people" has secured in our national mythos — despite historical barriers - the idea that Americans are a diverse people who overcome that diversity to work together toward common goals. This notion may seem clearer in civic situations, but since the U.S. Armed Forces is the embodiment of American ideology, they are equally, if not more so, expected to reflect this American diversity. Sometimes the emphasis on diversity is heavy handed, as in films like Windtalkers (2002) or Red Tails (2012) in which race inclusion is a major aspect of the plot, and a crucial feature that allows for American military success. These films, and others that include diversity without comment, demonstrate that even if social tensions persist in society at large, in the military and in combat specifically 
diversity becomes a strength rather than a weakness. This helps the audiences feel more connected with military service members because they are able to identify with a range of characters as well as the struggles which reflect broader social concerns.

As I mentioned above, diversity is not simply about race, social class, or other cultural markers. In many films, it also refers to the connections military characters have in addition to their military commitment. These connections show audiences that military personnel are often a micro reflection of society at large. This notion is reinforced through the commonly included discussions of families and interests they have outside of the military. In Windtalkers, one of the topics that Enders and Yahzee ultimately bond over is Yahzee's family and career aspirations after the war. Beyond family and significant others, the hobbies of service members-like Act of Valor's Lieutenant Rourke's (2012, Lt Rourke) interest in surfing or Walking Tall's Chris Vaughn's (2004, Dwayne "The Rock" Johnson) pick-up football team — help to create a sense that personnel are much like the general population. Overall, the emphasis on diversity and home life, as shown through personal hobbies, family, as well as other aspects, encourages audiences to understand personnel as people like them who have just happened to also pursue service in the military. In this way, military personnel are made relatable and sympathetic despite the demonstration of them also as eager and efficient fighters.

The humanizing of military service members does not always take this positive approach, however. While the State and its apparatuses would like to craft positive relationships with the public by emphasizing their similarities, a concern about the methods and purposes of the State persists in the public mind. One manifestations of this 
concern centers on the treatment of personnel and the effects of their service. In the past, constructions of service members as "mad dogs" suffering from post-traumatic stress encouraged audiences to perceive service members as potential threats. In the post-9/11 era, critical films that address the negative aspects of military service tend to encourage the public to sympathize and support personnel.

The protagonists of Jarhead and The Hurt Locker (2008) both demonstrate the humanizing of personnel by creating sympathy for service members as opposed to public rejection of them. In The Hurt Locker, Sergeant First Class William James (Jeremy Renner), is a bomb technician in Iraq, whose "reckless" and "rowdy" nature is a source of tension between him and his more rule-focused team. He repeatedly puts himself and even his teammates in danger but ignoring safety protocols. Near the end of the film, James and his fellow teammate Sergeant JT Sanborn (Anthony Mackie) agree that neither knows why James is "the way [he] is." But, while back in the States after his deployment, James is shown to be clearly uncomfortable not being in combat and tells his infant son that he thinks that defusing bombs might be the only thing he really loves. James ends up returning to Iraq as a bomb technician. This approach is not largely different from the opening and closing monologue from Jarhead, in which Swofford explains that once a man's hands have been trained to shoot a rifle, "no matter what else he may do with his hands...his hands remember the rifle." Even as James and Swofford embrace their military roles, they are still shown to be at least somewhat victimized by the Military system. The theorizing done by both characters encourages the American public to perceive military service members as deeply marked by their combat experiences while 
still privileging the fact that they are individuals who deserve some level of sympathy and not vilification.

Overall, both the positive and negative portrayals of personnel as "of the people"-as shown through personal hobbies, family, as well as other aspects - helps to personalize service members and reduce the tensions between personnel and the public. In this way, military personnel are made relatable and sympathetic despite the demonstration of them also as eager and efficient fighters who are sometimes so marked by their experiences that they can seem unpredictable or dangerous. The address of the tensions between personnel and the American public are perhaps the most important in negotiating the ideological understanding of military personnel identity. Though the audiences for these films are varied, they are likely mostly composed of civilians. The representations of the relationships between the Military, State, and personnel certainly help the public to understand service members as distinct members of State institutions and to see a more robust version of personnel. The film constructions of the public's relationship with personnel, however, are more likely to have an impact on real life interactions and to influence civilians' understanding of personnel as also (at least partially) members of the public. Further, through these film representations, the dominant ideological understanding of personnel is attempting to strike a balance between the elite and moral warrior and the average citizen who happens to also serve his or her nation.

\section{Conclusion}

The ways in which identities are understood and the expectations that surround them influence many of our everyday interactions with others. And, as discussed earlier, 
the ideological identity categories made available to us are equally important in shaping how we live our lives, the goals we pursue, and so on. Despite their power, these identity categories are rarely discussed in detail. Instead, we assume that other members of our society will know what we mean when we say that someone is an athlete or an author or a soldier, for example. That amount of knowledge that can be communicated through those identity labels is, of course, a benefit because it helps us to know and understand our world, and it helps to interact more efficiently_if not always correctly_with others.

Nonetheless, in this chapter, I have detailed some of the more common and consistent characteristics and expectations that contemporary Americans hold, or are encouraged to hold, about those who serve in the US Armed Forces. In doing so, I work to uncover some of the assumptions and implications that we carry with us when we think about and interact with military personnel. Contemporary service members are often seen as physically and morally strong; committed and loyal to each other and their duty; and innately qualified for the jobs they perform. As a result of both their civic service and these characteristics, they are also often constructed as elite members of our society. Despite this superior nature, however, members of the US military are also presented as a diverse set of individuals who reflect the American citizenry and are thus also "of the people."

The construction of service members in films presents the broad ideological understanding of military personnel identity. By considering all genres of film, rather than simply war films, we are able to see a fuller picture of how this identity is shaped. For the most part, particularly when considering personnel specifically, these representations are positive. When military characters are negatively marked in these 
films, we are encouraged to see them as either damaged by their service — such as in The Hurt Locker or In the Valley of Elah-or as aberrations within the identity, they kind of person who was not a true member of the group, such as the corrupted officer who partners with the villains in A-Team.

Despite the fact that the ideological construction of military personnel in films is overall supportive, other groups have taken up efforts to reshape the ways in which Americans imagine contemporary service members - in particular, the Military institutions and the personnel themselves. While the features and understandings that are promoted by these other entities are certainly important, what is compelling about their work is the strategies and tactics they use to intervene in dominant ideological perceptions of military personnel identity. In the next two chapters, I explore some of the characteristics of service members that the Military and personnel emphasize, add, or redefine in relation to the broad construction detailed here. I focus in those chapters, however, on the rhetorical strategies used by these groups to intervene in ideological understandings. While this chapter provides an overview of military personnel identity, the bulk of this project hopes to inform not only our understanding of service members but also how cultural beliefs about identity are shaped and negotiated by various members of the ideology. 


\section{CHAPTER III}

\section{BE ALL YOU CAN BE: THE MILITARY'S USE OF RECRUITING RHETORIC TO SHAPE OF PERSONNEL IDENTITY}

In 1973, in response to pressures from the American public as well as from within the military itself, the United States Armed Forces ended conscription and developed the All-Volunteer Force (AVF). Since then, as the name indicates, all personnel in the five military branches have volunteered for service - even in the most recent conflicts in the "War on Terror," which would have called up Selective Service personnel had it followed the AVF's original design. The American commitment to the AVF design (particularly as it is currently instituted) has significantly influenced not only the ways in which Americans imagine who military personnel are but also the ways in which potential personnel are recruited. While the AVF design and its continued existence may be hotly contested $^{5}$, the transition to the AVF necessitated a reimagining of military personnel identity and sparked the creation of what are now carefully developed recruiting campaigns.

Although the Armed Forces were aware that the AVF, at its inception, would require the enlistment of "tens of thousands of volunteers every month," neither the military branches nor the advertising companies with whom they had contracts initially

\footnotetext{
${ }^{5}$ For a more thorough entry point to this conversation, see David M. Kennedy's edited collection The Modern American Military. For additional readings, see Bacevich; Segal and Korb; Avant and de Nevers.
} 
realized the significance that marketing materials would ultimately have in the new system (Bailey 66). The Army's requested recruiting budget for 2013, for example, was $\$ 338$ million—a number that was reduced from previous years due to reorganization and reduced involvement in Afghanistan (Emmanuel). Through some trial-and-error over the first few years, the military branches and their marketing companies developed strong recruiting campaigns that now use almost all available media to reach potential recruits. Through these campaigns, the branches have worked to shape the American public's understanding of the branch, of their personnel, and of the work that they do. The Military's recruiting materials have done significant rhetorical work to further develop the dominant ideological understanding of service member identity, as well as personnel's relationship to the public, that is established through films and other entertainment programming. In this chapter, I examine the rhetorical strategies used by the Military in their recruiting materials to define Military Service Member identity and its significance for both potential recruits and more broadly the American public. Moreover, I argue that the Military's combination of provisional hailing, definitional rhetoric, and interpellation of secondary supportive identities offers a framework for how constitutive rhetoric functions in explicit recruiting contexts.

\section{History of Recruiting since the Creation of the AVF}

To better understand the relationship between recruiting materials and their audiences, it is worthwhile to consider the Military's concerns and goals regarding its recruiting efforts for the AVF. After a somewhat slow start, the military leadership and advertising companies realized the importance of well-developed recruiting campaigns. After all, the AVF had to compete in the capitalist market and convince young men (and 
later women) that military service was not only a viable career option but an ideal choice-whether that was for the short term or the long term. The development of enlistment benefits and the outsourcing of less "exciting" positions certainly helped to change the understanding of what military life was like, but these changes did not immediately register in the broader cultural understanding of military service (Bailey). As indicated in the previous chapter, the dominant messages about the military following Vietnam tended to emphasize that governmental and military leadership was morally corrupt and, in contrast, that lower level service men were those who had (ideally) prevailed in unfortunate circumstances. Even into the ' 90 s, when more positive representations of personnel and service started to gain ground, military life was still often represented as an isolating experience for one reason or another. Certainly, in the new century, the American public has continued to hold varying levels of concern about the work of the Military and the idea of young people enlisting in this service, even when the Military receives popular support. This concern is natural given the high-stakes nature of Military service. These public apprehensions have come to play a significant role in the rhetoric of Military recruiting since the institution of the AVF and the reliance on filling the ranks through persuasion rather than conscription.

Toward this end, the Military recognized it would need to shift its focus away from itself as an institution and instead emphasize the individual and what that person could offer. The most blatant effort to effect this change in focus was the Army's first AVF-era slogan for the Army was “Today's Army Wants to Join You," which expressed the branch's new approach and suggested that the Military was not simply using recruits for its own purposes (Bailey 74). The Army continued promoting this perspective over 
the years - through later slogans including Be All You Can Be, Army of One, and Go Army - and the other branches follow this pattern as well. Similarly, the Military aimed to reframe what Military work is like and how that work can benefit personnel. Recruiting materials began emphasizing possible jobs and experiences to show that military life is not about completing menial tasks but rather that it is exciting and rewarding and that it offers otherwise unattainable opportunities. By focusing on the exciting experiences and work of military, recruiters and their materials are also able to deflect attention from the ever-present concern about the life-or-death risk that is almost always associated with military work.

The new recruiting materials also addressed anxiety about the sacrifice the service member makes through his service - not only the possible loss of life, but also the loss of time and potential education that could occur during one's service. In response, recruiting texts place a heavy emphasis on the tangible and intangible compensation personnel receive through their service. The messages here vary depending primarily on the strength of the U.S. economy, but also in part on other factors of the cultural moment. When the Military transitioned to the AVF, they titled the new force a "volunteer" force - a word that is rife with associations to altruism, sacrifice, and other noble traits. Volunteers after all tend to serve (in whatever organization) for intrinsic rewards. Despite the use of "volunteer," Military leadership was, as I mentioned previously, starkly aware that military service needed to be a viable alternative to other career options. Research by communication scholars shows that recruiting materials strongly emphasize the tangible rewards of financial and economic benefits, educational benefits, and job training (Shyles 
and Ross; Griffith; Reichert, Kim, and Fosu). With these messages, recruiting materials have aimed to respond to the potential recruit's question of "what do I get for serving?"

Although the responses to public misgivings about the Military are prominently featured in recruiting materials, these materials also respond to the concerns of the Military leadership. During the Vietnam War, the Draft conscripted both unskilled and actively resistant personnel and led the Military leadership to support the transition to the AVF under the belief that it would mean only those who wanted and were able to serve would enlist (Bacevich; Bailey; Rostker). The concern about the quality of personnel appears in recruiting materials most clearly in the promotion of the intangible rewards that service members receive. This is because, as James Griffith explains, personnel who are motivated by intrinsic factors, such as loyalty and honor, tend to be better service members (216). In their efforts to improve the quality of enlistees, the Military also began constructing itself as a provider of social good since their personnel not only provide valuable experience but also develop positive character qualities - hard work, loyalty, investment in the development of their team. The promoted idea was that military service would develop recruits into better citizens. Mary F. Martin demonstrates in her analysis of more recent Army recruiting that some advertisements suggest that by not enlisting America's youth may instead become involved in gangs or other criminal activity (10). This attention to citizen quality and local communities is perhaps not surprising since the Military is after all an apparatus of the State. Still, these messages demonstrate that Military recruiting messages attend not only to public concerns but also a variety of concerns held by Military leadership. 
In addition, the Military is equally if not more interested in convincing the American public to "buy in" and support the institution and its work. Responding to the apprehensions discussed above certainly does a large part of this work. In his book Militainment, Inc: War, Media, and Popular Culture, Roger Stahl argues that the Military also creates public support by creating a spectacle of war and, in the most recent wars, by inviting the public to vicariously engage in the war through interactive opportunities. Although things like televised reporting of the initial "Shock and Awe" bombing of Iraq in 2003 are not official recruiting strategies, they definitely encourage the public to participate in positively marked — exciting but still safe — support of combat activities. This encouragement of vicariously-experienced war can be seen further in recruiting booths that bring military vehicles to public events and allow spectators to get in and touch real military equipment. These are just two of the examples Stahl includes to demonstrate the way in which the Military has worked to earn public support and normalize its operations, specifically since Desert Storm.

Across this scholarship, it's clear that Military recruiting attends to a variety of concerns, both internal and external, in its materials. Unsurprisingly, the recruiting messages attend to public perception and understanding, yet in doing so, as Stahl and others point out, this recruiting is also actively engaged in challenging, changing, and shaping conceptions of the Military for its own benefit. The previous work on military recruiting attends primarily to the ways in which the Military constructs itself, but these materials also actively participate in the construction of service member identity. The rhetorical strategies used in these recruiting agendas become clearer when we examine the rhetoric used to address the different potential audiences of recruiting materials. 
Typically, we imagine that recruiting materials are designed for the potential recruit, yet even the scholarship above shows that there are varied audiences for these texts, including the family and friends of potential recruits as well as the American public more generally. When we examine the messages sent to different audiences - the potential recruit but also others - we can see how recruiting rhetoric draws on the principles of constitutive rhetoric and also how this rhetoric addresses more than just the constituted audience.

This study primarily considers recruiting brochures and web materials, paying particular attention to repeated language and themes as well as how these are reinforced through other design and visual features. Print and web-based materials from each of the five branches of the U.S. Armed Forces—Army, Navy, Marine Corps, Air Force, and Coast Guard ${ }^{6}$ — were considered. Recruiting materials can vary greatly between branches but also between different recruiting offices for an individual branch. For example, the work of the Air Force deals primarily with technological and scientific concerns, and accordingly they have highly developed web recruiting materials, such as games and dynamic webpages. In contrast, the largest branch and the branch with the highest recruiting quota, the Army, makes the most extensive use of videos featuring personnel explaining basic training and other job specialties to make the branch more approachable and understandable in the eyes of the average American. Geographic location also shapes the kinds of recruiting materials that are readily available to potential recruits. Those living in coastal areas are much more likely to see television commercials for the Navy or

\footnotetext{
${ }^{6}$ The Coast Guard operates as a part of the Department of Homeland Security during peacetime, but can be transferred to the Department of the Navy during wartime. Because the Department of Defense includes the Coast Guard on its website as a member, I have included it here as a branch of the Armed Forces.
} 
the Coast Guard, whereas those branches do more interpersonal recruiting in the Midwest or other areas in which they may have a lower visibility.

To account for these geographic and inter-branch differences in recruiting, the primary texts considered for this study were brochures and web materials. Although some branches rely more heavily on brochures than other branches, each branch has some sort of physical textual recruiting material that is consistent across geographic areas, and web materials for these branches are consistent no matter the area from which they are being accessed. Using these two types of materials in conjunction with one another allows the discrepancy between brochure usage and website development to be balanced out. The selection of materials was ultimately designed to get an idea of the general recruiting strategies and messages being employed by the branches of the U.S. Armed Forces.

By focusing on repeated language and themes, I worked to draw out not only the Military's conception of service member identity but also how the institution works to shape that identity. In doing so, I aim to expose the ways in which ideological identity definitions are further developed by other invested State apparatuses, in this case the Military. It is important to note that while recruiting is one of the most direct avenues for defining military personnel identity, this definition is asserted in a somewhat circuitous manner. Rather than directly asserting who service members are, these materials frame these characteristics and traits as identity markers that potential enlistees can acquire or develop if they become service members. Although the arguments are often about potential, these materials still clearly define what it means to be a service member, and through these efforts we can see how rhetorical identity constitution functions in explicit recruiting contexts. 


\section{Recruiting Rhetoric and Identity Constructions}

Rhetorical theories of identity have drawn heavily on the understanding that identity, constructed and understood through language, is an essential and primary consideration in rhetorical efforts. Kenneth Burke famously argued that identification is prior to persuasion in rhetoric, and that a rhetor should focus first on establishing identity positions for him- or herself as well as audience members before moving into traditional persuasive strategies. Maurice Charland, drawing on Burke and others, added to rhetoric theories of identification through his development of a framework for constitutive rhetoric, which attends to the ways in which a rhetor persuades an audience to take up a particular identity. Many scholars have followed in this intellectual path-including myself — by considering the ways in which constitutive rhetoric succeeds, fails, allows for multiple identity positions, and so on (Tate; Zagacki; Kopelson).

In much of this scholarship, the person or group constituting the audience's identity is under the burden of convincing the audience to imagine themselves into the identity position and to act based on their acceptance of the identity. In these cases, the hailed audience can take up the identity without needing any sort of certification or explicit individual approval. In other words, I can claim to be a feminist and act accordingly without registering with an organization or getting any kind of official certification. In contrast, in explicit recruiting contexts, such as Military recruiting or even graduate and professional programs, the rhetor is under the burden of not only convincing the audience to take up the identity but also to seek out official sanction of their new identity. More concretely, the Army must convince potential recruits that they are soldiers, for example, and that they should enlist to fully realize that identity, thereby 
asking the Army to sanction their identity category. In this chapter, I examine the rhetorical strategies regarding identity constitution to develop a framework for what I will call recruiting rhetoric. Although many scholars studying rhetorical theories of identity use hailing, interpellating, and recruiting as roughly synonymous terms, in this piece I use recruiting rhetoric to specifically refer to strategies used in explicit recruiting contexts.

By understanding the Military's rhetorical work as recruiting rhetoric, a specialized context, we can better understand the ways in which the Military makes use of the available public constructions of service member identity, such as those promoted in films which were considered in previous chapter. The following examination of Military recruiting rhetoric elucidates three prominent strategies that work from existing perceptions of service members in an attempt to more precisely shape ideological understandings of personnel identity: provisional hailing, definitional rhetoric, and the constitution of supporting secondary identities.

On the whole, the Military claims about service member identity, as seen in their recruiting materials, draw from and reinforce the same messages that are disseminated in films and other entertainment programming. This is not altogether surprising for two reasons. First, the understanding of personnel promoted through entertainment media is largely positive. Second, as we learned in the previous chapter, the Military is often involved in the production of these movies and television shows-by offering financial support, providing filming locations and set materials, and so on. Still, the Military's rhetoric about personnel identity in recruiting materials works to develop the more general characteristics that are associated with the identity and to offer more consistent 
interpretations of those characteristics. In their recruiting materials, the Military focuses in particular on developing and defining the ideological understanding of service members' superiority.

\section{Hailing in Military Recruiting Rhetoric}

While the particulars of constitutive rhetoric have been covered in Chapter One, it is useful here to recount that in his seminal text on constitutive rhetoric Maurice Charland lays out three essential steps for this rhetoric. The first is creating an identification in the audience with the rhetor as well as other audience members; the second is establishing a historical precedent for the identity, and the third is compelling the audience to take up an action that seems like a choice but is in fact not if the identity is accepted. In his classic case study, Charland demonstrates this by explaining that the constitution of the peuple Quebecois (and the associated history and values) necessitated that those who took up this identity also take political action. Importantly though, the action proposed in the $3^{\text {rd }}$ step, argues Charland, must seem like a choice.

This is where recruiting rhetoric and constitutive rhetoric diverge. In recruiting rhetoric, at least as it happens in Military recruiting, the final action is necessary for the hailing and identification that occurs in the first step to be complete. Therefore, the identification that occurs in the first step is always provisional in recruiting rhetoric. More concretely, recruiting materials assert that the recruit is a certain kind of person but that to fully meet his or her potential that individual must enlist. Without completing the final action, in this case enlisting, that individual is missing key features that would qualify them to be the type of person they are hailed as being in the first step. In his famous essay on Ideology and ISAs, Louis Althusser similarly speaks to the physical 
actions taken by subject which constitute and reinforce their subjectivity within the ideology. As Althusser discusses them, these rituals and behaviors are not used explicitly as gate-keeping tools. For example, not going to Confession doesn't preclude a person from being Catholic. In the recruiting context, however, the final action is explicitly presented as a tool for sanctioning and acknowledging a person's identity category. In practice, in Military's case, not enlisting precludes the otherwise eligible person from becoming a military service member, and the initial hailing step is clearly provisional.

This process occurs in essentially the same manner for each branch, but it is clearest in the recruiting materials for the Air Force. Nearly all the recruiting materials for the Air Force address the primary audience, potential recruits, by describing the kind of person they are, the things they like to do, and so. Informational brochures about the Air Force describe potential recruits as "creative, innovative people who are interested in developing and using scientific technology" (Air Force Technical Degree) and as those with "high mental capabilities" and "aptitude" (Explosive Ordinance Removal; Now More than Ever). These qualities are certainly positively marked in contemporary American society, and the Air Force is encouraging potential recruits to identify with these characteristics and believe that they can succeed in the branch based on these traits.

While the Air Force is trying to secure recruits who already believe this about themselves, the materials still invite those who may be more reticent to identify fully with these characteristics. One informational brochure about jobs in the Air Force begins with a section titled "No Experience Required." Here the branch assures recruits that through discussions with a recruiters and testing the Air Force will help them discover "a job that you've already got a knack for-whether you know it or not" (Now More than Ever, 
emphasis mine). Again here we see an emphasis on the natural and inherent talent that Airmen (and arguably all service members) have. ${ }^{7}$ If the faith communicated in the recruiting materials is not enough reassurance for a potential enlistee, the Air Force website includes a range of games that offer the chance to explore Air Force jobs and to test these "natural" abilities.

The most explicit of these games is entitled "The IT Factor: Is it in your DNA?" ("The IT Factor"). The introductory video for this game fully participates in the hailing of potential recruits as individuals with natural superior talent while still ending with the challenge to the audience to test those abilities:

Where does a person get the courage to jump from an airplane at 50,000 feet into hostile territory at night?

What makes a human being push the envelope beyond what others believe impossible?

What sets certain men and women apart from the rest?

The answer? They all possess a trait we call the IT Factor. Come with us and see how individuals with the IT Factor play vital roles every day in the U.S. Air Force. And challenge yourself to see if you have it too.

Along with this audio, the video displays converging images of DNA strands and jet airplanes as well as a variety hexagon-shaped, moving images showing Airmen piloting jets, jumping from planes, reading displays, and so on. It also indicates the six components of the IT Factor which are tested in the game: memory, multitasking, spatial reasoning, concentration, observation, and logic. The player can test his or her ability in the game which offers a series of questions or activities for each component. Once the

\footnotetext{
${ }^{7}$ While inter-branch rivalry may encourage the Airmen to challenge the notion that service members in all branches have this natural talent, there is a consistent rhetoric across recruiting materials that appeals to inherent skills and dispositions. This section considers the Air Force specifically due to its more blatant and consistent use of this message.
} 
player has completed the task, he or she receives a score which can be shared through various social media platforms so that he or she can challenge and compete with his or her friends.

In this game, as in the brochures, the potential recruits are encouraged to believe that they should be members of the Armed Forces because clearly they already naturally have the traits that service members have-or so the message goes. Further, a sense of camaraderie with previous, current, and potential personnel is promoted through rhetorical moves like the final challenge for players of the IT Factor game to see if they "have it too" as well as brochures which promise enlistees will join a "tightly knit" community (Explosive Ordinance Removal). This call matches similar invitations in Army and Marine Corps materials. The Army asks potential soldiers to consider whether they "[have] got the motivation and ambition to succeed," "if [they] want to learn," and "if [they're] looking for experience and a challenge" (Being a Soldier; Army Skill Training; Rise to the Challenge). The Marine Corp adds that future Corpsmen have "courage," "recognize that these are historic times," and "wish to serve their country and communities" (Recruit Training; Take Your Place; Once a Marine). Across all these materials, it's clear that the recruiting rhetoric used here draws heavily on constitutive rhetoric by encouraging potential recruits to identify as military personnel by believing these descriptions of themselves to be true.

The catch in the recruiting message, however, is that to achieve this nearly destined identity the individual must enlist and make it through basic training.

As a result, the identity by which the target audience is hailed is withheld pending the completion of the necessary action. This last aspect is important to recruiting rhetoric 
because the primary goal is to ultimately fill the ranks - even as other purposes are achieved, namely, for this project, the definition of military personnel identity. Additionally, this withholding helps to reinforce the Military's broad message about military personnel identity, which is that they are superior, because even if the recruit has some of these traits, he or she can only fully reach his or her potential through military training.

This small difference between traditional constitutive rhetoric and recruiting rhetoric is important to understand because it demonstrates one way in which constitutive rhetoric can be adapted for different rhetorical situations. Recruiting rhetoric follows the basic tenets of constitutive rhetoric, yet the relationships between the different aspects of constitutive rhetoric are changed when the situation explicitly calls for recruiting. In this case, the rhetoric is not under the burden of making the compelled action seem like a choice; the action can — and in fact needs to be, for this purpose — a requirement.

\section{Definitional Rhetoric in Military Recruiting}

In addition to the way that recruiting rhetoric tweaks the hailing process of constitutive rhetoric, it also uses the rhetorical strategy of definition to add depth to the ideological understandings of military personnel identity, especially the idea that service members are elite. The activity of definition has been overlooked as a rhetorical activity in much of contemporary rhetorical studies, yet it arguably maintains a prominent role in public oratory and texts.

Definitional argumentation is essentially the assertion of the criteria or properties of a concept, situation, word, or whatever topic is at hand. In regard to establishing an identity category, definition lays the groundwork for the constitution of the identity. The 
articulation of this kind of rhetoric is seen primarily in stasis theory, which finds its early formations in Aristotle's work but is more comprehensively developed in forensic rhetoric scholarship by those such as Hermagoras, Cicero, Hermogenes, and the author of the Rhetorica ad Herennium. Stasis theory is a heuristic strategy for invention that assists rhetors in identifying and responding to the point of disagreement in an argument or debate. The four central stases proceed from questions of fact or existence, to questions of definition, to questions of quality or circumstance, to, finally, questions of procedure. In the second stasis, the goal of the rhetor is to assert the criteria or properties of the situation or issue.

The rhetorical nature of definition is further supported by contemporary rhetoricians, most prominently Chaim Perelman and Lucie Olbrechts-Tyteca in The New Rhetoric: A Treatise on Argumentation. As Perelman and Olbrechts-Tyteca explain, "the argumentative character of definitions is clearly apparent when various definitions occur of some term in ordinary language" (212). This understanding of definitions highlights the fact that definitions are essentially agreed upon understandings that are constructed through language. Further, they assert the important argumentative and rhetorical role of definitions by claiming that those engaging in definitional work want "to influence the use which would probably have been made of the concept had they not intervened and mostly to influence the relations of the concept with the whole system of thought" (213). Jeanne Fahnestock and Marie Secor extend this argument by claiming that agreed-upon definitions act as the underlying warrants for arguments and thereby control the choices and options available in an argument (225-6). In his succinct review of the strategy of definition Edward Schiappa distills these claims, as well as those of other philosophical 
scholars, claiming that "definitions function as strategies of social influence and control by establishing the 'correct' understanding" for words, concepts, etc. (171). From the relatively minimal Rhetoric and Composition scholarship on definitional rhetoric, it is clear that this strategy can essentially be understood as argumentation which aims to shape ideological understandings by establishing equality or other associations between a given concept and set of criteria or properties.

This scholarship tends to address explicit instances of definition—likely in an attempt to make clear the theories they are explaining — but the strategy of definition is often more subtle, as is the case in Military recruiting. Of course, the Military is not directly engaging in disagreement about who their personnel are — especially not with the broad ideological understanding promoted through films and other popular media. As we saw in the previous chapter, the construction of service member identity is largely positive. Yet, the Military is still interested in defining further certain aspects of the ideological understanding of personnel identity. It is in these efforts that Military recruiting takes up the strategy of definition, primarily as a method for declaring the criteria for "military superiority."

The idea that military personnel are "better" than the general American public (and arguably any other person) is a strong message in films that feature characters with military backgrounds. Often, as explained in the last chapter, this notion focuses on physical characteristics like fitness, strength, fighting skills, strategic and tactical reasoning, and so on. In some cases, though not as often, this idea is also connected to the service member's moral quality, yet in these cases that character is often acting without the consent or is acting against another authority-either military or government 
leadership or some other authority. Across these films, the general notion is spread that military personnel are elite, and yet the specifics of what that means tends to be tied to particular characters and varies almost as much as the specifics of the films. For these reasons, and likely others, one of the goals of Military recruiting rhetoric is to define the superior nature of its service members.

This message is communicated broadly through the assertion that enlistment, basic training, and the service experience will allow the recruits to achieve the best version of themselves. As explained in the previous section, the general potential is present in the recruits but it is the process of becoming and being a service member that allows them to reach their personal apex. Unlike film, however, that personal apex does not vary greatly between individual service members —at least as far as the recruiting materials are concerned. The general notion of "Be All You Can Be," even for the other branches, is articulated in very specific ways in the eyes of recruiters and the Military. While the Military further defines "military superiority" into a number of specific features—including ethical character and professionalism—one of the most prominent contemporary messages works to specify what it means to be a Military Warrior. The current popularity of "warriors" in American culture, as seen in the prevalence of superheroes and also popular protagonists like Katniss Everdeen from the Hunger Games series, has led the Military to more clearly articulate what it means to be a warrior in the U.S. Armed Forces.

In the epilogue to his recent book Breach of Trust, Andrew Bacevich draws on philosopher Alasdair MacIntyre to argue that the powerful "characters" in current American society are the Celebrity, the Geek, and the Warrior. "Characters" in this 
situation refers to types of people that are recognized in a given culture. Bacevich offers the Kardashians and the Clintons as examples of the Celebrity, and people like Bill Gates and Steve Jobs as Geeks. The "Warrior," he argues, in this post-9/11 era, is best exemplified by military personnel—but the prominence of this character can arguably also be seen in the types of films, books, and other popular media that have been popular over the past few years, such as, to name just one, The Hunger Games series.

Military recruiting materials aim to nuance and further define what "warrior" means in relation to service members - making military warriors better than "run of the mill" warriors. In many pop culture instantiations, particularly those in which the character is not affiliated with the military, warriors transcend difficult physical situations with their strength and often their cunning. This dominance and manipulation of the situation is what earns them the title of warrior. Certainly, this message is included in the Military's use of the label "warrior" for their personnel. The descriptions of warriors in the materials consistently reference the "strong mind, body, and spirit" needed to fulfill the warrior duties (Warrior Airmen). Yet this base understanding of the "warrior" only begins to describe the military warrior.

Military warriors add two important qualities to the warrior. First, they follow a moral code which is referred to as the "warrior ethos" by the Army's Soldier's Creed. This morality naturally works hand-in-hand with the assertion that moral superiority is an important feature of military elite-ness. In references to military warriors, nonetheless, there is almost always nod to "character." The warrior ethos has even, at least for the Army, become explicitly codified through the recent adaptation of the Soldier's Creed in 2003 (Bailey 248-49). The opening lines of this revised creed make two claims for the 
identity of the soldier: "I am an American Soldier. I am a warrior and a member of a team" (Be Army Strong). The Creed goes on to note the details of the warrior ethos and code, including traits like placing the mission first, never quitting, never leaving a fallen comrade behind, maintaining readiness, and so on. The military warriors constituted through the pledging of this creed "stand read to deploy, engage, and destroy the enemies of the United States of American in close combat" and are "guardian[s] of freedom." Military warriors, judging by the phrases associated with and defining "warrior" in these materials, are physically and mentally adept but they also follow an engrained code that guides the use of their superior skills and knowledge. Importantly, as Bailey adds and as is reinforced in the recruiting materials, they are able to follow this code under pressure (253). This is what makes military warriors "elite warriors."

In addition to the moral code that qualifies military personnel as superior versions of the Warrior, military warriors stand above others because they work as a team. It is perhaps unsurprising that most warriors glorified in popular culture are lone figures. Admittedly, there are exceptions, but even in teams of warriors there are leaders who clearly stand above the rest. For example, even in a film like The Expendables, in which the appeal of the film is strongly based on the inclusion of multiple high-profile action stars, Sylvester Stallone's character is clearly the leader and makes all the significant decisions and plans. In contrast to this popular understanding of warriors, Military recruiting materials strongly emphasize that military warriors function as a team. This can be seen not only in the Soldier's Creed asserting that warriors do not leave fallen comrades behind, but also in the Marine Corps materials which repeatedly refer to the Corps as being a "family of warriors" or a "brotherhood of warriors" (Be Army Strong; 
Once a Marine). While the emphasis on the warrior team primarily refers to groups of service members, it also importantly refers to these personnel acting as a team member when working in their communities. In the Marine's recruiting materials the idea of being an "elite warrior" is frequently immediately associated with being an "upstanding citizen." This combination reinforces the idea that warriors are not solo actors but also the idea that the superior military warrior is a warrior because he or she recognizes the importance of working together and of service.

The Military's articulation of the Warrior then uses the common understanding that warriors are physically and mentally skilled people who can overcome difficult physical situations but it adds that military warriors also follow a moral code and work as a team. In this way, the recruiting materials establish that the military warrior is of a higher caliber than the average warrior. It is also important that this understanding of the military warrior offers a way to encapsulate the ways in which military personnel are elite generally since it incorporates many of the other themes that argue for their superioritymorality, professionalism, physicality, and so on.

Across these recruiting materials then, it is clear that one main rhetorical strategy used by the Military is to define the criteria of the broad understanding of who service members are-especially the ways in which they are "superior." This definitional work is important for the Military in its efforts to shape the ideological understanding of personnel identity. Part of the reason that it is successful is because rather than contradicting what is established through ideological state apparatuses, like the Entertainment ISA, it reinforces and then nuances those understandings. This minimizes the dissonance the public might feel when being presented with varying representations 
of service members, and allows the Military to make more effective and far reaching claims about the identity of their personnel.

For the most part, the definitional claims being made in these materials primarily address potential recruits by telling them either what they are already, as I discussed above, or by telling them about what they will be perfected through military training. While these potential enlistees are the target audience for recruiting materials, there are also secondary audiences which are being addressed through these materials. The Military is similarly interested in shaping these audiences ideas of who service members are.

\section{Military Recruiting Rhetoric's Address of Secondary Audiences}

Most scholarship studying constitutive rhetoric and recruitment tends to identify the audience of this rhetoric as the individuals being recruited or constituted. Yet, some scholars investigating constitutive rhetoric have begun considering the possibilities of multiple audiences. In her article, "Risky Appeals: Recruiting to the Environmental Breast Cancer Movement in the Age of 'Pink Fatigue,"' Karen Kopelson argues that the rhetoric of the Breast Cancer Fund (BCF) is "working from, and offering audiences, more than one constitutive rhetoric" (130, emphasis in original). Kopelson's claim forces us to recognize that those using constitutive rhetoric are often making room for more than one audience, or type of person, to identify with the promoted subjectivity. While Kopelson's argument opens the door for analyzing multiple constitutive rhetorics from one rhetor, in her study, the BCF is still bringing different types of people into very similar subjectivities. Kenneth S. Zagacki’s study of President George W. Bush's failed constitutive rhetoric when addressing the Iraqi people offers insight into the way a rhetor 
can constitute two distinct identities simultaneously. Zagacki asserts that Bush's address was primarily designed for Americans, framing them as morally superior people who should "spread 'good' around the globe," but Iraqis were also hailed in Bush's rhetoric to take up similar democratically-driven identities that contradicted the Iraqis existing emphasis on religious affiliation. Although Zagacki's focus is on how Bush's rhetoric failed, his argument nevertheless lays the groundwork for considering the ways in which constitutive rhetoric can address multiple audiences. Military recruiting materials are a prime site for examining the way in which constitutive rhetoric addresses distinct audiences because, in addition to the Military's primary concentration on potential personnel, these materials must also address those who may influence a recruit's decision.

In the 40-plus years since the Vietnam War, the Americans have continued to wrestle with the public backlash to the actions of the U.S. government and military in Vietnam, as well as the resulting division between American citizens and the Military and its personnel. Because it is generally accepted that the enlisted personnel were unsupported in the aftermath of the war-both by the State and by the people- the current available discourse about personnel is primarily supportive and sympathetic, with critique directed toward Military leadership or, in rarer cases, service members who have violated core expectations about the morality of personnel. Nevertheless, the typically supportive response to service members is often reversed when parents and teachers are confronted with the possibility of individuals whom they know personally enlisting in the Armed Forces (M. Martin 13). At that point, the fears about the risks of service come flooding back into the conversation. 
To address this response, many of the branches' recruiting websites and social media accounts include separate sections for those who may influence a potential recruit's decision, such as parents, other family members, teachers, and counselors. Therein, the address is explicitly and logically directed toward those who might shape the potential recruit's decision, those whom recruiters call "influencers" (The Recruiter Handbook 5-3). What is more interesting for understanding the way in which constitutive rhetoric addresses multiple audiences, however, is that this audience, as well as the broader American public, is also addressed in the core recruiting materials. If we look past the heavy use of direct address in the brochures, videos, and websites, we see a second constitution that hails the American public as supporters and enablers of military personnel. Considering this secondary address is important to fully understanding the complex work of recruiting rhetoric, for one, because it adds another dimension to how constitutive rhetoric works in explicit recruiting contexts. In addition, it suggests that for recruiting and constitutive rhetoric to be successful the rhetor must (re)shape other identities to verify and reinforce the main identity being established.

Core recruiting materials most explicitly hail family members, but the rhetoric included in these materials also addresses educators, mentors, and the American public. These secondary audiences are constituted as being primarily proud, enabling, respectful, and grateful. For example, the Army repeatedly states that completion of basic training will result in a "sense of pride" for the individual and for their "parents, relatives, and friends" (The Making of a Soldier; Be Army Strong). The Marine Corps echoes this claim in their assertions that Marines "carry a lifelong pride that many will notice" (Take Your Place). In these examples, family members, friends, and even other citizens, are 
constituted along with the potential recruit. The interpellation of both in a single phrase binds these audiences in support of each other as well as in support of the Military. Moreover, these constructions posit the "appropriate" responses and beliefs for the recruit's friends and family. By framing these secondary audiences in this way, the Military uses recruiting materials not only to shape what it means to be a good American citizen, but also — and more to the point I'm making here — to reinforce and affirm Military Personnel identity.

While the references to proud family members offer more obvious examples of the hailing of secondary audiences, more often these secondary audiences are constituted implicitly. In some cases, this implicit hailing is done through the use of pictures that show supportive family. The Marines draw heavily on this strategy. In one brochure, a picture of a young Marine spending time with four other Marines of various ages directly supports the Marine Corps' claim about the history and brotherhood of the branch, but also suggests that family and friends will happily show their support of the potential recruit's choice. In another Marine brochure, in a section discussing a Marine's life outside the Corps, there is a picture of a young Marine holding a baby next to a smiling young woman - evoking the idea that family members would welcome the support that service in the branch would provide for the recruit and their family.

In fact, the Military's emphasis on the benefits of service not only helps them persuade recruits, it also suggests that unsupportive influencers would be depriving potential enlistees of experiences and advantages that they could not get elsewhere. It's not insignificant that claims about the benefits of service also implicitly address influencers by countering their concerns about the risks of service. While there are many 
benefits associated with service in the recruiting materials, one of the most prominent is the educational benefit, even beyond the financial support of the various G.I. bills. The training provided for individual service members' occupational specialties (which often occurs right after basic training) is framed as being even better than civilian training. Both the Army's and the Air Force's materials describe their training and technologies as "cutting edge," "the technology of tomorrow," "state of the art," "at the forefront" and more (Being a Soldier; Now More than Ever; Explosive Ordinance Removal). The Army goes on to claim that "Every training program employs the most modern teaching and learning methods available" and that "the quality of instruction you receive would be hard to match anywhere" (The Making of a Soldier). In turn, the Air Force describes its training as "world class" (Explosive Ordinance Removal). These opportunities, as the recruiting materials frame them, are not easily accessible so enlisting in the Armed Forces will grant the recruit access to advanced training which will in turn give them experience and skills that are nearly unavailable any other way. All of this deflection of concerns and fears is, of course, an obvious requirement when recruiting for a position that can be so high-risk. Still this focus only allows for positive discourse so that anybody discouraging enlistment is framed as withholding opportunities for social mobility and holding the recruiting back from reaching their true potential and from achieving the "American Dream." Thus, in addition to family members and friends being constructed as proud of personnel, all influencers are constituted as supportive enablers.

In addition to addressing secondary audiences who have personal relationships with the potential recruit, recruiting materials also hail the American public as respectful and grateful citizens. In the brochures and videos of all the Armed Forces, personnel are 
positioned as the defenders of the physical nation and also of the ideals of the United States of America. The materials of each branch make this clear through the reference to the historical work of the branch and also the assertion of their continued and future work in defending, protecting, and forwarding our country. As members of the Armed Forces, military personnel are able to "make a difference for [themselves], [their] family, and the nation" (Rise to the Challenge). Importantly, as a result of their military service, "The American people respect Soldiers for who they are, what they stand for and what they do for the nation" (Be Army Strong). Recruiters and their materials argue that the primary purpose of the Armed Forces is to assure the well-being of the country and her citizens. In doing so, the Military only acknowledges American citizens who recognize the work of service members with respect and gratefulness.

This rhetorical strategy of interpellating secondary audiences as people who acknowledge and support the primary identity is essential to the successful process of both recruiting and constitutive rhetoric. As Charland explains, an important step in constitutive rhetoric is establishing the heritage and precedence of the constituted identity. Most often, at least in scholarship on this topic, this step is achieved through references to shared events, activities, dispositions, and so on that are directly connected to the primary audience. In Military recruiting, though, the intentional hailing of other American subjectivities as supportive of the Military and its members works to encourage recruits to enlist, thereby completing the acceptance of the identity with the action made necessary in the provisional hailing.

\section{Military Recruiting: Provisional Hailing, Definition, and Secondary Confirmation}


Since the 1970s, Military recruiters have been forced to contend with changing cultural expectations and beliefs about itself and its members, fluctuating economic realities, and dynamic and often volatile political arenas, both domestically and internationally. Maintaining the All-Volunteer Force across these decades has required the Military attend to these issues and adapt their recruiting strategies accordingly.

One of the first challenges for recruiting personnel into the AVF was convincing young men and women that being a service member was a desirable and beneficial identity in American culture. As a result, Military recruiting became even more invested in the constitution of personnel identity in public forums. In recruiting materials, each branch of the Armed Forces directly addresses potential recruits, hailing them as the type of people who belonged in the branch because they already possessed the characteristics of service members. Importantly though, even as the materials promised potential recruits that they already had the necessary dispositions, the materials also argued that the recruits could not fully achieve their desirable and natural identity without enlisting. This provisional hailing functions much the same as mass identification in constitutive rhetoric, yet the caveat requirement of enlistment demonstrates an important way in which recruiting rhetoric is different from constitutive rhetoric.

Recruiting rhetoric also incorporates definitional rhetoric to make clear the traits and other markers of the identity. In addition, this strategy helps to strengthen the interpellation that occurs in the first step because it creates more opportunities for the potential recruit to recognize him- or herself in the description. In Military recruiting, we see this in the positioning of personnel as a special and superior kind of warrior. While the provisional hailing and definitional rhetoric primarily address the primary audience, 
the constitution of individuals into the recruited identity category is further affirmed through the hailing of supportive secondary identities. Military recruiting materials interpellate parents, friends, teachers, mentors, and other influencers into subjectivities that support and reinforce the constituted military personnel identity. The construction of these supportive identities encourage the primary audience to fully accept the identity into which they are being hailed, and take action based on their acceptance. This mostly implicit address to secondary audiences is a crucial aspect of constitutive rhetoric that has been often overlooked by scholars.

In this chapter, I have aimed to demonstrate the Military's focus on developing and nuancing ideological understandings of military personnel identity in the period following the 9/11 attacks. By considering these efforts in the context of Military recruiting materials, I have also worked to expand our understandings of how rhetorical identity constitution occurs in explicit recruiting contexts - an area that to the best of my knowledge has not been examined. The framework I have identified herein-the use of provisional hailing, definitional rhetoric, and construction of secondary audiencesfocuses only on the rhetorical strategies regarding identity in these contexts. As such, I leave the door open for further considerations of these explicit contexts, which remain important not only due to the Military's continuing All Volunteer Force but also for all situations in which individuals are being asked to seek institutional approval for the identities they claim. Such contexts include recruitment into graduate and professional programs and even the recruitment of professional athletes who increasingly must first be student-athletes. Further, this chapter gives us insight into the ways in which a repressive apparatus responds to and takes up ideological understandings disseminated by the State 
through other ideological apparatuses. It is important to recognize that even within the State different stakeholders are invested in creating and instilling different messages. It is also important, however, to recognize that the State and its apparatuses are not the only entities shaping ideological understandings. To that end, the next chapter examines the claims that military personnel make about their identity in public places and the strategies used by these individuals to support and/or challenge ideological beliefs about their cultural role and their identity. 


\section{CHAPTER IV}

\section{“THE GREATEST BRIDGING TOOL”: SERVICE MEMBERS' STORIES AS AN INTERVENTION IN PUBLIC DISCOURSE}

Military service members, both current and former, take advantage of a wide range of media to speak to public audiences. Just as in the past, it is common today for service members to publish memoirs of their experiences and to write articles for popular periodicals. It is almost more common though for these individuals to look to online venues for distributing their texts. A number of popular celebrity figures who have served maintain online presences, including actor and motivational speaker J. R. Martinez and Miss Kansas 2013, Theresa Vail. In addition to figures such as these who maintain sizeable followings, many service members take to YouTube-as well as other social platforms - to share videos and images of deployment, living on base, downtime adventures, or just explanations of what military life is like.

While the range of texts produced by service members is vast, many of these pieces use storytelling as a basis for sharing knowledge about military experiences. The method and package of the storytelling may vary depending on the platform, the genre, the context and so on, but nonetheless, sharing their personal stories is one of the primary ways in which service members reach out to the American public. The coordinator for the Veterans Resource Center at the University of Kentucky, Anthony Dotson, calls for the further use of this strategy, arguing that these stories are "the greatest bridging tool" for increasing understanding (Panel for Voices of Student Veterans: A Documentary Drama). 
The prominence of this strategy also makes these stories one of the main ways in which service members intervene in the public rhetoric about their identity. This should be somewhat unsurprising given that, as Judy Segal argues, "[personal] narratives have come, over the past 25 years or so, to be understood as a mode of knowledge" (19).

This chapter focuses on the ways in which military personnel, and organizations that support them, use storytelling, under a variety of names, to enrich and complicate popular understandings of their identity and experiences. This examination offers insight into how individuals who have been labeled, by choice or otherwise, with a particular identity create and circulate public rhetoric about themselves that interacts with the messages distributed by state apparatuses. To understand the ways in which military personnel are acting as individuals speaking back to the State, we need to explore the importance of storytelling in shaping cultural understandings, as well as the common rhetorical aspects of stories, that are shared with public audiences.

\section{Storytelling as an Ideological Tool}

The ideological power of stories has a much longer history than just the past twenty-five years. Jerome Bruner, in "Life as Narrative," claims that

one important way of characterizing a culture is by the narrative models it makes available for describing the course of a life... and the tool kit of any culture is replete not only with a stock of canonical life narratives... but with combinable formal constituents from which its members can construct their own life narrative. (694)

In other words, the stories of a culture are the knowledge base from which an ideology's subjects can learn about themselves. Stories interpellate subjects into particular available and sanctioned identities. Cultural narratives are circulated in many ways. In the two previous chapters, we've seen how movies and recruiting materials craft and circulate 
carefully developed constructions of who service members are. Stories become the available "tool kit," to use Bruner's phrase, for both military personnel and the broader American population to understand the "'possible lives"” and identities available to service members (694).

The stories of a culture, as was especially clear in chapter two, present a limited range of available narratives about identity and experiences. Although she is focusing on narratives about breast cancer, Segal rightly asserts that "personal narrative performs a regulatory function in public discourse" (3). Stories have this power because they are what Michel de Certeau describes as "well known, and therefore classifiable," meaning that they function to reinforce and enact sanctioned beliefs and practices (89). Continuing this somewhat disheartening description of the function of cultural stories, Bruner explains that sanctioned narratives "achieve the power to structure perceptual experience, to organize memory, to segment and purpose-build the very 'events' of a life" (692). In this scholarship, a dominant and deterministic ideology creates and distributes the available life narratives through stories, and thereby, according to Bruner, an individual's life is essentially crafted before it is even lived.

Yet, the deterministic model for how cultural stories function does not fully describe the role of such stories. De Certeau, in fact, argues that what is important about well-known stories is that they can be told tactically by the inclusion of an "extra element" which can undo a sanctioned purpose in the story (89). The "act of saying," or telling, creates an opportunity for the teller to push back against the deterministic attempts of the standard story. This use of storytelling as a form of disruption can be seen when stories are used in the form of testimony, counter-storytelling, or activism (Felman 
and Laub; Strejilevich; Delgado; Segal). As Segal explains, breast cancer narratives, though they do and have served other oppressive and normalizing functions, are a form of activism because they are also used to construct breast cancer as "normal" and "not shameful” $(6,9)$. Storytelling can be a useful tool for intervening in public rhetoric because, as Bruner argues, "the objective of narrative, then, is to demystify deviations... it locates them and makes them comprehensible" ("Self Making and World Making" 72). Thus, in this scholarship, we can see there is an opportunity for tactical stories, or tactical storytelling, to affect the ideological structure that has such a powerful role in shaping an individual's available life narratives. And, through their own efforts, we can certainly see service members taking up this cause of reshaping the available public discourse about personnel with their own stories.

\section{The Stories and Storytelling of Service Members}

One of the common goals for the many organizations that aim to assist current and former military personnel is to bridge the gap between service members and civilians. A number of these groups, such as Iraq and Afghanistan Veterans of America and Got Your 6, do this in part by actively recruiting members who have not served but who nevertheless support service members. More directly, though, these organizations and projects engage in activities that are designed to achieve this goal by adding to the public discourse about the military personnel population. The Student Veterans of America's (SVA) Million Records project, for example, researched and shared data about student veterans' academic success, and SVA's collaboration with Kognito produced interactive videos for both faculty and fellow students to increase the audiences' sensitivity and responsiveness to student veterans' positions and needs on campus. Often 
though, organizations addressing the needs of service members attempt to shape public understanding of military personnel by creating platforms for service members to share their personal experiences and stories.

Given the powerful cultural role of shared public stories, as discussed above, this chapter examines the shared rhetorical features of service members' stories, by focusing on a handful of different collections. There are three collections that make up the bulk of my archive: the Combat to Kentucky (C2KY) oral history interviews, Gawker's series True Stories of the VA, and a series of videos from an event hosted by Got Your 6 entitled Storytellers. The stories and experiences of service members are shared by many organizations and in many different manners, and while many of those have been considered here, these three collections offer enough variety of circumstance yet include enough shared moves to be relatively representative of the cultural work these stories do. Some of the details of these collections will be presented in the subsequent analysis, but in general each collection gives individual service members a platform for sharing the experiences they had while serving in the US Armed Forces. The rhetorical examination of service members' stories considers, in particular, the shared aspects of their stories and the work they do to intervene in the available public rhetoric about military personnel.

\section{Rhetorical Features of Public Stories}

One way to better understand the rhetorical work of publicly shared stories is to examine the shared features of a set or kind of stories. Among scholars of narrative, rhetoric, and communication (and very likely others), this line of examination has proved useful in understanding both the overall goals of a kind of story as well as the functions of aspects within a story, since that aspect may work individually and in service to the 
overall goal. The study of these features can certainly inform understandings about the structure of a kind of story but, as Bruner argues in "The Narrative Construction of Reality," they can also demonstrate how narrative "operates as an instrument of mind in the construction of reality" (6-5). Thus, a story's features give insight into form and purpose but also into the cultural work that the story is aiming to do.

Beyond the more obviously necessary features of characters and an arc of action, most stories also include information about why the story is being told (Norrick; Bruner, "Self Making"), an exceptional or unexpected moment (Bruner, "Self Making," "Narrative Construction"; de Certeau), and an explanation of the story's meaning (Norrick; Segal). My examination herein follows the scholarly work on narrative and storytelling by similarly focusing on both form and rhetorical purpose of each shared feature within service members' stories. Although there are certainly other aspects in the stories shared by military personnel, I consider in this article the following four features and their rhetorical goals: establishment of exigency, authority claims, discussion of a traumatic experience, and presentation of the intended message.

\section{Crafting Exigency - Developing the Historical Importance of Iraq and Afghanistan}

\section{Veterans}

Despite the cultural power of stories, most still require a justification when they

are shared. As Bruner argues, "narratives must answer the question 'Why?"” ("Self Making” 71). This justification, which is sometimes called the "why tell' function" (Bruner "Self Making") or the "serviceable abstract" (Norrick), offers the audience a hint of the story's importance and function. As a result, this aspect of a story offers a frame and context for the story. In the case of the stories shared by military personnel, this 
explanation tends to be offered in one of two ways and generally serves to craft the cultural exigency for the telling of this type of story, the personal stories of service members.

First, the form of the explanation is typically offered either by the storytellers themselves or, and more often, by the context through which the story is distributed. In cases in which the service member sharing the story is acting primarily on his or her own, the justification for the story is typically offered by the teller. J. R. Martinez is a good example of this because as a celebrity and motivational speaker, he is more likely to frame his story independent of the surrounding context. To be more concrete, when Martinez tells about his experience in Iraq and as a victim of an IED, he typically does so as a guest speaker or writer, and often not on a show or site that focuses on military personnel and their experiences. While Martinez has considerable cultural capital as an actor, a similar move can be seen in the range of informative videos about military experiences posted on YouTube by less famous individuals. ${ }^{8}$

More often, a service member's story is shared as part of a collection curated and promoted by an organization. For example, in the Gawker series, True Stories of the VA, each entry is actually a collection of stories from service members and their family members. Each entry begins with a contextualizing paragraph or two written by the Gawker editor organizing and monitoring the series, Hamilton Nolan, which explains issues with the Veterans Affairs office and links to other articles that discuss these concerns in more depth. Few of the actual stories from the service members address the current issues with VA because the justification for their storytelling is already articulated

\footnotetext{
${ }^{8}$ For examples of this see Martinez (2010) and relevant videos by YouTube user JimmyDShea.
} 
by the Gawker editor. Similarly, the $\mathrm{C} 2 \mathrm{KY}$ oral history project is hosted on a website designed to look like a typical blog with a short description of the project on the right hand side and menu tabs across the top that include pages such as About C2KY, Interviews, and Subscribe. On these sites, the organizations can articulate the "why tell" function for the collection as well as for the individual stories, rather than the tellers themselves.

Despite the important rhetorical work done in an organization's justification for a story, which I will return to in a moment, sometimes the storytellers participating in these collections include their own explanation of the significance of their story. Interestingly, for the most part these moments reinforce the shared goal to increase civilians' understanding of personnel. Travis Martin, as part of the $\mathrm{C} 2 \mathrm{KY}$ project, explains that sharing stories is important to service members—-himself and others he's worked withbecause "it's solidified ... you get to see that your words are going to be carried on, that they mean something to someone." Participants in the Gawker series reinforce Martin's words in the repeated claims that despite being painful to read, they are "a story that needs to be told" ("Dark Corners of My Mind").

Sometimes further explanations are offered as to why service members' stories need to be shared. In his C2KY oral history, Phillip McKenzie echoes the experiences of many of the other storytellers when he describes the accusations that his fellow college students had in response to learning about his service, including the infamous notion that he "killed women and children." McKenzie highlights the importance of stories when he explains that "the problem is that no one knows your story. No one knows where your road has taken you ... It's hard not to argue with them and fight their ideas of who you 
are." Similarly, many service members use their stories to increase understanding by explaining what common military situations are like, including boot camp or being attacked. In the C2KY series, many storytellers talk about what it's like to be shot at or to be face-to-face with an individual who is trying to kill you (Robinson; Gayheart). The drive for service members to shape cultural understanding through stories is clear in these moments. These storytellers were given justifications when asked to participate in these series; that their personal explanations mirror those of the curating organizations demonstrates that the sharing of these stories is seen as powerful rhetorical move for this community as they speak back to the American public.

The explanations offered by individuals and by organizations help these stories conform to the conventional structure that their audiences expect. In addition, these justifications work to craft an exigency for the curated stories. It may seem that the cause for these stories is apparent. As the wars in Iraq and Afghanistan ostensibly come to an end, many of the service members involved in these engagements are returning to positions in which they are more likely to interact with civilians. While that is certainly true, and is a fact consistently drawn on by those invested in the well-being of service members and veterans across many contexts and fields, there is not much opportunity in public discourse for individual service members' stories to be highlighted. The organizations creating and promoting these collections of stories are working to create and thus craft that public discussion. While this happens in many ways, here I will focus on one strategy that is shared across some of the justifications offered for these stories: the labeling of these stories as oral histories. The use of this term, I argue, works to frame these stories as important and necessary, and works to create a need for the stories to be 
collected and heard at this moment. Using the term oral history adds an extra layer of significance to the stories that are being told. In his Washington Post article titled "Passing Down Memories," Richard Harwood explains that researchers often collect oral histories to allow us "to collect or preserve material" that "major historians" do not collect because "they have always been primarily concerned with kings and queens, generals, tycoons, ... and other movers and shakers in the world." Oral history projects offer what Studs Terkel describes as a "challenge to the official word" and thus add an individual nuance and more complex perspectives to the historical record (vxiii). While they often provide non-standard perspectives, oral history projects have grown in popularity over the $20^{\text {th }}$ century, becoming an acceptable research process and methodology. I would argue that in a time when personal stories abound, using the label oral history gives these service members' stories an added importance because the term suggests that the service members' stories are part of, or should be part of, the codified record about this time in American history. This move not only raises the significance of the stories, but it also works to create the exigency for the stories and offer the audience a justification for the telling of the story.

The use of this term is clearest in the Gawker True Stories from the VA series and in the $\mathrm{C} 2 \mathrm{KY}$ collection. To understand how the use of "histories" as a label for service members' stories works as a rhetorical tool to shape both exigency and significance, we must first consider other genre expectations that are at play in a news blog context such as Gawker's.

First, the Gawker series was run on the popular news blog. The site is a powerful cultural force with a wide readership. As a blog site though, allowing not only comments 
on the articles but also frequently featuring full posts by readers, it is often critiqued as a whole for being sensationalist, and individual commenters and even some authors of the posts are accused of being biased or distorting and omitting relevant information for stories. In this context, the True Stories of the VA series could well be viewed with some skepticism about its authenticity and purpose.

To counter this perception, the editor Hamilton Nolan also uses the introductions to improve the credibility of the series, its editor, and its participants. Part of this occurs in the discussion of the current concerns about the VA and the inclusion of supporting links. As mentioned earlier, this offers a justification for the story but it also articulates the kairotic moment that shapes the exigency and purpose of these stories. Further, in the third entry in the series, Nolan re-states the purposes and limits of the series, focusing on two points. He defends the authority of the speakers against commenters by asserting that the focus is on the Office of Veterans Affairs's bureaucratic processing problems and lack of funding/support for qualified medical personnel, and he explicitly wards off dismissive comments about the mental health of the author-participants. In his second point, Nolan concedes that personal stories are necessarily "subject to biases, the subtle distortions of memory, and what not," but goes on to emphasize that "personal histories... paint a picture of reality that is hard to find elsewhere" ("PTSD and Me"). In Nolan's introductions and in his definition of the series' purpose and value, there is a clear rhetorical move to establish a necessary space and audience within public discourse for service members' stories. In these places, but particularly in the rhetorical use of "histories," Nolan imbues the series, the stories, and the participant-authors with a sense of historical and cultural significance. 
This strategy is not unique to the Gawker series though. A similar move can be seen in the $\mathrm{C} 2 \mathrm{KY}$ series, which is associated with arguably more reputable institutions in the Louie B. Nunn Center for Oral History and the University of Kentucky. The C2KY series describes itself as an "ongoing oral history project" ("From Combat"). As discussed above, the term oral history invokes a particular set of genre conventions. Yet, the oral histories presented in the $\mathrm{C} 2 \mathrm{KY}$ series are, in practice, more of a combination of multiple genres: interviews, conversations, and oral histories. In gathering these artifacts, service members - most of them veterans, but some current Reserve personnel—sat down with a fellow veteran and spoke about their time in the military, their return to the States, and their interactions with civilians (mostly but not exclusively, their classmates). In discussing the project, Nunn Center director Doug Boyd, pointed out that the interviewer had to be a fellow service member because it allowed those telling their stories to be more comfortable and open (Panel following Voices of Student Veterans). In turn, this makes the full length oral histories often seem like recorded conversations just as much as interviews. Certainly, the videos in the $\mathrm{C} 2 \mathrm{KY}$ series more closely adhere to the genre conventions of oral histories. However, the rhetorical move of labeling this project and its pieces in this way works to create a space in public discourse that not only sanctions the telling of service members' stories but also frames the telling of these stories as necessary to the understanding of this cultural moment in American history. The stories become more than just another personal narrative. The term oral history sanctions the stories as important and powerful and meaning-making. Establishing Authority 
The naming of service members' stories as oral histories offers audiences a way to understand the importance of the stories while also giving the project a sense of credibility and authority. This demonstration of ethos is equally important to the storytellers themselves, and the primary way in which the storytellers show their credibility is through the naming of the branch in which they served, their rank, their job, and how long and where they served. Sometimes other information is included, but these basic elements are almost always delivered as a way to prove their identity and their authority to speak on the topic of military service and experiences.

In many ways these opening ethos-asserting claims are straightforward. The information provided at this moment provides basic identifying information while also positioning themselves within the broad and varied category of "service member." Nonetheless, within this typically brief and seemingly simple declaration, there are a few interesting rhetorical moves occurring. While generally service members offer a somewhat succinct introduction for themselves, to offer a more considered analysis of the rhetorical aspects of this ethos-building strategy, I present here the contextualizing information provided by the first participant in the Gawker True Stories of the VA series:

I was based on Naval Amphibious Base Coronado, in San Diego. My command existed to give intelligence support to deployed SEAL Teams. We worked long, hard hours but we had the satisfaction of knowing that our work helped keep our guys alive. ...

Since I was an intelligence person, I wasn't out shooting people. Most of my work was done on our base, though we would tag along with the shooters under certain circumstances. ...

My deployment wasn't one where I was shot at frequently, it was one where we were (generally unsuccessfully) bombed. ("We Want Veterans to Share True Stories of the VA")

Like most of the other participants in the Gawker series, this sailor does not give his 
name, yet he does provide the other positioning information that affirms his authority to be speaking about military experience — that he has served and was deployed.

Interestingly, as he does this, it's clear that he is able to rely on a range of cultural constructions and knowledge about military personnel. The most obvious example of this is the way that he references the SEAL Teams without explanation and also attempts to give his position more significance by explicitly associating his role with this high profile group. Even before the contemporary popular attention featuring SEAL teams, such as the films Act of Valor and Zero Dark Thirty, or other popular media coverage on the SEALs, this elite group within the Navy has been well-known among the American public. Service members often rely on this kind of popular culture knowledge as they tell their stories. Sometimes the information is used to confirm the public perceptions, and sometimes it is used to complicate those assumptions, which is seen as he explains that although he was deployed, and with a group that often engages the enemy directly, he was not typically "out shooting people." As I mentioned above, this introduction is a bit lengthier than some other introductions, but its complexity offers a clearer representation of how military personnel often draw on available public rhetoric even as they aim to intervene in such discourse.

Additionally, although this is somewhat outside the scope of this chapter, these positioning and ethos-asserting moves are often not presented simply for civilians. They also communicate authority to other service members. In the Gawker story just discussed, one of the early commenters questions the legitimacy of the author's story, for many reasons, one of which being that, from his own experience, Navy SEAL teams would not deploy, or at least would not leave base, with support personnel as the author had 
described. While the commenter later recants a bit for his lengthy questioning, his response suggests that the presentation of the service member's rank, position, deployments, and other contextualizing information is also designed to validate the teller's service to other personnel. Between these two individuals at least, the proof was not strong enough. This critique may be due in part to a heightened alertness for impersonators among military personnel, a common concern among service members and those close to them. Nevertheless, this interaction reveals that the early identifying information is provided for multiple audiences, and it encourages further study into the ways in which military personnel regulate potential interventions into public rhetoric about themselves.

\section{Sating the Public's Vicarious Desires}

As we've seen the framing of these stories and their openings often focus on creating a moment and cultural significance for the sharing of the stories in public discourse. Following these opening rhetorical moves, most service members' stories tend to include the recalling of a "traumatic" experience. ${ }^{9}$ Being deployed to a combat area and having a near-death experience or being attacked are experiences that mark what many consider as "real" military service, despite the fact that many personnel, 40\%, are never deployed at all, making it unlikely that they have combat experience (Defense Business Board 23). This conception of "real" military service is primarily held by civilians, but it is sometimes shared by service members themselves. This cultural expectation stems in part from the increasing opportunities for civilians to experience

\footnotetext{
${ }^{9}$ The quotes around traumatic in this case are meant to indicate that while not all service members personally interpret these experiences as traumatic, the presentation of these moments often participates in discourse that frames the experiences in that way.
} 
"war" through the media, including news reporting, films, reality television, video games, and so on (Stahl). The sharing of these traumatic experiences works toward two main rhetorical goals: offering more proof of the storyteller's credibility and fulfilling the listeners' vicarious desire so that the teller's "real" message can be shared.

While identifying their name, rank, role, and so on does the primary work of establishing credibility for the teller, an individual's service is further judged based on their position and experiences. Namely, most audiences are eager to hear about any neardeath or traumatic experiences that the storyteller had. This is part of what Roger Stahl, among other scholars, describes as the American media's construction of war as a vicarious experience - which invites citizens to feel as though they know what war is like without actually enlisting, deploying, or investigating the realities of war. This desire is likely also driven, following scholars such as Michael Warner, by the mass public's fascination with trauma more generally, as a part of an attempt to reaffirm their own identity as well as their expectations about others' identity. The public's "need" to learn about a person's trauma has also made experiencing and retelling trauma to be one of the most legitimizing aspects of military service whether or not the individual was, one, sent to a combat area, and, two, whether or not he or she was engaged in combat with the enemy. In turn, most audiences expect members to share a "traumatic experience" as an ethos-affirming move.

When service members tell of these experiences, they often include a few rhetorical moves that help to establish their roles as diligent workers, defenders of America, and "good" people. The telling of the traumatic story normally begins with explaining what led up to the incident. Often this is framed as a typical behavior. In his 
retelling of the first mission on which he was shot at by the enemy, Jonathon Herst explains,

Uh, I remember-- I was on a-- a gun team, like I said and we were in the back of a humvee. So I was the assistant gunner. The gunner was up on the-- standing up in the back of a humvee with his fifty cal-- or excuse me, his mark two forty machine gun. Um, we came to a T intersection, two roads. And as soon as we inched up to the, uh, the roadway, the first vehicle took a rocket pro-- propelled grenade right across the front hood. So we dismounted all four vehicles and we ran towards the enemy, or where the shot came from. We were just gonna try to clear the street. (Herst)

Of course, for those who haven't deployed to combat areas as military personnel, this excerpt may not seem "normal." Yet, the even-keeled description of positions, weapons, and movement in this introduction treat the activity as fairly typical. Further, the use of just in the last sentence excerpted here also emphasizes the generally "normal" beginning to this incident. The soldiers in this moment responded to being attacked in the way in which they were trained. Herst was actually serving as part of the initial invasion into Iraq, so his idea of typical duties may be somewhat skewed in relation to other personnel's. Still, the treatment here matches that of most of the near-death stories that are shared by service members. It is important, when considering the rhetorical work achieved through these stories, to acknowledge that the framing of the activity as typical also constructs the service members as normal workers, people doing a job, while the context of being deployed and interacting with a foreign population constructs them as defenders and representatives of the nation (as doing civic work).

Often the teller transitions to explaining the action of the incident by explaining what happened that was different than most other instances of this activity. In Herst's explanation this begins when he mentions the rocket-propelled grenade that was shot at their truck. In many cases, they reference how they were trained to deal that specific 
possibility—what to do when being mortared, or what to do when a villager approaches a car or check point, or what to do when there is a possible IED. Then, for the most part, they tell how they followed those instructions and then what happened. For example, Herst goes on to explain that many in the caravan jumped from their vehicles to engage the enemy, including the driver of the Humvee in which he was riding. Because of this, he had to take over the driving duties so that the gunner on top of the Humvee could get into the necessary position.

What is rhetorically interesting about the way in which they wrap up these stories is that the teller often tries to help the civilian understand what that experience felt like emotionally and psychologically. This discussion often addresses whether the teller felt scared, if they relied on their training, and how they dealt with the experience in the aftermath. It is in this discussion also that the service member constructs military personnel (as a group) as "good" people. Instead of the common refrain of "you do what you have to do in the moment," these stories often attempt to gain empathy from the listener by framing the experience as an "us vs. them" situation. Herst offers one example of this common point made by those who have been attacked by enemy combatants: "And right then and there I knew, you know, this is serious. They're-- they're out there trying to kill me. So it was a-- interesting situation. But that was an eye opener to say the least." In this case, Herst attempts to disrupt the more common abstract ways of thinking about war with the very personal perspective of those engaged in combat.

While this mindset can be unsettling for many civilians, the perspective is often presented in a way that is meant to be explanatory, the teller is trying to help the listener understand the psychological experience/position. For example, after explaining that his 
experience of being attacked made him "pissed off," Herst goes on to say that his anger manifested as being protective of his fellow soldiers: "I didn't go out looking to hurt anybody. But I definitely would protect my guys at any cost. And I-- it was heightened that day [that the Humvee caravan was attacked]." In these comments, Herst admits to the intense and personal responses he had to being shot at, but in his telling he tries to explain why he felt that way and also attempts to temper any fear that he would retaliate in illegal or extreme ways

In telling these stories, service members perpetuate the cultural belief that "real" or "fulfilling" military service involves both deployment and enemy engagement. In addition, they reinforce civilian complacency with war by allowing civilians to experience war at a distance, allowing them to "feel the danger" while not actually being in danger at all. Still, the sharing of these traumatic experiences is often essential in gaining and maintaining the audience at all. Thus, service members often include these experiences in their stories as a way to hook the reader before introducing their intended purpose or point - a rhetorical move considered in the next section.

\section{The Real Message - Changing the Available Topoi}

So far we've seen that service members' stories, even across different genres, tend to begin with two rhetorical moves: one that works to establish exigency and credibility, and one that hooks the audience by fulfilling their desire to hear about the "realities of war." Given that these two features are designed largely to build the speaker's and/or curator's ethos and to intrigue the audience, basically functioning as introductory moves, it makes sense that most often these two moves precede a transition to discuss the storyteller's intended topic. In many cases, service members' are using their stories to 
spark and perpetuate a discussion of needs; thus, the next common feature of service members' stories is the aspect of the story in which the speaker address a problem and either explicitly or implicitly calls the audience to action based on the situation the teller is presenting.

In many cases the traumatic or near-death experience that the service member experiences is presented as part of the transitioning move. While this transitioning aspect appears in each of the collections examined herein, the rhetorical efforts are clearer in the Storytellers series presented by Got Your 6. In these videos, former service members briefly discuss their service, typically their combat experiences, and then frame those experiences as the catalyst for the nonprofit they started or for the mindset they then took up. The goal of the Storytellers event is to gain financial or other support from Got Your 6 and its funding partners. Jake Harriman, founder and CEO of Nuru International, offers a prime example of this move. Following his retelling of watching Iraqi military personnel murder the family of a man seeking refuge behind American lines, Harriman explains how this experience led him to start Nuru International, the company on which his talk actually focuses:

This guy lost everything he had in this world in two seconds. And for the first time in the war, everything slowed down for me, and I put myself in this guy's shoes. I asked myself, you know, I live in a world of choices. Where do I want to go to school, where do I want my kids to grow up, what do I want to wear tomorrow? What were this guy's choices when he woke up this morning? He could watch his kids starve to death, he could strap a bomb to himself and blow himself up. He could make some desperate attempt to cross our lines. And then I got really, really angry. This was not fair. It wasn't fair that the GPS coordinates of someone's birth place could dictate the choices they have in this world. And I had an awakening experience that really put me on a different path in life. 
At the end of this excerpt, Harriman makes a direct connection between watching this man's family being killed to his decision fight poverty and terrorism by founding Nuru International. The narrative is crafted in such a way that the telling of the traumatic event is not only fulfill the audience's desire but use that desire to introduce a new idea to the audience.

When service members use their stories to call listeners to action, they do so by changing the topoi that are available in the public rhetoric about them. Often when military personnel are discussed in public forums, such by politicians, news media, or even entertainment media, these conversations draw on themes such as service member needs (PTSD, funding, support), patriotism (sacrifice, courage, honor), and superiority. These topoi are certainly present to varying degrees in service members' stories, but there are two important differences in the topoi commonly used in their stories.

First, service members are using their stories to add "military-civilian relations" to the common topoi. This addition is important because unlike the other topoi which keep service members at a distance from other Americans, the goal of the use of this topoi is to build relationships. This purpose is perhaps clearest in the C2KY series since it is curated specifically so that service members have a forum through which to speak to the public about their experiences. In nearly every interview in this collection, service members speak about the difficulty they have interacting with those who have not served, consistently remarking that, as Joseph Tyler Gayheart puts it, "It's harder for me to communicate those experiences or ideas or ideologies or feelings to somebody that doesn't" have what he described as a "shared rhetoric." Although this point is often presented as a lament, when it is considered as a feature of a collection that is designed to 
increase public understanding of service members, it can also be read as a tool being used to discuss "military-civilian relations" and also as a call for the improvement of these relations. Thus, the prominence of this topic can be seen as a rhetorical strategy to change public conversation and thereby affect the ideological understanding of service member identity.

In addition to adding to the available topoi, military personnel also work to change the way in which current topics are used in public discussions. Namely, in their stories, service members often discuss their needs, but they do so in a way that does not match the common way in which these topoi are used. In these moments, service members are enacting what de Certeau describes as a tactical move in stories-using the stereotypical structure but adding a surprising difference that creates an unexpected meaning (89). To see the difference, we must first note that perhaps the most common theme when discussing military personnel is that this population needs more-more money, more doctors, more civic support, more psychological support, more jobs, more opportunities... the list goes on. Civilians are generally presented with two versions of American service members. Personnel are either strong and moral and unbeatable; or, they are broken by traumatic combat experiences, and therefore should be pitied and/or feared. When service members' needs are discussed, often it is some variation of the second version that is presented.

Despite this, or perhaps because of this unfair binary, service members also use the topoi of "service member needs" in their stories but they use it in a way that focuses on the empowerment and benefits that could be achieved through the fulfillment of these needs. Many needs are addressed in the stories shared by personnel, but here I want to 
focus on the way in which two storytellers take up the topoi of service members and (un)employment. Organizations and politicians across the country are eager to develop programs that reward employers for hiring veterans. Although the discourse from these programs and pundits does argue that service members make ideal employees, on the whole it tends to focus on how companies will benefit from hiring veterans, pointing out that it is the patriotic thing to do or that they will receive benefits from the government. This is rhetorically logical since the intended audience is not veterans but the companies or employers. Unfortunately, as the Bureau of Labor Statistics demonstrates, unemployment rates for veterans are consistently higher than those for non-veterans, including rates specifically for post-9/11 veterans (Bureau of Labor Statistics "Employment Situation of Veterans Summary"; Bureau of Labor Statistics "Employment Situation Summary").

In service members' stories that work from this topos, the storytellers certainly make clear that more companies need to hire veterans and that veterans need employment. Instead of citing statistics, or pointing to the discrepancy between said statistics and the promises made by recruiters and organizations about veteran employability, these individuals briefly address the need for employment and move quickly to making clear what they can contribute. In many cases, the construction of personnel in this moment draws heavily on the same messages promoted in the recruiting materials: service members are good leaders, they are productive, they are experienced, etc. Phillip McKenzie succinctly highlights a common argument throughout the C2KY oral histories when he argues that while service members are seeking support from universities, "soldiers have something to offer. Not just the school itself but the student 
body as a whole. You know, we can help programs build... we know how things should be structured. That's what the military preaches: there's a structure to everything, how things should be in order." McKenzie's emphasis on the strengths and skills of military personnel reinforces the construction of this population as productive problem-solvers, and that while they made need support, they have much to give in return for the opportunity to do so.

Similarly, in his Got Your 6 Storytellers presentation, Tim Kudo acknowledges the popular public discourse about veterans being good employees due to traits including "leadership, teamwork, courage, [and] sacrifice." Kudo, however, changes this exhausted refrain by arguing that those skills can also be true, and sometimes more true, of nonmilitary applicants. He argues that military training and experience offers the oftenoverlooked yet most important ability that service members gain: experience as practiced moral decision makers.

One of my first days in Afghanistan, I received a call on the radio from a young Marine. He was at an outpost pretty far away and he saw someone digging by the side of the road, and he called me up and asked me if he could shoot them. Was this a farmer working on their irrigation or was this a member of the Taliban planting a roadside bomb? Do we shoot them and then in the morning find out that we've killed innocent civilians? Or, do we let them go and the next patrol that goes out ends up with one of my Marines losing his legs?

I didn't always make the right decisions when it came to these kinds of things. In war, much as in life, you try and do the right thing but it can have a terrible consequence, but what I came to realize was that decisions like this were things that you got better at with practice. Moral decision making was a skill that could be learned. And overtime, I believe I did get better.

In this excerpt, Kudo draws on a difficult experience—as I discussed above- to transition into his intended argument about what veterans can add as an employee that nonveterans cannot. Because the opening to his piece addresses employability of 
veterans, the combination of the familiar topoi and the reference to his service in Afghanistan make Kudo's story fit the expectations of the audience for a service member's story. His additional construction of military personnel as "moral decision makers" acts as the unexpected tactical move, a move that changes what representations and understandings are available about service members in public discourse.

While circulating unconventional ideas does help to affect the available public rhetoric, Kudo also includes a challenge to his audience in an attempt to give his alternative construction of service members more power. First, he asserts that "Ethics isn't just an academic issue, and it's not something that only happens in war. When I look around, ... I see people making decisions without realizing that the consequences extend beyond the bottom line, and it's something that's even more important today than it ever has been before." His point here is that employers need to view this ability and skill as important to their organizational model. Kudo's challenge does not end there, however; he goes on to argue, "Perhaps now you can see that we offer a skill that is translatable... It's something that has imbued all of our actions with a strong moral compass, and it's something every organization should be excited to invest in." Not all the storytellers in the collections examined here take such a direct approach to reframing the public discourse about military personnel. Nevertheless, the participants all contribute to the same goal of increasing civilian understanding of their experiences and identity, and they so do by adapting both available and new topoi to their purposes.

Finally, the rhetorical tactic of adapting conventional structures and topoi often gives the service member's story a coda, which is sometimes explicit and is sometimes implicit. In a story, a coda offers an answer to the "so what" question (Norrick 33). By 
offering the "so what," the coda is similar to the justification aspect discussed earlier; it differs though, in that in instances in which the coda is explicit it tends to come toward the end of the story. Thus, while the justification acts somewhat as an introduction, the coda acts in a more conclusionary manner. Kudo's final challenge is an example of a more explicit coda: hire veterans, they offer an essential decision-making perspective that nonveterans don't. In some cases, as Segal observes in regard to breast cancer narratives in which the coda is "Be like me," this claim can be more implicit (4). This is true across most of the $\mathrm{C} 2 \mathrm{KY}$ oral histories, where the participants are using a coda more along the lines of "learn my story, understand me better," as indicated by the lament discussed above about the lack of understanding. Across the many stories shared by service members, codas take a variety of forms, but, as suggested above, these codas seem to draw heavily on the idea that service members need to be better understood and that better understanding can lead to more productive relationships since their skills and knowledge could then be capitalized on. Kudo points this out specifically in the example just discussed, as do many of the other Got Your 6 Storytellers participants. It can also be seen in the $\mathrm{C} 2 \mathrm{KY}$ interview in which contributors often bring up the skills and knowledge they can bring to projects and the other kinds of service they've been trained to provide.

Service members do seem to be achieving some success through these stories. In responses to Gawker's True Stories of the VA series, many of the commenters are service members adding their stories, but a fair share of the comments are posted by people seeking resources and opportunities to personally help veterans, and not just by donating money. Many of the common tropes about service members persist—for example, that 
they deserve better support to compensate for their sacrifice- - but the presence of different messages in the comments section suggests that new topoi and new ideas about military personnel are taking root. Ultimately, by adding to and changing the available topoi about service members, personnel also change the public rhetoric about themselves and are thereby able to affect ideological understandings of their role and identity.

\section{Story Telling and Curating as an Institutionalizing Practice}

The stories shared by military personnel, in these collections but also in other instances, can also be understood as part of a larger strategy for intervening in public rhetoric about service members that I will refer to as institutionalization. In using this phrase, I'm drawing in part on Althusser's concept of Ideological State Apparatuses and also imagining these apparatuses as cultural institutions. Thus, with the phrase institutionalization, I am referring to a process by which a relatively unofficial and/or marginalized group attached themselves and their efforts to powerful ideological and cultural entities.

In the introduction to this dissertation, I noted that service members-especially enlisted personnel-hold a unique ideological position in that they are simultaneously members of the populace and of the State. This dual position is emphasized in the U.S. Armed Forces since the military is idealized as being representative of a diverse yet unified American population. Service members are consistently articulated as being both an embodiment of the State and also as committed members of their personal communities, a construction we've seen in both films and recruiting materials. This tension certainly leads to tensions in some scenarios, but in their efforts to advocate for themselves, many service members take advantage of this dual position by capitalizing 
on their familiarity with institutional expectations and behaviors to gain recognition and support from a wide range of institutions. This can be seen in the growing number of high-profile organizations dedicated to supporting veterans as well as currently-serving personnel.

While lobby groups and non-profits have advocated for service members and veterans for decades, there is a growing presence of formally recognized and active student groups at universities across the U.S., including the national Student Veterans of America as well as smaller university-specific groups. The institutionalization approach is clearly present since many of these organizations, especially student-veteran organizations and support services, have been founded by students themselves. At Texas State University_-San Marcos, the TutorCorps was created in 2013, as part of the university's writing center, to offer academic support to student-veterans. Micah Wright recognized that many student-veterans were not taking advantage of the other offered services because they were uncomfortable working with non-veterans, so he worked with the university and other academic support offices on campus to create a service specifically for student-veterans (Tydach; Wright). Similarly, at Eastern Kentucky University, Travis Martin helped develop a Veteran Studies Program (VSP) that is open to those who have served as well as others. The goal of the VSP is to create a space for open conversation about important and relevant civic issues and to create greater understanding between military personnel and civilians ("Veterans Studies Program"). To increase interest from those who have not served or are not interested in serving, many of the courses are listed as Cultural Diversity courses, which draws in a broader range of students since students at state universities in Kentucky must earn a number of diversity 
credits (T. Martin, “After Action Review”). In each of these examples, student-veterans identified a need and developed a solution that was adopted by their respective universities. Each also offers a prime example of how veterans collaborate with powerful institutions, in these cases actual institutions, to gain power and to thereby be more effective.

Service members do not only target universities in these institutionalizing efforts, though. University of Kentucky student veterans and theater students decided to create a documentary drama play based on the $\mathrm{C} 2 \mathrm{KY}$ interviews. Together these students and their instructor developed the play and solicited a range of institutional supporters. Outside of the university and the Nunn Center, they were also helped by the UK Women \& Philanthropy Network. This allowed the play to be performed across the state. Similarly, the Got Your 6 campaign, organized by the nonprofit Be The Change, Inc., actively seeks out collaboration with partners in the government, nonprofit, and entertainment sectors. Importantly, as managing director and Army veteran Chris Marvin notes, the Got Your 6 organization works with its entertainment to address the "need for 'neutral' depictions of vets in everyday life," pointing out Ed O'Neil's Modern Family character and Sam Waterston's The Newsroom character as positive examples (Elber). These examples demonstrate that the service members' institutionalizing efforts are not limited only to universities, but that this strategy is in fact a widespread approach that targets a range of ideological institutions. This approach allows those with military experience to develop powerful partnerships that in turn give service members greater and more visible opportunities for intervening in public rhetoric about their cultural role and identity. 
One double-edged aspect of this approach is that by partnering with institutions, the storytelling and new narratives produced by service members (or other groups using this approach) become normalized, and thus lose their tactical effect. In some cases, this normalizing process can lead to some co-opting of the original message, for purposes that are incongruent with those of the original storytellers. For example, U.S. News and World Report annually publishes a list entitled "Best Colleges for Veterans"-which is in line with the consistent call for more and better resources for student-veterans-yet this list is created based on self-reporting from universities with little to no input from studentveterans themselves (Brooks and Morse). Still, universities ranked on this list are happy to publicize their accomplishment. Some suspect situations like this are not uncommon in a cultural moment that pats institutions and companies on the back for helping veterans. Nevertheless, it is important to remember that, as de Certeau argues about tactics and as Warner argues about counterpublics, the goal of such non-sanctioned efforts often is to have the non-standard beliefs or practices normalized. Thus, even if more shows and movies incorporate characters who have served in combat zones-reproducing the belief that "real" service is marked by combat experience - these character nevertheless participate in the positive normalization of military service. Part of what is interesting about the institutionalization approach, specifically as it is used by military personnel, is that these individuals are often intimately familiar with the slow-moving bureaucratic nature of institutions yet they still recognize and aim to capitalize on the power that comes with the institution, despite the inherent risks.

\section{Service Members' Storytelling as an Intervening and Reconstituting Practice}


The notion of the citizen army that has been so strongly rooted in the ideological understandings of the U.S. Armed Forces has become complicated since the end of the Vietnam War and the institution of the All-Volunteer Force. Their dual position as members of the State and of the people theoretically gave American personnel an advantage. One that continues to be emphasized in film constructions of service members, as seen in the diverse teams represented in popular films like Windtalkers, Jarhead, and The Lucky Ones. However, across these service members' stories, tellers have lamented civilians' lack of understanding about personnel and their experiences. It is one of the driving reasons for the creation and circulation of their stories. The concern can be seen in Anthony Dotson's description of stories as the "greatest bridging tool," in Tyler Gayhart's claim that civilians don't have a "shared rhetoric" for talking to service members, and even in Tim Kudo's perceived need to explain the value that service members add to the workplace. As the misunderstanding between civilians and personnel has grown, we find that service members' dual position results now in many cultural disadvantages, such as feeling isolated and unsupported.

The examination herein though suggests that while that dual position may currently lead to cultural disadvantages, it does offer some rhetorical advantages. Service members' familiarity with the Military institution has encouraged and facilitated their partnerships with other cultural institutions. These partnerships have led to greater awareness of and support for personnel. On university campuses, as one kind of example, projects like Combat to Kentucky, the Eastern Kentucky University Veteran Studies minor, and the Texas State University Tutor Corps have created opportunities that not only support service members but also inform civilians about military experiences. 
Further, the common features of service members' stories demonstrate that their dual position gives them rhetorical advantages, since they are familiar with the desires of the typical civilian audience member and capitalize on those expectations. This is of course most clearly seen in the telling of the "traumatic" event as a transition tool for introducing a different concern, as Jake Harriman does to explain the reason he started Nuru International. The manner in which service members introduce new topoi and adapt existing ones also suggests a facility for making use of what is available and intervening in subtle but specific ways.

It is important to note that service members' interventions in public discourse are aided by the use of social media and the current popularity of personal narrative. Although scholars have long debated the whether digital arenas offer more opportunities to subvert or to replicate ideological standards, the efforts of service members show that the answer is that both actions are possible. The partnerships with institutions certainly requires that service members share messages that are not too far from standard expectations, yet these storytellers do use tactical messages to influence what the standards are - as we see, when Phillip McKenzie lists the positive contributions he made to the local community while he was deployed to Iraq. These messages are more widely circulated as a result of their easy accessiblity on sites like YouTube. Instead of attending a speaking event, civilians can learn more about military personnel and experiences by watching the $\mathrm{C} 2 \mathrm{KY}$ videos or reading the Gawker series wherever they are most comfortable. Travis Martin, who now teaches at Eastern Kentucky in the Veteran Studies Minor, often assigns the $\mathrm{C} 2 \mathrm{KY}$ videos as homework and encourages other instructors to do the same (T. Martin, “After Action Review"). 
While Segal argues that the popularity of the personal narrative has led to the uncritical use and consumption of the genre, the fact remains that this genre allows service members and others who use it to reach more audiences and to engage more people, precisely because of its popularity (18). Listening to a story is easier for many people than being directly challenged by lecture or reading a critical piece on the U.S. military actions. Also, given Bruner's claim that one purpose of narrative is to "demystify deviations," these narratives are also likely popular because they encourage social bonding and understanding through the sharing of unique experiences ("Self Making and World Making" 72). The study here also suggests that the use of personal narrative is not always uncritical, or at least the features of the story are carefully crafted and delivered to achieve particular ends. The opportunity for many personal narratives to be shared and to be institutionalized through projects like the Gawker series and $\mathrm{C} 2 \mathrm{KY}$ is full of both risks and rewards, but the potential benefits seem to justify the continued use of personal narrative as a bridging tool, particularly when the stories achieve the kind of rhetorical work seen here.

Overall, the approaches of storytelling and institutionalization have been used by service members to intervene in the available public discourse shaping ideological constructions of their identity. Although these messages are sometimes over-powered by more visible ones from the Entertainment industry or the Military or other powerful parties, service members persist in their efforts and seem to be having some success in introducing new public perceptions of who they are and what their role is in current American culture. There are growing conversations, in our own field as well as in many other public arenas, about the value of understanding and investing our military 
personnel, not only as members of the Military but as productive citizens in the private sector. The rhetorical approaches employed by service members reveal the advantages and disadvantages of the dual ideological position held by personnel. Additionally, they can offer some comparative models for considering interventions made in public discourse by other groups as they attempt to change their ideological identity constructions. 


\section{CHAPTER V}

\section{RE-SHAPING MILITARY PERSONNEL IDENTITY: INTERVENING IN AND WITH CONSTITUTIVE RHETORIC}

As a family member to military personnel in all five branches, the concerns of this project have long been important to me. When I began exploring military personnel identity in an academic manner, the US had recently marked the ten-year anniversary of the "Global War on Terror," and our military service men and women were still engaged in Afghanistan and even in Iraq, where the war had officially ended in December of 2011. It is fitting then, perhaps, that as I draw this project to a conclusion that President Obama has recently declared the end of the war in Afghanistan, one of America's longest military engagements. And, that in January 2015, the film American Sniper has broken multiple records, making it one of the most profitable films featuring a military character ever.

Reports on both the film and the war in Afghanistan, however, point out that the US military's engagement in the "War on Terror" have not ended, nor will they in the foreseeable future. In Afghanistan specifically, troops will continue to be deployed and redeployed in a "support capacity," training the Afghan military and continuing their attempts to stabilize the region. In addition, these reports continue to point to the distance between those who serve and the civilian population. In Queens, New York, home to Sgt. First Class Ramon Morris who was killed in action in December 2015, officials did not lower the flags on government buildings until his friends and family called to complain. 
"They had forgotten... The whole country has forgotten," a friend of Morris lamented (Philipps). Gayle Tzemach Lemmon, journalist and Senior Fellow at the nonprofit Council on Foreign Relations, responded to the success of American Sniper with an article for the Atlantic's Defense One in which she highlighted the gap between service members and civilians by pointing out that despite reality most Americans do not imagine the country as being at war and do not think about the country's military activities, "[e]xcept when it comes to the movie theaters. And then the country decides to stop all its doing and go see a war story."

Our cultural conceptions of the Military and its members do not, for the most part, align with reality. This is obviously a concern for those in the Military and those close to them. For the boarder American culture, this lack of understanding is also concerning because, without civilian awareness and investment in its military service members, military personnel become marginalized, which in turn provides the State unchecked power in how it uses the Military and allows for the degradation of service members' support services. More generally, when a culture ignores a population, those in power are able to take advantage of the isolated group. In this project, I have investigated the ways in which different stakeholders in the post-9/11 era attempt to address the general mismatch between dominant perceptions of military life and the lived experience of such service. In chapter four, the stories of military personnel revealed that they are actively working to bridge the gap between themselves and the rest of the population. The Military and various State apparatuses are also working to increase visibility and understanding of military personnel. This can be seen, for example, in the Army's use of "behind the scenes" videos for basic training and "experiences" booths they set up at 
public events to give civilians — and obviously potential recruits — a better idea of what military life is like. The Entertainment industry is partnering with organizations like Got Your 6 to develop more characters with military background even when military experience is not directly part of the plot. Through all these efforts and more, individuals and institutions are clearly invested in reshaping and updating American ideological understandings of who military service members are and what that means in our culture.

\section{Intervening in and with Constitutive Rhetoric}

This project demonstrates that ideological standards and expectations are almost constantly being negotiated by various stakeholders within the ideology, including the State, different apparatuses, and even individuals themselves. Given the well-known cultural studies scholarship advocating for individuals' agency within ideological systems (de Certeau; Hall; Butler), the fact that ideologies change over time is not especially surprising. However, the post-9/11 American cultural context has made military personnel identity a ripe site for the consideration of how ideological identity negotiation works. First, the actions of the Military and personnel show that stakeholders often work together as they attempt to change dominant perceptions of an identity, as opposed to working against one another. Moreover, the Military's and service members' efforts provide a more robust understanding of how constitutive rhetoric is used to intervene in standard representations of identity categories, including the adaptation of constitutive rhetoric for explicit recruiting contexts and the reinterpretation of existing topoi. In considering the efforts of these stakeholders, this project helps us to better understand the processes by which ideologies evolve and the rhetorical strategies that can be used to intervene in and update dominant representations. 
While there is a temptation to imagine discontent subjects of an ideology working in opposition to the State and its apparatuses, I have argued in this project that the State, its apparatuses, and individuals are willing to work together — at least in some cases — as they negotiate dominant perceptions. Rather than presenting radical constructions of service member identity, the Military and personnel typically begin with dominant representations, such as those seen in film, and either add to those representations or redefine them. As discussed in Chapter 3, the Military is less interested in disavowing the kinds of military characters that are shown in movies. Instead, they take a popular construction, like the idea of military personnel as warriors, and offer a different understanding of what that idea means for service members. For example, contemporary military warriors, the Military asserts, are individuals who are guided by their ethics and who work together to achieve moral goals; military warriors are not simply strong, purposeful fighters who fight alone like many other popular warriors. Various stakeholders work together in other ways also. As I argued in Chapter 4, military service members often partner with powerful institutions, including universities, Congress, and nonprofit organizations, to develop a greater visibility for their experiences and their goals. Of course, by partnering with institutions, military service members' stories and representations are likely edited, regulated, and polished. Yet, given their unique ideological position as members of the State and the citizenry, many service members choose to partner with institutions and thereby intervene in dominant perceptions within sanctioned places. Across these chapters, the different stakeholders demonstrate the ways in which their work is inter-related and often inter-dependent - a view of ideological institutions and subjects that is rarely seen. 
Together, the chapters in this project reveal how the State, the Military, and military service members have engaged in a long tradition of negotiating ideological standards and expectations by working in response to one another as well as with one another. It is clear that dominant constructions distributed by the State are not the ultimate arbiter of an individual's identity or role, and that those powerful constructions change over time as a result of interventions by different stakeholders. With this close look at the efforts of specific stakeholders, I offer new understandings of the rhetorical strategies and tactics used in the negotiation of cultural understandings. Moreover, I argue that the efforts of the Military and personnel demonstrate specific strategies and tactics for intervening in dominant and available rhetoric.

Most scholarship on identity constitution focuses on how those in power persuade others to adopt a certain identity. Scholars of constitutive rhetoric have considered how such rhetoric might fail (Zagacki), what happens when it is co-opted by oppositional forces (Tate), how such rhetoric constitutes multiple but compatible identity positions (Kopelson), and even how such rhetoric can be embodied (Gruber). The efforts of the Military and personnel seen in this project have shown that identity constitution is a multi-directional process. Herein, I have treated film constructions as having the dominant influence on cultural understandings of military personnel identity. Certainly, the Military also holds considerable power in shaping this identity. Nevertheless, the Military must contend with the popular representations portrayed in movies, television, and other popular media. Thus, the Military's definitional work is an example of how constitutive rhetoric circulates and evolves as stakeholders make use of the available language and representations. 
The constructions of service member identity shown in films and the Military's recruiting materials are, however, largely compatible. The Military's messages may be more specific as they work to further nuance who service members are, but the messages are not very different from those seen in many popular movies. In contrast, the work of military service members demonstrates how individuals constituted into an identity can take up existing rhetoric and reshape it for new purposes. In their stories, personnel use tactics to intervene in dominant ideological understandings of their identity and their cultural role. This can be seen in the way they use the telling of a traumatic experience to transition into a new message, such as when Jake Harriman talks about seeing an Iraqi man's family shot to death as a way to introduce the nonprofit he started. Service members also use existing dominant topoi, such as the idea that veterans are good employees, to introduce new versions the commonplace that in turn intervene in dominant perceptions of service member identity.

In addition to offering insight into the ways that constitutive rhetoric circulates among stakeholders, the Military's recruiting materials show that Charland's original principles for constitutive rhetoric can be adapted and added to for particular contexts, in this case explicit recruiting contexts. In most cases considered in the scholarship, those using constitutive rhetoric do not require their intended audience to officially declare that they have taken up the intended identity category. For example, the Iraqis that President Bush attempts to constitute as democratic people were never asked to take a pledge to a new government, and certainly they didn't need to take a test to prove their ability to take up this new identity (Zagacki). When the Military constitutes potential recruits as military personnel, it is a provisional hailing that in fact does require the recruit to seek the 
Military's sanction of their new identity category. This adaptation of constitutive rhetoric as, what I term, recruiting rhetoric can help rhetoricians better understand how identity constitution happens in explicit recruiting contexts, such as enlisting in the military or enrolling in a professional or graduate program.

While the Military and service members' efforts to shape dominant cultural understandings of personnel identity show us much about constitutive rhetoric, they also highlight how important it is for people to be critical of competing representations of an identity category. As I've pointed out in this project, one driving force behind the current negotiation of military personnel identity is the significant gap in understanding between American military members and their civilian counterparts.

In examining the Military's and service members' efforts to intervene in dominant cultural understandings of personnel identity, I have also offered two other important contributions. First, it is clear that there are available rhetorical strategies and tactics for communicating our identity and relationships to those around us. These rhetorical efforts offer ways to manage the differences between the dominant representations of the identities one claims and the lived experiences of those identities. Second, the messages of military personnel in particular - and the widely supported gap in understanding between service members and citizens - show that Americans should be more responsive to this population's stories and seek ways to increase cultural understanding of military life. Not just by seeing films or reading the crafted memoirs of service men and women, but also - perhaps more so - by listening to the stories of the service members around us. A number of rhetoric and composition scholars have explored the implications of discussing veterans' experiences in first-year composition classrooms, including Travis 
Martin's discussion of showing the Combat to Kentucky oral history interviews to students and Roger Thompson's recent chapter arguing that instructors be tactful when discussing student-veterans' military experiences, keeping in mind veterans might not want to discuss their service in class. As fellow rhetoric and composition scholars and as citizens, we can begin this process in our own classrooms and lives by setting positive, respectful, and responsive examples for those around us.

\section{Future Research}

Although this project offers important contributions to cultural studies, rhetoric, and composition scholarship, it also suggests new opportunities for exploring how identity constitution functions in particular contexts and how groups manage their intervention efforts. Rhetoric scholars are increasingly interested in constitutive rhetoric, and the Military's recruiting materials reveal new avenues of consideration. Thus far, as I mentioned earlier, constitutive rhetoric has focused on the speaking individual or organization and the intended audience. Military recruiting materials, however, have shown that secondary audiences are also constituted to reaffirm the construction of the primary identity. More work on this approach in constitutive rhetoric could offer insight into the complexity of identity construction. Also, as I argued in Chapter 3 and mentioned above, military recruiting offers an introductory framework for recruiting rhetoric, the strategy for identity constitution in explicit recruiting contexts. Rhetoric scholars should pursue further analysis of the rhetoric used in these contexts, because such analysis would contribute to a more robust understanding of the strategies used to shape and reinforce identities as well as the function of particular identities within an ideology. 
Rhetoric and composition scholars would also benefit from further examining the ways in which personnel—or, more generally, members of any identity group—regulate their ideological intervention efforts and manage what representations of their identity are “accurate." In the fourth chapter, when discussing Gawker's True Stories... series and the readers' comments, I briefly pointed out that other military personnel are quick critique the veracity of these published stories. This anticipated critique, as well as other cultural expectations, makes it important for service members to prove and build their ethos as military personnel. The practice of service members openly sanctioning others' stories of military service, however, suggests that this group is carefully and aggressively managing what representations are acceptable for the general public. Research on this practice is needed as it could offer important insights about how counterpublics and other identity groups work to successfully intervene in ideological understandings.

In addition, the work of this project should be extended by investigating in more depth the effects of the rhetorical strategies seen in Military recruiting and service members' narratives. Investigations of service members' constructions of themselves should also dig deeper into the circulation of new and adapted identity constructions. In this project, I examined the rhetorical strategies that stakeholders use in response to dominant constructions of military personnel identity, and the tactics the Military and personnel use to intervene in the available discourse about this identity. With these contributions, I also lay some groundwork for future research on the effectiveness of the strategies and tactics seen herein. By engaging directly with personnel and civilians, future studies would be able to better elucidate how effectively service members' messages influence civilians' understanding of military identity and military life. 
Scholars need to engage in these kinds of studies to enrich our understanding of which rhetorical strategies are most useful for intervening in dominant and available discourse regarding identity categories.

\section{Conclusion}

Throughout this dissertation, I've shown how popular representations of military personnel strongly influence how other Americans imagine, talk about, and respond to military service members. With comparably few Americans currently serving in the Armed Forces, it is not surprising that so many others would look to these dominant constructions of personnel to better understand who military personnel are and to better understand the role personnel are playing in the post-9/11 cultural moment. Yet, the efforts of the Military and service members - together and separately — make it clear that the current popular representations of personnel are not satisfactory, at least in the minds of personnel themselves. The public negotiation of military personnel identity in films, Military recruiting, and the public narratives of service members shows not only the power of ideological understandings but also reveals the rhetorical strategies that stakeholders can take up as they intervene in those powerful constructions.

Rhetoric can be a great tool of ideology, regulating and normalizing the beliefs

and expectations of the ideology's constituents. However, as I have argued in this project, both individuals and organizations can capture and re-use the existing rhetoric and representations of the State to promote new understandings. Through the use of competing constitutive rhetoric and the reshaping of existing topoi and available language, institutions and individuals are able to reshape and update dominant constructions of an identity, ultimately also intervening in the ideology itself. The 
strategies and tactics employed by the Military and military personnel offer rhetoric scholars, as well as individuals, practical guidance in the effort to promote ideological constructions that more accurately reflect the lives of those taking up, in particular, Other-ed identities. In addition, these examples can offer us hope and inspire us to take action when the gap between dominant understandings and lived experiences becomes too large. Moreover, efforts of the Military and service members shown within this dissertation can remind us to be more responsive listeners and to advocate for more complex representations of military service members. 


\section{REFERENCES}

Air Force Technical Degree Sponsorship Program (TDSP): Learn While You Earn.

Schertz, TX: Air Force Recruiting Service, n.d. Print.

Althusser, Louis. "Ideology and Ideological State Apparatuses: Notes toward an Investigation.” Lenin and Philosophy, and Other Essays. Trans. Ben Brewster. New York: Monthly Review Press, 2001. 85-126. Print.

Altman, Rick. “A Semantic/Syntactic Approach to Film Genre.” Cinema Journal 23.3 (1984): 6-18. Print.

Anson, Chris and Shawn Neely. "The Army as Textual Community: Exploring Mismatches in the Concepts of Attribution, Appropriation, and Shared Goals." dot mil: Rhetoric, Technology and the Military. Spec. issue of Kairos 14.3 (Summer 2010): n.p. Web. 28 Apr 2011.

Army Skill Training. Washington, DC: United States Government Printing Office, 2010. Print.

Bacevich, Andrew. Breach of Trust: How Americans Failed Their Soldiers and Their Country. New York: Metropolitan Books, Henry Holt and Company, 2013. Print. Bailey, Beth. America's Army: Making the All-Volunteer Force. Cambridge: Harvard U P, 2009. Print.

Be Army Strong. Washington, DC: United States Government Printing Office, 2012. Print. 
Being a Soldier in the U.S. Army. Washington, DC: United States Government Printing Office, 2012. Print.

Bolter, Jay David and Richard Grusin. Remediation: Understanding New Media. Cambridge: The MIT Press, 2000. Print.

Boyd, Doug. Voices of Student Veterans: A Documentary Drama Panel Discussion. University of Louisville, Louisville, KY. 6 April 2014. Panel Discussion.

Brooks, Eric and Robert Morse. "Best Colleges for Veterans Methodology.” U.S. News \& World Report. U.S. News \& World Report LP, 11 Nov 2013. Web. 8 Aug 2014. Bruner, Jerome. “Life as Narrative.” Social Research: An International Quarterly 71.3 (Fall 2004): 691 -710. Print.

---. "Self-Making and World-Making.” More Ways of Worldmaking Spec. Issue of Journal of Aesthetic Education 25.1 (Spring 1991): 67-78. Print.

---. "The Narrative Construction of Reality." Critical Inquiry 18.1 (Autumn 1991): 1-21. Print.

Burdick, Melanie. "Grading the War Story." Teaching English in the Two-Year College 36.4 (May 2009): 353-354. Print.

Burgess, Jean and Joshua Green. YouTube: Online Video and Participatory Culture. Cambridge: Polity Press, 2010. Print.

Burke, Kenneth. Rhetoric of Motives. New York: G. Braziller, 1955. Print. Butler, Judith. Giving an Account of Oneself. New York: Fordham U P, 2005. Print. ---. Gender Trouble: Feminism and the Subversion of Identity. New York: Routledge, 1990. Print. 
Butler, Judith, Peter Osborne, and Lynne Segal. "Gender as Perfomance: An Interview with Judith Butler.” In Readings on Rhetoric and Performance. Eds. Stephen Olbrys and Phaedra C. Pezzullo. State College, PA: Strata Pub, 2010. 202-14. Print.

Carter, Geoffrey and Bill Williamson. "Diogenes, Dogfaced Soldiers, and Deployment Music Videos." dot mil: Rhetoric, Technology and the Military. Spec. issue of Kairos 14.3 (Summer 2010): n.p. Web. 28 Apr 2011.

Champlin, Charles. "Introduction." In Guts \& Glory: The Making of the American Military Image in Film. By Lawrence Suid. Lexington, KY: University Press of Kentucky, 2002. Print.

Charland, Maurice. "Constitutive Rhetoric: The Case of the 'Peuple Québécois."” Quarterly Journal of Speech 73.2 (May 1987): 133-50. Print.

Corley, Liam. "'Brave Words': Rehabilitating the Veteran-Writer.” College English 74.4 (Mar 2012): 351-365. Print.

DeCerteau, Michel. The Practice of the Every Day. Berkeley, CA: U of California P, 1984. Print.

Defense Business Board. "Reducing Overhead and Improving Business Operations: Initial Observations.” 22 July 2010. Web. 23 Jun 2014.

Delgado, Richard. "Storytelling for Oppositionists and Others: A Plea for Narrative." Critical Race Theory: The Cutting Edge. $2^{\text {nd }}$ ed. Eds Richard Delgado and Jean Stefanic. Philadelphia: Temple U P, 2000. 60-70. Print. 
Doe, Sue and Lisa Langstraat. "Introduction." In Generation Vet: Composition, Student Veterans, and the Post-9/11 University. Eds. Sue Doe and Lisa Langstraat. Logan, UT: Utah State U P, 2014. 1-27. Print.

Dotson, Anthony. Voices of Student Veterans: A Documentary Drama Panel Discussion. University of Louisville, Louisville, KY. 6 April 2014. Panel Discussion.

Elber, Lynn. "Hollywood Reconsiders Its Portrayal of Veterans." MSN News. Microsoft, 29 May 2014. Web. 1 July 2014.

Emmanuel, Adeshina. "Like the Army Itself, Recruiters Prepare to Make Do with Less." The New York Times. The New York Times Company. 5 Sep 2012. Web. 2 Mar 2014.

Explosive Ordinance Removal. Schertz, TX: Air Force Recruiting Service, nd. Print.

Fahnestock, Jeanne and Marie Secor. A Rhetoric of Argument. New York: McGraw-Hill, 1990. Print.

Felman, Shoshana and Dori Laub. Testimony: Crises of Witnessing in Literature, Psychoanalysis, and History. New York: Routledge, 1991. Print.

Foucault, Michel. Discipline and Punish: The Birth of the Prison. New York: Pantheon Books, 1977. Print.

"From Combat to Kentucky." From Combat to Kentucky: Interviews with Student Veterans. Louis B. Nunn Center for Oral History, University of Kentucky Libraries, 2014. Web. 5 April 2014.

Gayheart, Joseph Tyler. Interview by Sarah Piester. 21 Apr 2010. Lexington, KY: Louie B. Nunn Center for Oral History, University of Kentucky Libraries. Web. 6 May 2014. 
GotYour Six. "Got Your 6 Storytellers - Jake Harriman." Online Video. YouTube. YouTube, 10 Nov 2013. Web. 4 Aug 2014.

---. "Got Your 6 Storytellers - Tim Kudo." Online Video. YouTube. YouTube, 10 Nov 2013. Web. 4 Aug 2014.

Griffith, James. "After 9/11, What Kind of Reserve Soldier?: Considerations Given to Emerging Demands, Organizational Orientation, and Individual Commitment." Armed Forces and Society 35.2 (Jan 2009): 214-40. Print.

Gruber, David R. "The (Digital) Majesty of All Under Heaven: Affective Constitutive Rhetoric at the Hong Kong Museum of History's Multi-Media Exhibition of Terracotta Warriors.” Rhetoric Society Quarterly 44.2 (2014): 148-167. Print. Guzzetti, Barbara. 2006. "Cybergirls: Negotiating Social Identities on Cybersites." $E$ Learning 3.2. (2006): 158-169. Print.

Hall, Stuart. "Signification, Representation, Ideology: Althusser and the Post-structuralist Debates." Cultural Studies and Communications. Eds James Curran, David Morely, and Valerie Walkerdine. New York: St. Martin’s Press, 1996. Print. ---. “Who Needs 'Identity??” Eds. Stuart Hall and Paul du Gay. Questions of Cultural Identity. Thousand Oaks, CA: Sage, 1996. Print.

---. "Encoding/Decoding." In Culture, Media, and Language: Working Papers in Cultural Studies, 1972-79. Ed. Stuart Hall. London: Centre for Contemporary Cultural Studies, 1980. Print.

--- "The Work of Representation.” In Representation: Cultural Representations and Signifying Practices. Ed. Stuart Hall. Thousand Oaks, CA: Open University, 1997. Print. 
Harwood, Richard. "Passing Down Memories: The Importance of Oral History." The Washington Post (pre-1997 Full text) 30 Jan 1996. Proquest. Web. 10 Feb 2015. Herst, Jonathan Patrick. Interview by Joseph Tyler Gayheart. 29 Jan 2010. Lexington, KY: Louie B. Nunn Center for Oral History, University of Kentucky Libraries. Web. 6 May 2014.

Hinton, Corrine E. “'Front and Center': Marine Student-Veterans, Collaboration, and the Writing Center." In Generation Vet: Composition, Student Veterans, and the Post-9/11 University. Eds. Sue Doe and Lisa Langstraat. Logan, UT: Utah State U P, 2014. 255-81. Print.

Jenkins, Henry. Convergence Culture: Where Old and New Media Collide. New York: New York U P, 2006. Print.

Kopelson, Karen. "Risky Appeals: Recruiting to the Environmental Breast Cancer Movement in the Age of 'Pink Fatigue."' Rhetoric Society Quarterly 43.2 (2013): 107-33. Print.

Lemmon, Gayle Tzemach. "If Only America Cared about Actual Wars as Much as War Movies.” Defense One. National Journal Group, Inc., 6 Jan 2015. Web. 20 Jan 2015 .

Leonhardy, Galen. "Transformation: Working with Veterans in the Composition Classroom." Teaching English in the Two-Year College 36.4 (May 2009): 339352. Print.

Manovich, Lev. The Language of New Media. Cambridge: MIT Press, 2002. Print. 
Martin, Mary L. Changes in the Army's Recruiting Practices. Research Report, Air Command and Staff College, Air University. Maxwell Air Force Base: April 2006. Print.

Martin, Travis. "After Action Review: Writing Veterans into Higher Education and the Community." Conference on College Composition and Communication. St. Louis, MO. 20 Mar 2014. Conference Presentation.

---. Interview by Mark Tyler Scott. 3 Jun 2011. Lexington, KY: Louie B. Nunn Center for Oral History, University of Kentucky Libraries. Web. 7 May 2014.

Martinez, J. R. "Discover the Joy of Helping Others." CNN Heroes. Turner Broadcasting System, Inc., 24 Dec 2010. Web. 8 Aug 2014.

McKenzie, Phillip. Interview by Mark Tyler Scott. 11 Mar 2011. Lexington, KY: Louie B. Nunn Center for Oral History, University of Kentucky Libraries. Web. 7 May 2014.

Nilges, Mathias. "The Aesthetics of Destruction: Contemporary US Cinema and TV Culture." In Reframing 9/11: Film, Popular Culture and the "War on Terror." Eds. Jeff Birkenstein, Anna Froula, and Karen Randell. New York: Continuum, 2010. 23-34. Print.

Nolan, Hamilton. "PTSD and Me: True Stories from Military Veterans." Gawker. Gawker Media Group, 19 Aug 2013. Web. 5 April 2014.

---. “True Stories from Veterans: ‘The Dark Corners of My Mind.”' Gawker. Gawker Media Group, 3 Sept 2013. Web. 5 April 2014.

---. "We Want Veterans to Share True Stories of the VA." Gawker. Gawker Media Group, 12 Aug 2013. Web. 5 April 2014. 
Norrick, Neal R. Conversational Narrative: Storytelling in Everyday Talk. Amsterdam, Netherlands: Benjamin, 2000. Print.

Now More than Ever Our Jobs Fit You. Schertz, TX: Air Force Recruiting Service, nd. Print.

Once a Marine, Always a Marine. Quantico, VA: United States Marine Corps, nd. Print. Paquette, Paige and Mike Warren. "Telling War Stories: The Things They Carry.” dot mil: Rhetoric, Technology and the Military. Spec. issue of Kairos 14.3 (Summer 2010): n.p. Web. 28 Apr 2011.

Perelman, Chaim and Lucie Olbrechts-Tyteca. The New Rhetoric: A Treatise on Argumentation. South Bend, IN: U of Notre Dame P, 1969. Print.

Pew Research Center. The Military-Civilian Gap: War and Sacrifice in the Post-9/11 Era. Washington, D.C.: Pew Research Center, 2011. Print.

Philipps, Dave. "Mission Ends in Afghanistan, but Sacrifices are Not Over for U.S. Soldiers.” The New York Times. The New York Times Company, 31 Dec 2014. Web. 25 Jan 2015.

Powers, Stephen, David J. Rothman, and Stanley Rothman. Hollywood's America: Social and Political Themes in Motion Pictures. Boulder, CO: Westview Press, 1996. Print.

Randell, Karen. “'It Was Like a Movie': The Impossibility of Representation in Olive Stone's World Trade Center." In Reframing 9/11: Film, Popular Culture and the "War on Terror." Eds. Jeff Birkenstein, Anna Froula, and Karen Randell. New York: Continuum, 2010. 141-152. Print.

Recruit Training. Quantico, VA: United States Marine Corps, nd. Print. 
Reichert, Tom, Joo Young Kim, and Ignatius Fosu. “Assessing the Efficacy of ArmedForces Recruitment Advertising: A Reasoned-Action Approach.” Journal of Promotion Management 13.3-4 (July 2007): 399-412. Print.

Rise to the Challenge. Washington, DC: United States Government Printing Office, 2011. Print.

Robinson, Christopher. Interview by Ryan Donahue. 30 Jun 2011. Lexington, KY: Louie B. Nunn Center for Oral History, University of Kentucky Libraries. Web. 6 May 2014.

Rostker, Bernard D. I Want You!: The Evolution of the All-Volunteer Force. Santa Monica: CA: RAND, 2006. Print.

Schiappa, Edward. "Definition." Encyclopedia of Rhetoric and Composition: Communication from Ancient Times to the Information Age. Ed. Theresa Enos. New York: Routledge, 2009. 170-71. Print.

Segal, Judy Z. "Breast Cancer Narratives as Public Rhetoric: Genre Itself and the Maintenance of Ignorance." Linguistics and the Human Sciences 3.1 (2007): 3 23. Print.

Selfe, Cynthia L., and Richard J. Selfe, Jr. "The Politics of the Interface: Power and Its Exercise in Electronic Contact Zones." College Composition and Communication 45.4 (Dec 1994): 480-504. Print.

Shyles, Leonard and Mark Ross. "Recruitment Rhetoric in Brochures Advertising the All Volunteer Force." Journal of Applied Communication Research 12.1 (Spring 1984): 34-49. Print. 
Stahl, Roger. Militainment Inc.: War, Media, and Popular Culture. New York: Routledge, 2010. Print.

Strejilevich, Nora. "Testimony: Beyond the Language of Truth." Human Rights Quarterly 28.3 (Aug 2006): 701-13. Print.

Student Veterans of America. "Million Records Project." Studentveterans.org. Student Veterans of America, 24 March 2014. Web. 2 April 2014.

Student Veterans of America. "Veterans on Campus: Support Training."

Studentveterans.org. Student Veterans of America, 2013. Web. 2 April 2014.

Suid, Lawrence. Guts \& Glory: The Making of the American Military Image in Film. Lexington, KY: University Press of Kentucky, 2002. Print.

Takacs, Stacy. "The Contemporary Politics of the Western Form: Bush, Saving Jessica Lynch, and Deadwood." In Reframing 9/11: Film, Popular Culture and the "War on Terror.” Eds. Jeff Birkenstein, Anna Froula, and Karen Randell. New York: Continuum, 2010. 153-163. Print.

Take Your Place among the Few. Quantico, VA: United States Marine Corps, nd. Print. Tate, Helen. "The Ideological Effects of a Failed Constitutive Rhetoric: The Co-option of the Rhetoric of White Lesbian Feminism." Women's Studies in Communication 28.1 (Spring 2005): 1-31. Print.

Terkl, Studs. Hope Dies Last: Keeping the Faith in Troubled Times. New York: The New Press, 2003. Print.

“The IT Factor.” Airforce.com. U.S. Air Force. Nd. Web. 12 Mar 2014.

The Making of a Soldier. Washington, DC: United States Government Printing Office, 2012. Print. 
Thompson, Roger. "Recognizing Silence: Composition, Writing, and the Ethical Space for War." In Generation Vet: Composition, Student Veterans, and the Post-9/11 University. Eds. Sue Doe and Lisa Langstraat. Logan, UT: Utah State U P, 2014. 199-215. Print.

Tydach, Glen. "Tutoring Program Aims to Help Student Veterans.” The University Star, 5 Feb 2013. Web. 6 Aug 2014.

U.S. Bureau of Labor Statistics. Economic News Release: Employment Situation of Veterans Summary. 24 Mar 2014. Web. 2 Aug 2014.

U.S. Bureau of Labor Statistics. Economic News Release: Employment Situation Summary. 1 Aug 2014. Web. 2 Aug 2014.

United States Army Recruiting Command. USAREC Manual No. 3-01: Recruiter Handbook. Fort Knox, KY: United States Army, 2011. Print.

Warner, Michael. Publics and Counterpublics. New York: Zone Books, 2002. Print. Warrior Airmen. Schertz, TX: Air Force Recruiting Service, nd. Print.

Wright, Micah. “Re: Question about TutorCorps.” Message to Author. 26 Aug 2014. Email.

"Veterans Studies Program." Eastern Kentucky University - University Programs. Eastern Kentucky University, 2011. Web. 15 Aug 2014.

Zagacki, Kenneth. "Constitutive Rhetoric Reconsidered: Constitutive Paradoxes in G. W. Bush's Iraq War Speeches.” Western Journal of Communication 71.4 (2007): 272-93. Print. 
APPENDIX A

\section{MOVIES FEATURING CHARACTERS WHO SERVE(D) IN THE}

MILITARY, 2001 - 2013

Act of Valor. Dir. Kurt Johnstad. Perf. Alex Veadov, Roselyn Sanchez, Nestor Serrano. $20^{\text {th }}$ Century Fox Home Entertainment, 2012. DVD.

Basic. Dir. John McTiernan. Perf. John Travolta, Samuel L. Jackson, Connie Nielsen. Sony Pictures Entertainment, 2003. DVD.

Battle Los Angeles. Dir. Jonathan Liebesman. Perf. Aaron Eckhart, Michelle Rodrigues, Bridget Moynahan. Columbia Pictures, 2011. DVD.

Battleship. Dir. Peter Barg. Perf. Alexander Skarsgard, Brooklyn Decker, Liam Neeson. Universal Pictures, 2012. DVD.

Behind Enemy Lines. Dir. John Moore. Perf. Owen Wilson, Gene Hackman. Twentieth Century Fox Film Corporation, 2001. DVD.

Black Hawk Down. Dir. Ridley Scott. Perf. Josh Harnett, Ewan McGregor. Sony Pictures Releasing, 2001. DVD.

Captain America: The First Avenger. Dir. Joe Johnston. Perf. Chris Evans, Hugo

Weaving, Samuel L. Jackson. Paramount Pictures, 2011. Blu-ray.

Dear John. Dir. Lasse Hallstrom. Perf. Channing Tatum, Amanda Seyfired, Richard Jenkins. Son Picture Releasing, 2010. DVD.

Flags of our Fathers. Dir. Clint Eastwood. Perf. Ryan Phillippe, Barry Pepper, Joseph

Cross. Continental Film, 2007. Blu-ray. 
Green Zone. Dir. Paul Greengrass. Perf. Matt Damon, Jason Isaacs, Greg Kinnear.

Universal Pictures, 2010. DVD.

GI Joe: Rise of Cobra. Dir. Stephen Sommers. Perf. Dennis Quaid, Channing Tatum, Marlon Wayans. Paramount Pictures, 2009. DVD.

Inglourious Basterds. Dir. Quentin Tarantino. Perf. Brad Pitt, Diane Kruger, Eli Roth.

The Weinstein Company, 2009. Blu-ray.

In the Valley of Elah. Dir. Paul Haggis. Perf. Tommy Lee Jones, Charlize Theron,

Jonathan Tucker. Warner Independent Pictures, 2007. DVD.

Iron Man 3. Dir. Shane Black. Perf. Robert Downey, Jr., Guy Pearce, Gywneth Paltrow. Walt Disney Studios Motion Pictures, 2013. Blu-ray.

Jarhead. Dir. Sam Mendes. Perf. Jake Gyllenhaal, Jamie Foxx, Lucas Black. Universal Pictures, 2005. DVD.

Lions for Lambs. Dir. Robert Redford. Perf. Tom Cruise, Meryl Streep, Robert Redford. Metro-Goldwyn-Mayer, 2007. DVD.

Rambo. Dir. Sylvester Stallone. Perf. Sylvester Stallone, Julie Benz, Matthew Marsden. Nu Image Films, 2008. DVD.

Red Tails. Dir. Anthony Hemingway. Perf. Cuba Gooding, Jr., Gerald McRaney, David Oyelowo. Twentieth Century Fox Film Corporation, 2012. DVD.

Shooter. Dir. Antoine Fuqua. Perf. Mark Wahlberg, Michael Pena, Rhona Mitra. Paramount Pictures, 2007. DVD.

Stealth. Dir. Rob Cohen. Perf. Josh Lucas, Jessica Biel, Jamie Foxx. Sony Pictures Entertainment, 2005. DVD. 
Tears of the Sun. Dir. Antoine Fuqua. Perf. Bruce Willis, Cole Hauser, Monica Bellucci. Sony Pictures Entertainment, 2003. DVD.

The A-Team. Dir. Joe Carnahan. Perf. Liam Neeson, Bradley Cooper, Sharlto Copley. Twentieth Century Fox Film Corporation, 2010. DVD.

The Guardian. Dir. Andrew Davis. Perf. Kevin Costner, Ashton Kutcher, Sela Ward. Buena Vista Pictures, 2006. DVD.

The Hurt Locker. Dir. Kathryn Bigelow. Perf. Jeremy Renner, Anthony Mackie, Brian Geraghty. Summit Entertainment, 2008. Blu-ray.

The Lucky One. Dir. Scott Hicks. Perf. Zac Efron, Taylor Schilling, Blythe Danner. Warner Bros., 2012. DVD.

The Lucky Ones. Dir. Neil Burger. Perf. Rachel McAdams, Tim Robbins, Michael Pena. Blue Sky Media, 2007. DVD.

The Manchurian Candidate. Dir. Jonathan Demme. Perf. Denzel Washington, Live Schreiber, Meryl Streep. Paramount Pictures, 2004. DVD.

The Pacifier. Dir. Adam Shankman. Perf. Vin Deisel, Brittany Snow, Max Thieriot. Buena Vista Pictures, 2005. DVD.

Walking Tall. Dir. Kevin Bray. Perf. Dwayne Johnson, Ashley Scott, Johnny Knoxville. MGM Distribution, 2004. DVD.

We Were Soldiers. Dir. Randall Wallace. Perf. Mel Gibson, Madeleine Stowe, Greg Kinnear. Paramount Pictures, 2002. Blu-ray.

Windtalkers. Dir. John Woo. Perf. Nicolas Cage, Adam Beach, Peter Stormare. MetroGoldwyn-Mayer Distributing Corporation, 2003. DVD. 
Yours Mine and Ours. Dir. Raja Gosnell. Perf. Dennis Quaid, Rene Russo, Jerry O’Connell. Metro-Goldwyn-Mayer, 2005. DVD.

Zero Dark Thirty. Dir. Kathryn Bigelow. Perf. Jessica Chastain, Joel Edgerton, Chris Pratt. Columbia Pictures, 2012. DVD. 


\section{CURRICULUM VITAE}

\section{Ashly Bender Smith}

2023 Grasmere \#2

HM 315

Louisville, KY 40205

Louisville

albend02@1ouisville.edu

KY 40292

210-844-9613
Department of English,

University of

Louisville,

Education

$\mathrm{PhD} \quad$ Rhetoric and Composition, University of Louisville, expected 2015

Dissertation: "A Few Good Men and Women: The Rhetorical Constitution of Military Personnel Identity"

Committee: Bronwyn T. Williams (chair), Karen Kopelson, Debra Journet, Aaron Jaffe, and D. Alexis Hart

MA Rhetoric and Professional Communication, New Mexico State University, 2010

Master's Portfolio: From Teacher to Compositionist: The Evolution of My Core Identity in Three Semesters

Committee: Kathryn Valentine (chair), Jen Almjeld, and Julie Rice

BA English and History, Texas State University - San Marcos, 2008

\section{RESEARCH AND TEACHING INTERESTS}

Rhetoric and Identity

Composition Pedagogy and Practice

Digital Composition and Pedagogy

Theories of Ideology

Veterans and Military Studies

\section{Publications}

Submitted for Review

"The Greatest Bridging Tool": Service Members' Stories as an Intervention in

Public Discourse.” Rhetoric Society Quarterly. Submitted 20 September 2014. 33 mspps. 


\section{Peer-Reviewed Publications}

"Exploring Student-Veteran Expectations about Composing: Motivations, Purposes, and the Influence of Trauma on Composing Practices." Generation Vet: Composition, Student Veterans, and the Post-9/11 University. Eds. Sue Doe and Lisa Langstraat. Logan, Utah: University of Utah State Press, Forthcoming 2014. 33 mspps

\section{Other Publications}

"Creating 'Living' Messages with a Capstone Multimodal Remix Project." Teacher to Teacher: "Multimodal Mondays." Bedford Bits: Ideas for Teaching Composition. Bedford/St. Martin's. 28 April 2014. Web.

"Avatars and (Alternative) Representation in Digital Spaces: An Instructor's Challenging Journey." New Mexico English Journal (March 2010).

\section{Conference Presentations}

Workshops

"Working with Post-9/11 Student-Veterans: A Workshop for Composition Teachers, Scholars, and WPAs," Conference on College Composition and Communication, March 2015, Tampa, FL

"Competency-Focused Rubrics: Instruction, Coaching, and Assessment," Co-presenters Kristen Lucas and Jacob Rawlins, Association of Business Communication Conference, October 2014, Philadelphia, PA

\section{Presentations}

“'What up, Creeper?': Re-imagining the Role of the Participant-Observer," Copresenter Barrie Olson, Conference on College Composition and Communication, March 2015, Tampa, FL

"Be All You Can Be: The Rhetoric of Military Recruiting and Identity," Association of Business Communication Conference, October 2014, Philadelphia, PA

“@WritingCenters and \#Outreach: Effective and Responsive Uses of Writing Center Social Media Accounts," Watson Conference, October 2014, Louisville, KY

"Entering the Twittersphere: Effective Approaches for Social Media Use by Writing Centers," Council of Writing Program Administrators Conference, July 2014, Normal, IL

"The Invisible Writer: Approaches for Effective Online Tutoring," Co-presenters Adam Robinson, Jessica Winck, and Jennifer Marciniak, Southwest Writing Center Association - Kentucky, Tutor Appreciation Day and Creative Collaborative, September 2013, Richmond, KY

"Mobilizing YouTube: Soldiers, PTSD, and Digital Composition," Conference on College Composition and Communication, March 2012, St. Louis, MO

"Warrior Writers: Investigation the Relationship between Military Personnel and Academic Writing," Council for Programs in Technical and Scientific Communication Conference, October 2011, Harrisonburg, VA 
"Marcus Magill and the Case for Literary Collaboration" Indiana University Bloomington Interdisciplinary Graduate Conference, March 2011, Bloomington, IN

"Can You Hear Me in the Back?: How Graduate Instructors Enact Multiple

Positionalities Purposefully in the Classroom," College English Association, March 2010, San Antonio, TX

"Critical Readers, Savvy Researchers, and Proficient Writers: Students Well-Prepared for College-Level Research Assignments," Co-presenters Nancy Wilson, Sue Beebe, Stephanie Noll, and Michael Noll, National Council of Teachers of English, November 2009, Philadelphia, PA

"Avatars and Identities: How We and Our Students Explore Identity in Virtual and Real Spaces," Co-presenters Rebecca Powell and Erin Reardon, New Mexico Council of Teachers of English, October 2009, Carlsbad, NM

"Teaching Test-Taking Strategies," Texas State University - Student Academic Support Services, August 2007, San Marcos, TX

"Methods of Outreach: Connecting Their Space to Our Space in a World Full of Noise," Co-presenter Justin Boyle, International Writing Center Association, April 2007, Houston, TX

\section{AWARDS}

\section{ABC Graduate Student Travel Scholarship}

Association of Business Communication

Faculty Favorites Award, Fall 2011

University of Louisville

\section{TEACHING EXPERIENCE}

Graduate Teaching Assistant - Instructor of Record

University of Louisville, 2010-present.

Engl 101 - Introduction to College Writing (3 sections)

Engl 102 - Intermediate College Writing (5 sections)

Engl 105 - Advanced Composition for Freshmen (1 section)

Engl 303 - Scientific and Technical Writing (1 section)

\section{Graduate Teaching Assistant - Instructor of Record}

New Mexico State University, 2009 - 2010

Engl 111 - Rhetoric and Composition (2 sections)

\section{Administration}

\section{Assistant Director of the BizComm Writing Lab}

University of Louisville, 2014-2015

Served as the writing and communication consultant for College of Business students and faculty. Assisted in the development of the Business Communication program by creating resource materials for students. Worked with faculty to create and revise writing assignments for business courses. 
Writing Center Assistant Director, University of Louisville, 2012-2014

Developed and maintained Writing Center social media accounts on Facebook, Twitter, and Wordpress. Assisted in website site design and content creation. Mentored writing consultants. Participated in Writing Center-led workshops. Assisted in 3 dissertation writing retreats.

Writing Center Office Manager, Texas State University - San Marcos, 2007-2008 Assisted with scheduling 25 consultants. Reviewed, updated, and maintained writing resources for students. Organized workshops about common college writing topics. Provided workshops for writing counselors about common writing center topics.

\section{ACADEMIC EMPLOYMENT}

Writing Center Work

Writing Consultant, University of Louisville, 2011 - present

University of Louisville Writing Center

Writing Consultant, University of New Mexico State, 2009-2010

NMSU Writing Center

Writing Counselor, Texas State University - San Marcos, 2006 - 2008

Texas State University Writing Center

Other Appointments

Web Designer, Design Center

New Mexico State University, 2008-2009

Supplemental Instructor, Texas State University - San Marcos, 2007 - 2008

Student Learning Assistance Center

\section{Professional DeVelopMent}

\section{Participant, Rhetoric Society of America Summer Institute}

University of Kansas, June 2013

Seminar: Rhetorical Approaches to the 2012 Presidential Campaign. Workshop: Rogue Publics in a Digital Age.

Writing Fellow, Borderlands Writing Project - National Writing Project

New Mexico State University, June 2009

Participated in four week professional development seminar. Developed and researched teacher inquiry project. Developed promotional multimedia projects.

Participant, Writing Across the Curriculum Seminar

New Mexico State University, May 2009

Participated in one week professional development seminar. Developed a major writing project using WAC best practices.

\section{Professional Memberships}

Rhetoric Society of America

Association of Business Communication 


\section{SERVICE}

Co-presenter, Working with Student-Veterans: Pedagogy Workshop, with Brittany Kelley and Ashley Ludewig. University of Louisville, April 2014

Graduate Mentor, Rhetoric and Composition Peer Mentoring Program University of Louisville, 2012-2013

President, English Graduate Student Organization

New Mexico State University, 2009-2010

Visiting Instructor, Writers in the Schools Program

Sierra Middle School, $6^{\text {th }}$ grade English Pre-AP, 2009-2010

Coordinator, 17th Annual NMSU Marathon Reading, April 2010

Silent Auction Coordinator, Writers' Harvest Hunger Benefit, October 2009

Camp Administrator, Texas State Creative Writing Camp, June 2007

\section{GRADUATE COURSEWORK AT UNIVERSITY OF LOUISVILLE}

\section{Rhetoric and Composition}

Critical Theory and Literacy in Composition Studies - Bronwyn Williams

Genre Theory and Composition Pedagogy - Bronwyn Williams

New Media and Composition Pedagogy - Bronwyn Williams

Perspectives on Literacy - Carol Mattingly

Writing in the Disciplines - Joanna Wolfe

History of Rhetoric I - Stephen Schneider

History of Rhetoric II - Carol Mattingly

Research in Composition - Debra Journet

Teaching College Composition - Joanna Wolfe

\section{Literature and Literary Theory}

Trauma Narrative - Suzette Henke

$19^{\text {th }}$ Century British Poetry and Prose - Mary Rosner

$20^{\text {th }}$ Century Literature - Aaron Jaffe

\section{Graduate Coursework at New MeXico State University}

\section{Rhetoric and Composition}

Pro-seminar in Rhetoric and Professional Communication - Monica Torres

Rhetorical and Cultural Studies - Kathryn Valentine

History and Theory of Composition - Chris Burnham

Graduate Study in Literacy - Kathryn Valentine

Online Identity Performance and Construction - Jennifer Almjeld

Topics in Writing Program Administration - Kathryn Valentine

Approaches to Composition (Secondary Education) - Cheryl Nims

Composition Pedagogy - Patricia Wojahn

Online Pedagogy - Jennifer Sheppard

Technical-Professional Communication: Theory and Pedagogy - Jennifer Sheppard

Borderlands Writing Project - Chris Burnham

Graduate Study in Writing - Chris Burnham

Empirical Research - Jen Almjeld 
Preparing a Professional Portfolio - Jennifer Sheppard 